\title{
Understanding the Growth of Interfacial Reaction Product Layers between Dissimilar Materials
}

\section{Tomi Laurila \& Aloke Paul}

To cite this article: Tomi Laurila \& Aloke Paul (2016) Understanding the Growth of Interfacial Reaction Product Layers between Dissimilar Materials, Critical Reviews in Solid State and Materials Sciences, 41:2, 73-105, DOI: 10.1080/10408436.2015.1053603

To link to this article: http://dx.doi.org/10.1080/10408436.2015.1053603

\section{册 Published online: 09 Oct 2015.}

\section{Submit your article to this journal $\sqsubset$}

Џlll Article views: 222

Q View related articles $\square$

View Crossmark data ¿ 


\title{
Understanding the Growth of Interfacial Reaction Product Layers between Dissimilar Materials
}

\author{
Tomi Laurila ${ }^{1, *}$ and Aloke Paul ${ }^{2}$ \\ ${ }^{I}$ Department of Electrical Engineering and Automation, School of Electrical Engineering, Aalto University, \\ Espoo, Finland \\ ${ }^{2}$ Department of Materials Engineering, Indian Institute of Science, Bangalore, India
}

\begin{abstract}
When one starts to analyze the evolution of the interfacial reaction product layers between dissimilar materials it is often found out that as the number of interacting species grows, the complexity of the analysis increases extremely rapidly. It may even appear that the task is just too difficult to be completed. In this article we present the thermodynamic-kinetic method, which can be used to rationalize the evolution of interfacial reaction layers and bring back the physics to the analyses. The method is conceptually very simple. It combines energetics-what can happen-with kinetics-how fast things take place. Yet the method is flexible enough that it can utilize quantitative and qualitative data starting from the atomistic simulations up to the experiments carried out with bulk materials. Several examples about how to utilize this method in material scientific problems are given.
\end{abstract}

Keywords thermodynamics, phase diagrams, diffusion in solid state, intrinsic diffusion, physicochemical approach, thermodynamic-kinetic method

Table of Contents

1. BACKGROUND

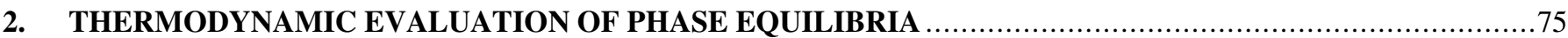

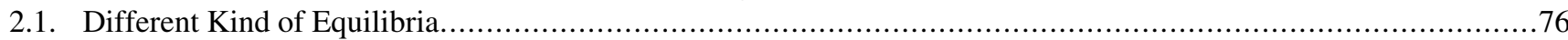

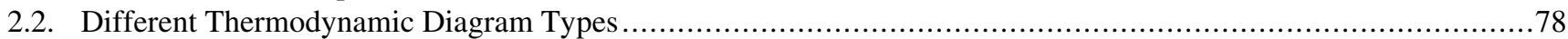

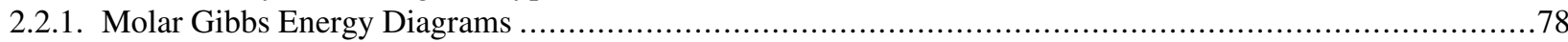

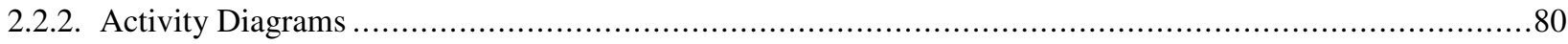

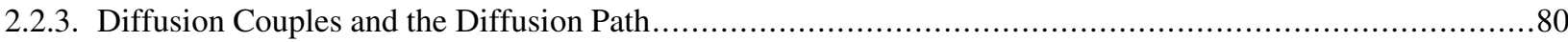

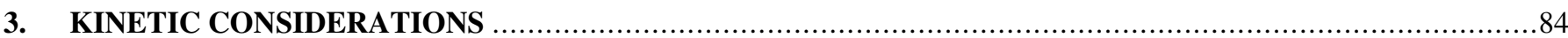

3.1. A Physico-Chemical Approach to Explain the Morphological Evolution in an Interdiffusion Zone ......................86

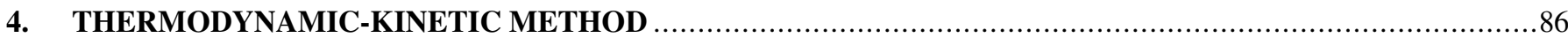

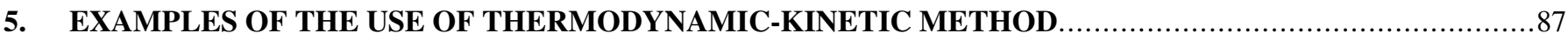

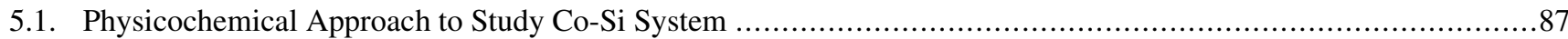

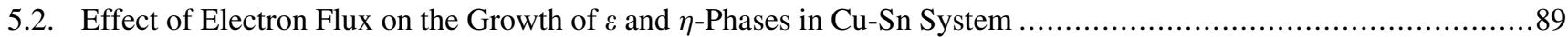

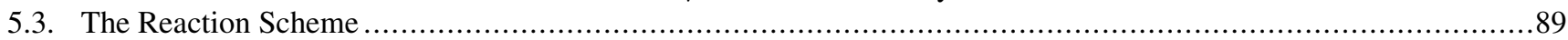

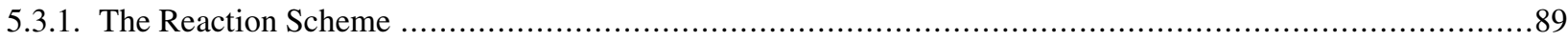

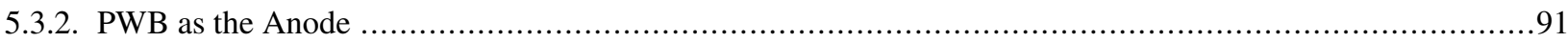

*E-mail: tomi.laurila@aalto.fi

Color versions of one or more of the figures in this article can be found online at www.tandfonline.com/bsms. 


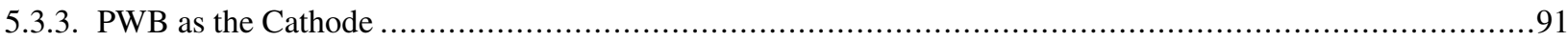

5.3.4. Combined Effect of Electrical and Chemical Potential Gradients ................................................92

5.4. Use of Stability Diagrams to Rationalize Reactions in the Cu-Si-Ta-O-C System ......................................93

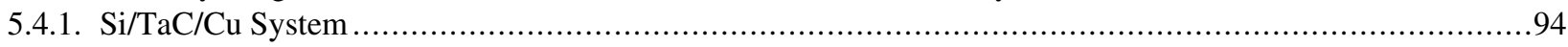

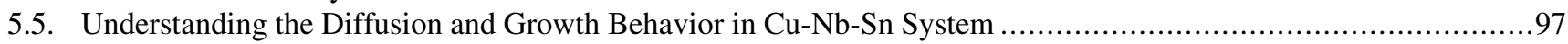

6. CONCLUSIONS 100

REFERENCES.

100

APPENDIX.

102

\section{BACKGROUND}

Multimaterial structures are everywhere around us. A wide variety of devices are based on the utilization of properties that arise when two or more different materials meet. However, it is common knowledge that at this intermaterial region, in addition to the desired functions, problems also frequently appear, owing to the excess growth of intermediate reaction product layers, for instance. To optimize the desired interfacial properties and at the same time to minimize the possible problems related to these same interfaces is a challenge that is not easy to meet. While striving for this goal one needs fundamental understanding about the evolution of the interfacial area under various environmental conditions.

The thermodynamics of materials provides information about the stability of phases (e.g., phase diagrams) and on the driving forces for chemical reactions and diffusion processes (for example, molar Gibbs energy and activity diagrams). This information is valid even though complete phase equilibrium (global) is seldom met in practical applications. However, stable or metastable local equilibria are generally attained at interfaces, and this provides a feasible method - together with kinetic information - for analyzing the progress of interfacial reactions in various multimaterial systems. ${ }^{1-3}$ To further aid this task concepts like the "local nominal composition" (LNC) in the effective reaction region, which utilize both thermodynamic and kinetic data, have been developed. ${ }^{4}$

During recent years it has become feasible to utilize atomistic calculations to obtain either missing data, such as enthalpies of formations of compounds, for thermodynamic calculations or to predict structures and formation energies of metastable or even hypothetical structures. This has greatly broadened the scope of the energetic description of materials. Several examples where ab initio calculations have been used to obtain thermodynamic knowledge of the system exist in the literature. ${ }^{5-13}$

When one attempts to take into account the time frame of the changes taking place in the system under investigation, kinetic analyses must be combined with energetics. Here, one typically introduces different types of diffusion parameters extracted from experiments carried out under various conditions. Unfortunately, the use of, for example, different diffusion coefficients in the literature is often vague and even erroneous. ${ }^{14}$ As, for example, interdiffusion, intrinsic, and tracer diffusion coefficients represent different type of information, it is important to know what coefficient to use under which conditions. The available thermodynamic data can be utilized in the kinetic calculations to provide for example driving forces for diffusion of different species or to investigate changes in the intrinsic fluxes of the diffusing elements and so forth. ${ }^{2,3}$ Often, one is also interested in the atomistic mechanisms of diffusion in addition to the above mentioned phenomenological approach. Here, in addition to the more traditional thermodynamic data, atomistic simulations can provide valuable insight when various diffusion mechanism and formation energies of defects for instance are considered. ${ }^{15}$ Finally, it is to be noted that, although assessed thermodynamic data for practically all important binary systems and a few relevant ternary (or even quaternary) systems are available, the diffusion kinetic data, even in binary systems, are generally limited, especially at low $\left(\mathrm{T} \leq 150^{\circ} \mathrm{C}\right)$ temperatures.

When one starts to analyze the evolution of interfacial region between dissimilar materials it is often found out that one needs to deal with a large number of special techniques and to master large quantities of data. It may appear that the task is just too formidable to be completed. In this review we will present the so called thermodynamic-kinetic method which is conceptually very simple. It combines energeticswhat can happen - with kinetics-how fast things take place (Figure 1). However, it is flexible enough that it can incorporate data starting from the very detailed atomistic simulations ending up to results obtained from the experiments carried out with bulk materials. The method can be used as a guide for ones thinking even in the absence of any quantitative data. Further, it provides simple means to assess, for example, the effect of current flow on the evolution of interfacial reaction layer growth or how alloying elements may change the kinetics of phase growth kinetics. ${ }^{16}$

It is frequently found out that when dealing with diffusion in ternary or even higher-order systems the mathematics becomes very complicated and the physical picture of the phenomena 


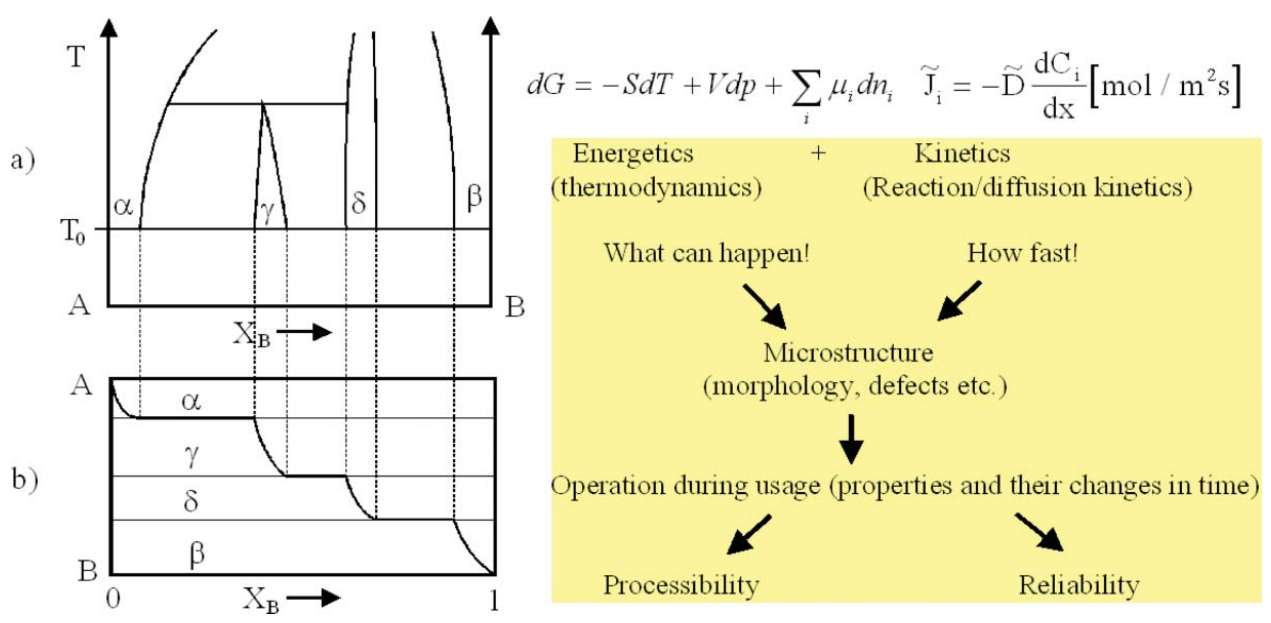

FIG. 1. Schematic presentation of the thermodynamic-kinetic method.

under investigation may be blurred or disappears totally. ${ }^{17} \mathrm{It}$ will be shown below that the thermodynamic kinetic method can be used to greatly simplify the analyses and bring back the physics to the phenomena under investigation. Finally, as graphical methods are frequently used in the thermodynamic kinetic method it will be shown that a large amount of quantitative data can be condensed into relatively simple diagrams.

In this article we will first briefly describe the fundamentals of the energetics part of the method. We will also introduce several diagram types that are frequently used in the thermodynamic-kinetic analyses. Then the kinetics part is discussed and especially the various diffusion parameters are introduced in considerable detail. After that we proceed to the actual thermodynamic-kinetic method. We will explain the basic assumptions that must be made when the method is used and on what they are based on. We will then continue to present several examples how useful this method is before going into final conclusions and to pointing out some future directions how the method could be further improved.

\section{THERMODYNAMIC EVALUATION OF PHASE EQUILIBRIA}

In principle, the constituent atoms and the basic laws of physics determine the properties of any given material. Therefore, it should be possible to predict the properties of different materials by using only the composition as the input knowledge. The approach that tries to achieve this is commonly referred as first principles or ab initio calculations. ${ }^{18}$ During recent decades approaches based on the Density Functional Theory (DFT) have started to live up to the above discussed expectations. ${ }^{19-26}$ The success of the approach is due to its ability to make quantitative predictions about many material properties that would otherwise be hard or even impossible to access experimentally in the laboratory. However, there are still many issues related especially to the utilization of the output of the ab initio calculations in real material scientific problems. One approach is to use ab initio results as input data for other more "macroscopic level" simulation tools such as the Computer Calculations of Phase Diagrams (CALPHAD) approach. ${ }^{27}$ In addition, during recent years it has become possible to calculate so called ab initio phase diagrams ${ }^{28,29}$ that can then compared with the phase diagrams calculated with CALPHAD method. In this way, a direct link from atomic level information to the macroscopic thermodynamic data can be achieved.

The data that goes into the thermodynamic assessment of a given system include all kind of experimental and theoretical information, such as calorimetric data, activity values from electrochemical measurements, vapor pressure measurements, microstructural information and results from ab initio calculations, ${ }^{29,30}$ for instance. There are a wide variety of different mathematical models for various kinds of phases that can be used to represent the available thermodynamic data for a given phase. $^{29,30}$ In this article, we will not consider these models or the actual assessment procedure in any detail, as there are several comprehensive treatments available for the interested reader. ${ }^{29,30}$ On the contrary, we will focus here on the utilization of this assessed thermodynamic data in the analyses of the evolution of the interfacial region between different materials as well as show examples of how to visualize the data obtained with relatively simple diagrams.

When the models for the phases to be considered are formulated and all the available experimental and theoretical data has been fitted into these, the phase equilibria are computed by summing up all the Gibbs (free) energies (see Note 1) of individual phases and then minimizing-according to the second law of thermodynamics - the total Gibbs energy of the n-component system at constant temperature and pressure:

$$
G_{\text {tot }}=\sum_{\phi} \sum_{i}\left(\mu_{i}^{\phi} n_{i}^{\phi}\right)=\sum_{\phi} y^{\phi} \sum_{i=1}^{n}\left(x_{i} \mu_{i}^{o}+R T \sum_{i}^{n} x_{i} \ln x_{i}+G_{m}^{E}\right),
$$


where $\mathrm{y}$ is the relative amount of a phase $\phi, \mathrm{R}$ is the universal gas constant, $\mathrm{T}$ temperature (in Kelvin), and $\mathrm{x}_{\mathrm{i}}$ is a mole fraction of a component $i$ in the system. The parameters $\mu_{i}^{o}$ in Equation (1) represent the partial molar Gibbs energies or chemical potentials of the pure components and are taken either from available databanks or from the literature. At this point it must be emphasized that as only relative values of thermodynamic functions can be determined, an agreed reference state has to be established for each element or species in order to make thermodynamic treatment quantitative. In principle, the choice of the reference state is arbitrary as long as the chosen state is used consistently throughout the analysis. The chosen state is then defined to be zero and all other possible states of the element are compared against the reference state to obtain their relative stabilities. It should be noted that there are often some uncertainties related to the usage of reference states in the literature $^{2,3,30}$ and thus one must be careful when carrying out the assessment work.

The total Gibbs energy of the system can be expressed as a function of chemical potentials, which are related to the activities of the components as follows:

$$
\mu_{i}^{\phi} \equiv \mu_{i}^{0}(T)+R T \ln a_{i}
$$

where $a_{i}=\gamma_{i} x_{i}$ and $\gamma_{i}$ is the activity coefficient. It is the difference in the chemical potentials of individual elements inside and between different phases that will drive the diffusion of elements in a system under investigation.

\subsection{Different Kind of Equilibria}

The chemical potential (or activity) of a component $i$ will have the same value in all the phases that are in complete mutual equilibrium, and therefore the driving force for its diffusion will vanish in the system. However, in the case of reactions between dissimilar materials the equilibrium is typically attained only at the interfaces and, even though the activity of a component has the same value at the interface, there are activity gradients in the adjoining phases. These gradients, together with diffusivities, determine the diffusion of components in various phases of the reaction region.

The equilibrium states to be considered within the framework of this review are: (i) complete thermodynamic equilibrium; (ii) local thermodynamic equilibrium; and (iii) metastable equilibrium. It is to be noted that partial equilibrium, in which only some of the components fulfill the equilibrium condition, is also possible.

(1) Complete Equilibrium. As stated above, when the system is in complete equilibrium its Gibbs free energy has reached its minimum value and then the system is in mechanical, thermal, and chemical equilibrium with its surroundings: ${ }^{31}$

$$
\begin{aligned}
& d G=0 \text { or } \\
& \mu_{\mathrm{i}}^{\alpha}=\mu_{\mathrm{i}}^{\beta}=\ldots=\mu_{\mathrm{i}}^{\phi} .
\end{aligned}
$$

In other words, when complete equilibrium is obtained the activities of all components $(\mathrm{i}=\mathrm{A}, \mathrm{B}, \mathrm{C} . .$.$) are the same in all$ phases $(\alpha, \beta \ldots \phi)$ and there are no gradients inside the phases. Naturally, complete (or global) thermodynamic equilibrium is seldom met in practical applications.

(2) Local Equilibrium. Local equilibrium means that the equilibrium exists only at the interfaces between different phases present in the system. The thermodynamic functions are continuous across the interfaces and the interfacial compositions can be obtained from the equilibrium phase diagrams. Therefore, the local equilibrium at the interphase between the $\alpha$-phase and $\beta$-phase can be defined as: ${ }^{31}$

$$
\begin{aligned}
& \mu_{i}^{\alpha}=\mu_{i}^{\beta} \\
& \mu_{i}^{\alpha}={ }^{0} \mu_{i}^{\alpha}+R T \ln a_{i}^{\alpha}={ }^{0} \mu_{i}^{\alpha}+R T \ln x_{i}^{\alpha}+R T \ln \gamma_{i}^{\alpha} \\
& \mu_{i}^{\beta}={ }^{0} \mu_{i}^{\beta}+R T \ln a_{i}^{\beta}={ }^{0} \mu_{i}^{\beta}+R T \ln x_{i}^{\beta}+R T \ln \gamma_{i}^{\beta}
\end{aligned}
$$

where ${ }^{0} \mu_{i}$ is the chemical potential of pure $i$ in the standard state, $\mu_{i}^{j}$ the chemical potential of component $i$ in phase $j, a_{i}^{j}$ the activity of component $i$ in phase $j, x_{i}^{j}$ the mole fraction of component $i$ in phase $j, \gamma_{i}^{j}$ the activity coefficient of component $i$ in phase $j, R$ is the gas constant, and $T$ the temperature. The local equilibrium concept is especially important when analyzing the interphasial reactions based on the so-called diffusion couple approach. ${ }^{32-34}$ When local equilibrium can be assumed to be fulfilled in the system, the reaction products formed between components in a binary system can be predicted by using the relevant phase diagram. After annealing at a certain temperature for a sufficiently long time, all the thermodynamically stable phases of the system at that particular temperature (and only them) will exist as layers between the end members. According to the Gibbs phase rule, only singlephase regions can be formed and the interfaces between the phases have to be macroscopically planar under constant pressure and temperature. For example, when pure $\mathrm{Cu}$ is in contact with liquid $\mathrm{Sn}$ at $250^{\circ} \mathrm{C}$ the intermetallic compounds that are formed in the interphasial region can be derived from the phase diagram (see Figure 2, red contact line). From the critically assessed thermodynamic description of the system more information can be obtained by utilising the Gibbs free energy diagram (see Figure 3), where the molar Gibbs energy curves of the solution phases fcc $(\alpha)$, bct $(\beta)$, and Liquid (Liq) are presented with solid green, blue, and red lines, respectively. The intermetallic compounds $\mathrm{Cu}_{6} \mathrm{Sn}_{5}(\eta)$ and $\mathrm{Cu}_{3} \mathrm{Sn}(\varepsilon)$, which have a narrow homogeneity range, have been modeled as stoichiometric line compounds. Here we have defined the $\beta$-Sn with body centered tetragonal and $\alpha-\mathrm{Cu}$ with face centered 


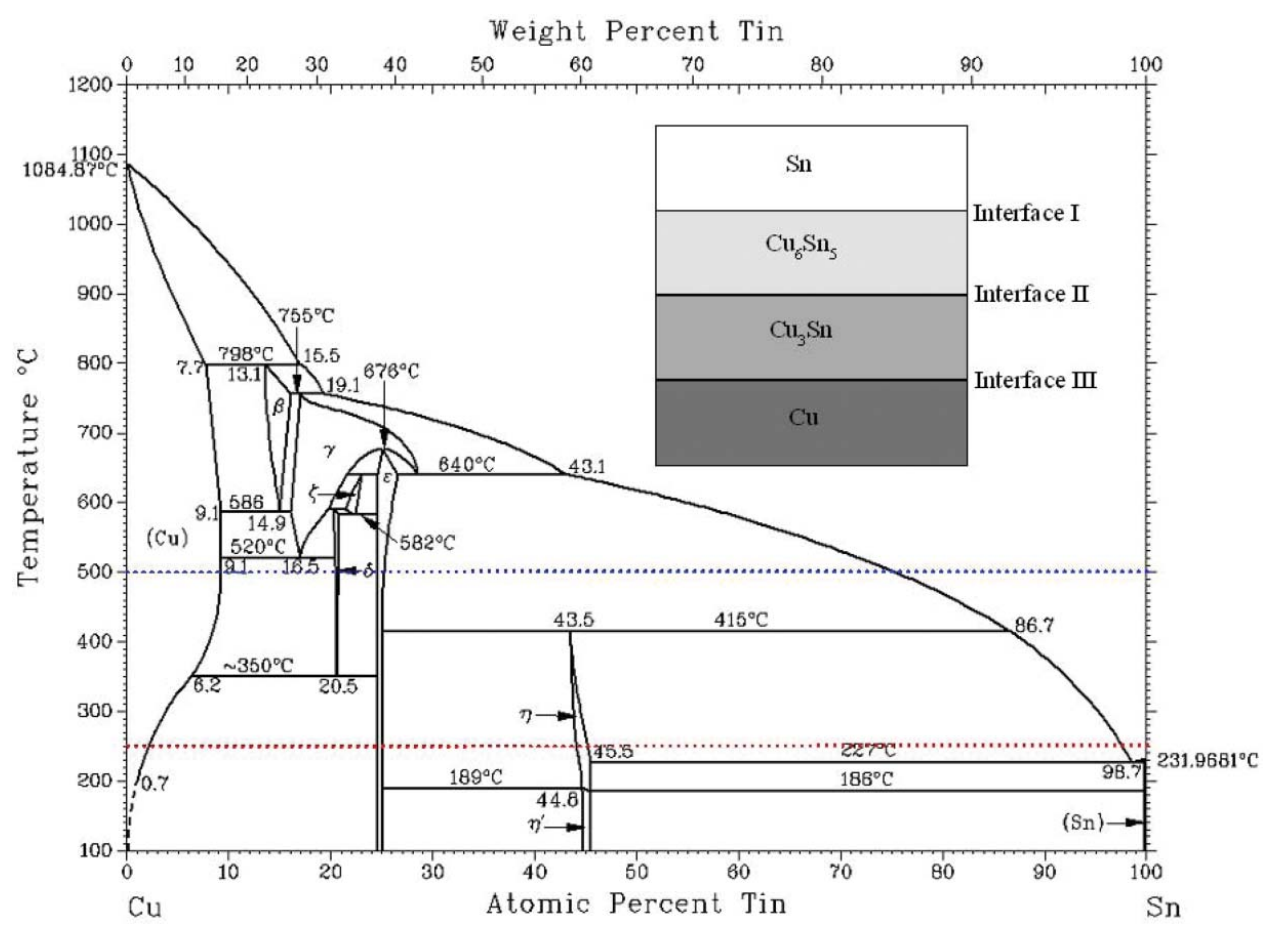

FIG. 2. Binary $\mathrm{Cu}-\mathrm{Sn}$ phase diagram showing the schematic reaction structure as well the two temperatures considered.

cubic structure as the references states for the pure $\mathrm{Sn}$ and $\mathrm{Cu}$, respectively. Thus, the stability of other structures in the system will be compared to the "zero-level" defined by the above reference states. The local equilibria at the interfaces I, II, and III, marked with dashed, dotted, and double-dashed lines, respectively, are: $\mu_{S n}^{L i q}=\mu_{S n}^{\eta}$ and $\mu_{C u}^{L i q}=\mu_{C u}^{\eta}, \mu_{S n}^{\eta}=\mu_{S n}^{\varepsilon}$ and $\mu_{C u}^{\eta}=\mu_{C u}^{\varepsilon}$, as well as $\mu_{S n}^{\varepsilon}=\mu_{S n}^{\alpha}$ and $\mu_{C u}^{\varepsilon}=\mu_{C u}^{\alpha}$.

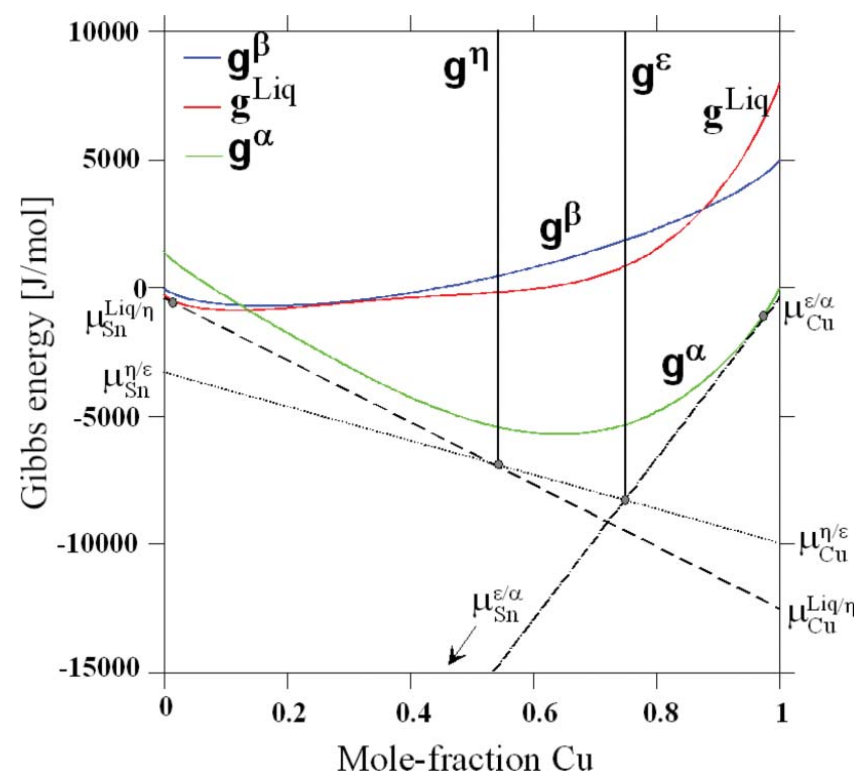

FIG. 3. Gibbs energy diagram of the $\mathrm{Cu}-\mathrm{Sn}$ system at $250^{\circ} \mathrm{C}$.
Both intermetallic phases $\left[\mathrm{Cu}_{6} \mathrm{Sn}_{5}(\eta)\right.$ and $\left.\mathrm{Cu}_{3} \mathrm{Sn}(\varepsilon)\right]$ can be observed after 64 min annealing as shown in Figure 4a. It is to be noted that the local equilibrium between $\mathrm{Sn}$ and $\mathrm{Cu}$ is, naturally, a function of temperature. If the temperature is raised to $500^{\circ} \mathrm{C}$ (see Figure 2, dotted blue contact line), $\mathrm{Cu}_{6} \mathrm{Sn}_{5}$ is not stable anymore and liquid $\mathrm{Sn}$ comes into direct equilibrium with $\mathrm{Cu}_{3} \mathrm{Sn}$, which can also be experimentally verified (see Figure $4 \mathrm{~b}$ and $4 \mathrm{c}$ ). Another phase $(\delta)$ becomes stable and can be observed between $\mathrm{Cu}_{3} \mathrm{Sn}$ and $\mathrm{Cu}$. The Gibbs free energy diagram at $500^{\circ} \mathrm{C}$ for the $\mathrm{Cu}-\mathrm{Sn}$ system is presented in Figure 5. In addition to the interfacial compositions (such as $x_{\mathrm{Cu}}^{L i q \mid \varepsilon}$ and $x_{\mathrm{Cu}}^{\delta \mid \alpha}$ ), the driving forces for diffusion can also be obtained from the Gibbs energy diagram. For example, $\Delta_{r} G_{C u}^{I}$ represents the driving force for a pure $\mathrm{Cu}$ atom to diffuse through the $\delta$ - and $\varepsilon$-phases to the liquid| $\mid \varepsilon$-interface to react with $\mathrm{Sn}$ atom, as will be discussed later on.

(3) Metastable Equilibrium. Metastable equilibrium can be defined as a local minimum of the total Gibbs energy of the system. Therefore, in order to obtain the global stable equilibrium some activation (e.g., thermal energy) must be brought into the system. It is to be noted that metastable equilibrium can also be complete, local, or partial; out of these the local metastable equilibrium concept will be used frequently in the thermodynamic-kinetic method. Very often one or more intermetallic compounds, which should be thermodynamically stable at a particular temperature, are not observed between two materials and these interfaces are therefore in local metastable equilibrium. Another situation where it is commonly 

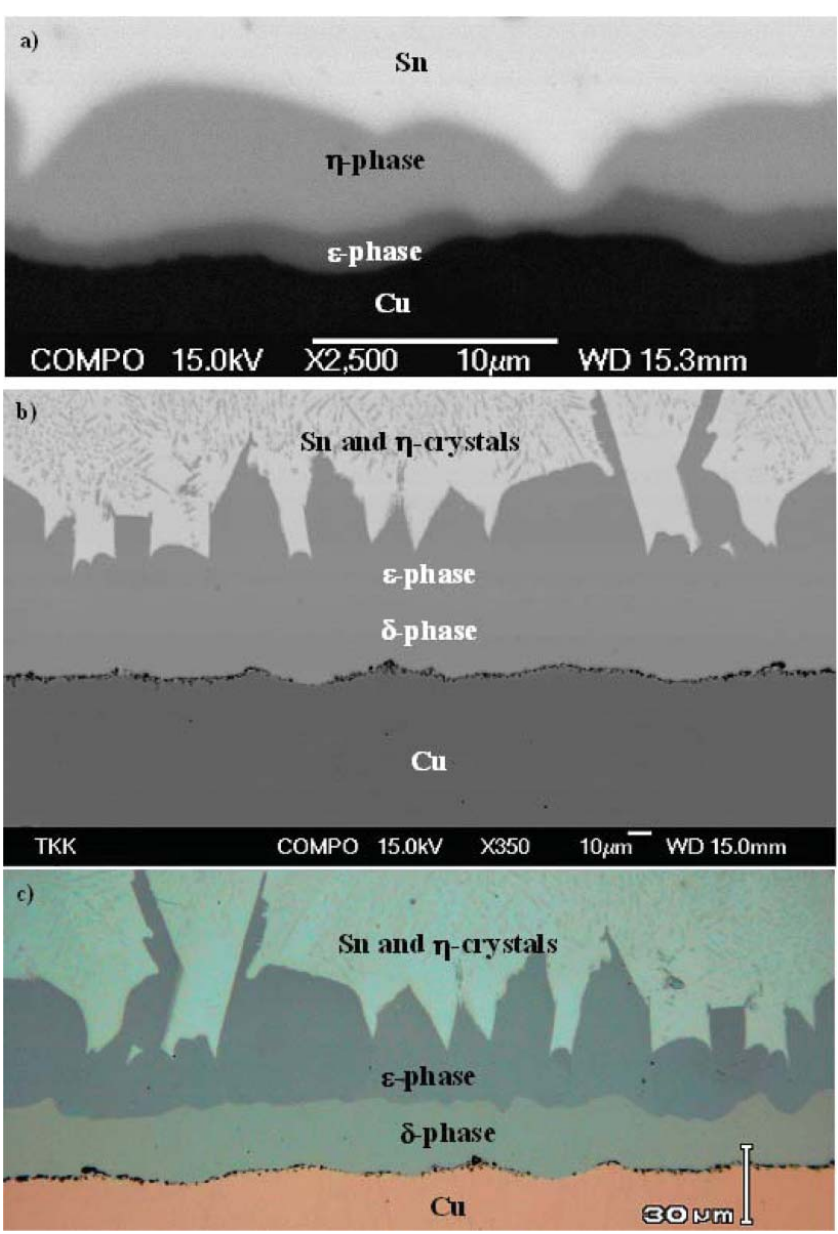

FIG. 4. SEM micrographs from the $\mathrm{Cu}-\mathrm{Sn}$ reaction structure (a) at $250^{\circ} \mathrm{C}$, (b) $500^{\circ} \mathrm{C}$, and (c) optical micrograph at $500^{\circ} \mathrm{C}$.

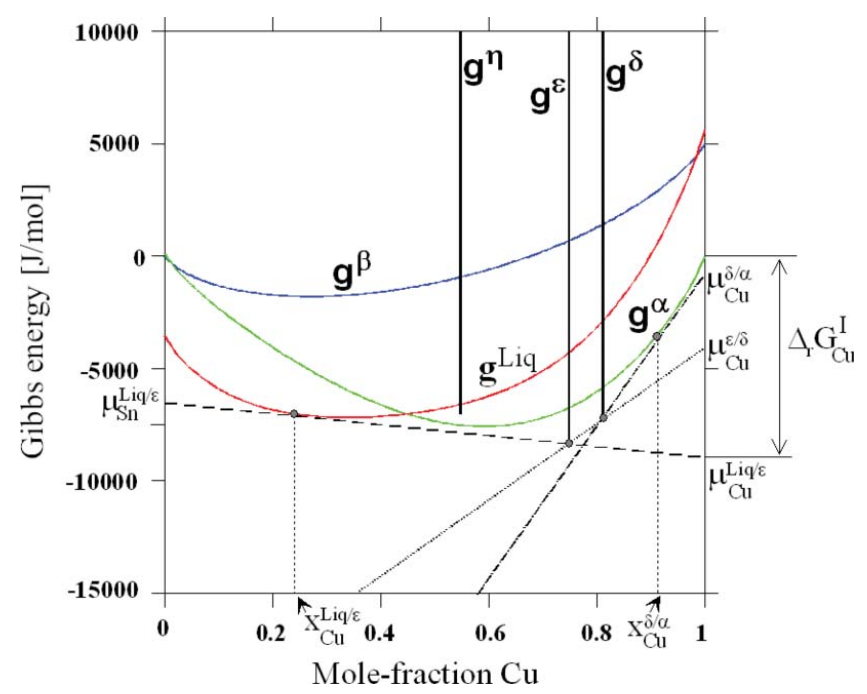

FIG. 5. Gibbs energy diagram from $\mathrm{Cu}-\mathrm{Sn}$ system at $500^{\circ} \mathrm{C}$. encountered is in rapid interfacial reactions when one of the reacting materials is in a liquid state. Then, during the few first seconds, the solid material is in local metastable equilibrium with the liquid containing dissolved atoms, before the intermetallic compound(s) is formed at the interface. This can also be analyzed with the help of Gibbs energy diagrams, as explained in the next section.

\subsection{Different Thermodynamic Diagram Types}

Here, we will present some of the thermodynamic property diagrams that are most frequently used in the context of thermodynamic-kinetic method. We will assume that the reader is familiar with the common temperature composition diagrams $^{35}$ and instead concentrate on other perhaps less familiar diagram types.

\subsubsection{Molar Gibbs Energy Diagrams}

The molar Gibbs energy diagrams are extremely useful for analyzing interfacial reactions. A detailed presentation about their properties, use and so forth can be found from Hillert. ${ }^{30}$ In Figure 6 the molar Gibbs energy diagram for the binary system $\mathrm{Cu}-\mathrm{Sn}$ at $235^{\circ} \mathrm{C}$ is shown. For instance, the common tangent between the curves $g_{\text {bin }}^{L}$ and $g^{n}$ gives the equilibrium solubility of $\mathrm{Cu}$ to a liquid solder (L), which is given as ${ }^{e} X_{\mathrm{Cu}}^{L}$. The equilibrium solubility is the amount of $\mathrm{Cu}$ that can be dissolved infinitely slowly to liquid solder before the $\eta$-phase comes into equilibrium with the liquid. The formation of the $\eta$-phase does not, however, occur with this composition, as the driving force is zero at this point (no supersaturation). In real cases the dissolution of $\mathrm{Cu}$ does not take place infinitely slow and, therefore, the equilibrium solubility is generally

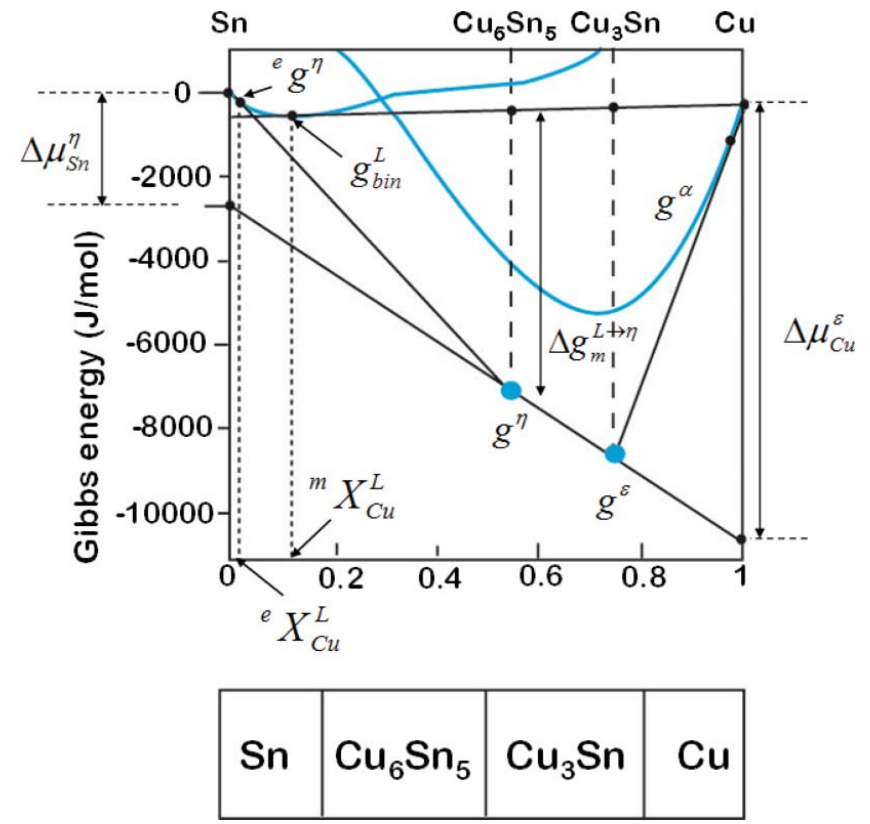

FIG. 6. Gibbs energy diagram from $\mathrm{Cu}-\mathrm{Sn}$ system at $235^{\circ} \mathrm{C}$. 
exceeded. The solubility of $\mathrm{Cu}$ does not increase infinitely, but there is an upper limit for its value and this can also be determined from Figure 6. When more and more $\mathrm{Cu}$ dissolves into liquid eventually a situation is faced where the dissolution of more $\mathrm{Cu}$ would lead to the precipitation of pure metallic $\mathrm{Cu}$ out of the supersaturated solder. This corresponds to the common tangent construction between the solder and pure $\mathrm{Cu}$. The tangent point in the liquid curve at this metastable equilibrium gives the upper value of $\mathrm{Cu}$ that can be dissolved into liquid solder at any rate, i.e., the metastable solubility ${ }^{m} X_{C u}^{L}$. When this value has been reached, also the driving force for the formation of the $\eta$-phase has reached its maximum (shown in the diagram as $\Delta g^{L \rightarrow n}$ in Figure 6). Since the metastable solubility is directly related to the dissolution rate of a given metal to a solder in question, it provides important information about the formation of intermetallic compounds between different metals and solders. In many cases its value is about 2-3 times larger than the equilibrium solubility. ${ }^{2}$

The common tangent construction can be used to determine the driving forces for diffusion of $\mathrm{Cu}$ through $\mathrm{Cu}_{3} \mathrm{Sn}$ and $\mathrm{Sn}$ through $\mathrm{Cu}_{6} \mathrm{Sn}_{5}$ in Figure 6. $\Delta \mu_{C u}^{\varepsilon}$ is the chemical potential difference of $\mathrm{Cu}$ between interfaces $\mathrm{Cu}_{3} \mathrm{Sn} / \mathrm{Cu}$ and $\mathrm{Cu}_{6} \mathrm{Sn}_{5} /$ $\mathrm{Cu}_{3} \mathrm{Sn}$, which drives the diffusion of $\mathrm{Cu}$ through $\mathrm{Cu}_{3} \mathrm{Sn}$ and $\Delta \mu_{S n}^{\eta}$ is the chemical potential difference of $\mathrm{Sn}$ between the interfaces $\mathrm{Sn} / \mathrm{Cu}_{6} \mathrm{Sn}_{5}$ and $\mathrm{Cu}_{6} \mathrm{Sn}_{5} / \mathrm{Cu}_{3} \mathrm{Sn}$, which drives the diffusion of $\mathrm{Sn}$ through the $\mathrm{Cu}_{6} \mathrm{Sn}_{5}$ layer. It is easy to realize that changes in the stabilities of the $\eta$ and $\varepsilon$ phases (in their Gibbs free energy) will change the values of $\Delta \mu_{S n}^{\eta}$ and $\Delta \mu_{C u}^{\varepsilon}$ and thus increase or decrease the driving forces for diffusion of components in the system. This is shown in Figure 7. It is to be noted that the Gibbs energy diagram in Figure 7 is not a binary one, but a vertical section from a ternary 3-dimensional $\mathrm{Cu}-\mathrm{Ni}-\mathrm{Sn}$ Gibbs energy diagram. It is to be noted that in ternary systems the tie-lines are not usually in the plane of the vertical sections. ${ }^{35}$ Therefore, the free energy values must be obtained along the diffusion paths (following the tie-lines) as done here. More details about this procedure can be found for example from Laurila et al. ${ }^{2}$ and $\mathrm{Yu}$ et al. ${ }^{36} \mathrm{Sn}$ is known to be the main diffusing species in $\mathrm{Cu}_{6} \mathrm{Sn}_{5}$ whereas $\mathrm{Cu}$ is the main diffusing species in $\mathrm{Cu}_{3} \mathrm{Sn}^{37,38}$ From Figure 7 one can see

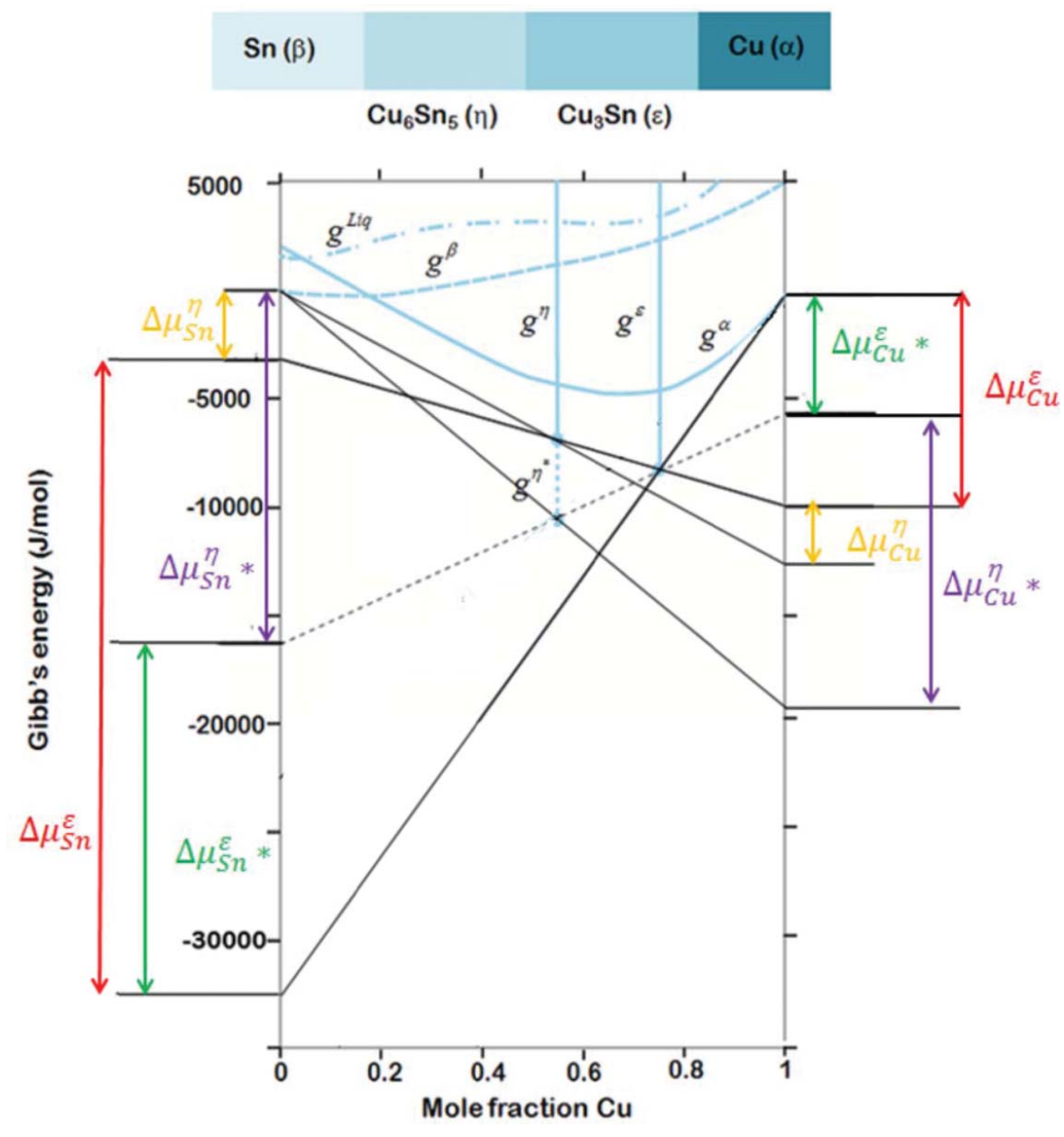

FIG. 7. Superimposed Gibbs energy diagrams from $\mathrm{Cu}-\mathrm{Sn}$ and $\mathrm{Cu}-\mathrm{Ni}-\mathrm{Sn}$ systems showing the changes in the driving forces for diffusion. 
that when, for example, 10 at- $\% \mathrm{Ni}$ is added to $(\mathrm{Cu}, \mathrm{Ni})_{6} \mathrm{Sn}_{5}$ its stability will increase as already reported earlier ${ }^{39}$ and also indicated by first-principle calculations. ${ }^{40}$ This will have effect on the chemical potentials (and thereby activities) at the $\mathrm{Sn} /$ $(\mathrm{Cu}, \mathrm{Ni})_{6} \mathrm{Sn}_{5}$ and $\mathrm{Cu}_{3} \mathrm{Sn} / \mathrm{Cu}$ interfaces in such a way that the driving force for example for $\mathrm{Sn}$ diffusion through $(\mathrm{Cu}$, $\mathrm{Ni})_{6} \mathrm{Sn}_{5}$ increases from $\Delta \mathrm{G}_{\mathrm{Sn}}$ to $\Delta \mathrm{G}_{\mathrm{Sn}} *$ (almost four times $\Delta \mathrm{G}_{\mathrm{Sn}}$ ) whereas the driving force for diffusion of $\mathrm{Cu}$ through $\mathrm{Cu}_{3} \mathrm{Sn}$ decreases from $\Delta \mathrm{G}_{\mathrm{Cu}}$ to $\Delta \mathrm{G}_{\mathrm{Cu}}{ }^{*}$ (about $3 / 5 \Delta \mathrm{G}_{\mathrm{Cu}}$ ). From Figure 7 one can also reason that driving force for diffusion of $\mathrm{Sn}$ over $\mathrm{Cu}_{3} \mathrm{Sn}$ decreases and diffusion of $\mathrm{Cu}$ through $\mathrm{Cu}_{6} \mathrm{Sn}_{5}$ increases in comparison to binary case. As the diffusion flux is linearly proportional to the driving force, the material flux can be expected to grow over $\left(\mathrm{Cu}_{6} \mathrm{Sn}_{5}\right)$ and to decrease over $\mathrm{Cu}_{3} \mathrm{Sn}$. When combined with the diffusion kinetic data from the system ${ }^{39}$ this information can be used to calculate changes in the intrinsic fluxes of $\mathrm{Sn}$ and $\mathrm{Cu}$ inside the intermetallic compounds for instance.

\subsubsection{Activity Diagrams}

The activity diagram shown in the right-hand side of Figure 8 is one form of many different types of stability diagrams. In such a diagram the thermodynamic potential of one of the components is plotted as a function of the relative atomic fractions of the other two components at constant temperature and pressure. The activity values which are needed in the construction of such a diagram can be obtained from the assessed thermodynamic data. When calculating the activities of the components, the activities of the stoichiometric compounds at equilibrium are regarded to be one. It should be noted that the precision of the calculations is very much dependent on the accuracy and consistency of the thermodynamic data used. Therefore, great care should be exercised when using data from different sources.

The edges of the diagram shown in Figure 8 represent the binary systems ( $\mathrm{Sn}-\mathrm{Bi}, \mathrm{Sn}-\mathrm{Pb}$, and $\mathrm{Pb}-\mathrm{Bi})$. The ternary phase relations are represented by the inside of the diagram. In activity diagrams the stoichiometric single-phase regions are represented as vertical lines, one phase regions with extensive solubility as well as two-phase regions as areas and three phase equilibria as horizontal lines. It should be noted that tie-lines are valid inside the two-phase regions also in these diagrams. The diffusion path (see below) should therefore cross the two phase regions along a tie-line, as will be discussed below. In Figure 8 the identical phase regions in the ternary isotherm and in the activity diagram at the same temperature are identified with the same color. The three-phase equilibiria are shown as red triangles in the isothermal section and as red horizontal lines in the activity diagram. As will be explained later on, if one wants to investigate the odds of diffusion of certain elements in a given reaction layer structure in a ternary system, activity diagrams for all the elements must be calculated. For example, in Figure 9 the activity diagrams for all three species of the C-Si-Ta system are shown. Figure 10 shows the corresponding isothermal section. The activity diagrams provide useful information about the formation of the reaction layer sequence when used together with the isothermal sections as will be shown.

\subsubsection{Diffusion Couples and the Diffusion Path}

Despite the fact that diffusion kinetics is formally introduced in Section 3, we will here discuss about the extremely important related concepts of diffusion couple and diffusion path, as the latter especially is very much thermodynamic in

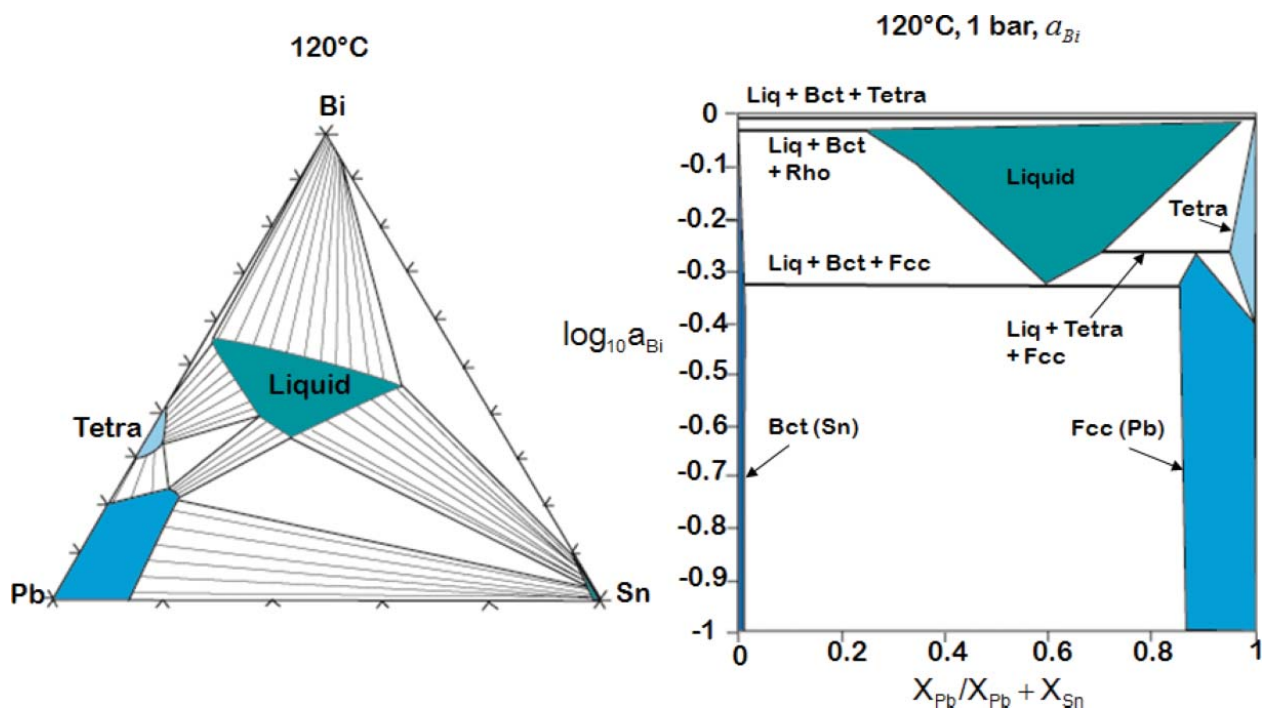

FIG. 8. Isothermal section from the $\mathrm{Bi}-\mathrm{Pb}-\mathrm{Sn}$ ternary system at $120^{\circ} \mathrm{C}$ and the corresponding activity diagram (showing the activity of $\mathrm{Bi}$ ) at $120^{\circ} \mathrm{C}$. 


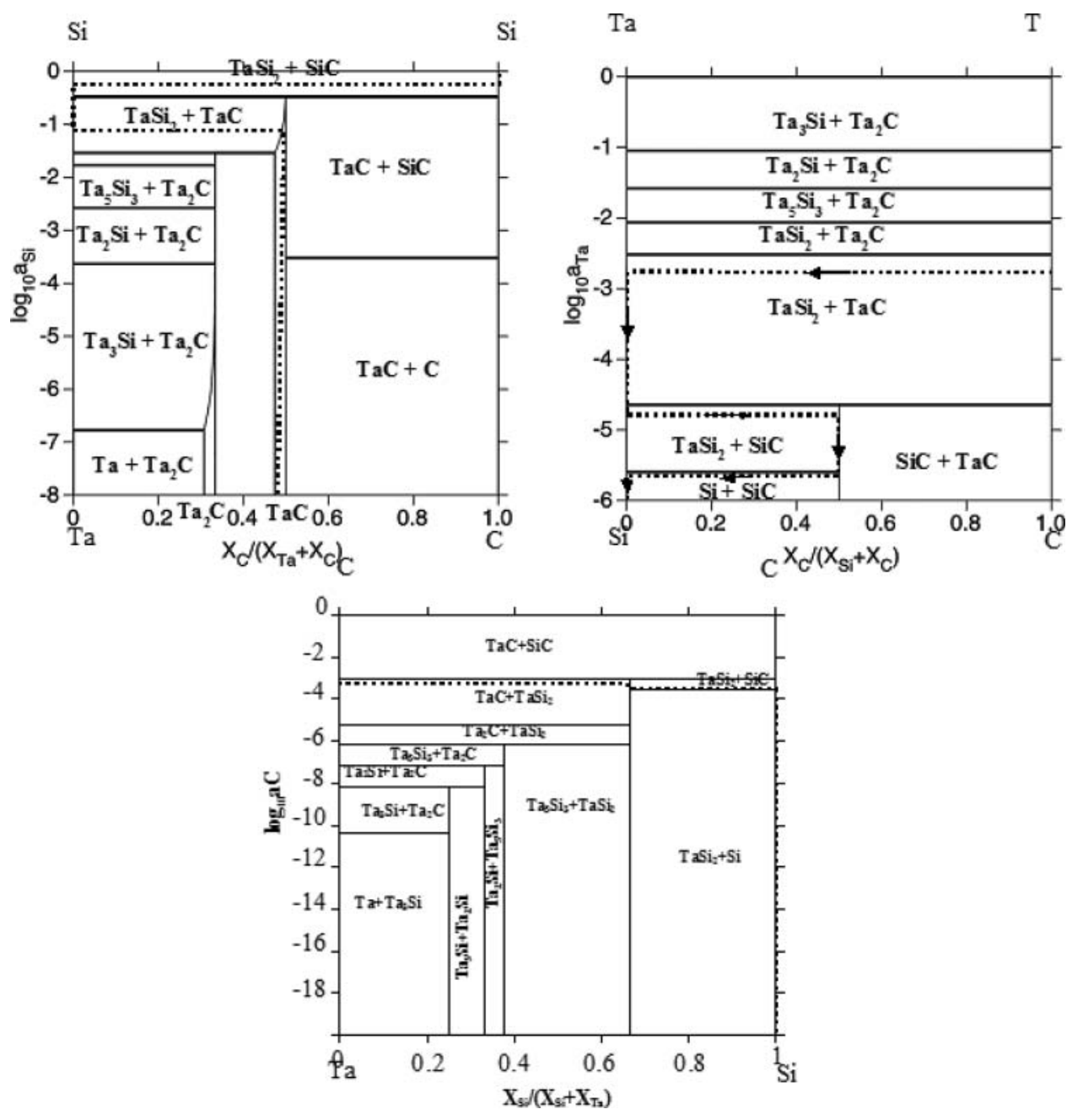

FIG. 9. Activity diagrams for $\mathrm{Si}$, Ta, and $\mathrm{C}$ in the $\mathrm{C}-\mathrm{Si}$-Ta system at $800^{\circ} \mathrm{C}$.

its origin. Generally, in a binary system the interaction between components and the resulting reaction products can be predicted by using the relevant phase diagram. After annealing at a certain temperature for sufficiently long time, all the thermodynamically stable phases of the system at that particular temperature (and only them), will exist as layers between the end members. According to the phase rule only single-phase homogeneous regions can be formed, the interfaces between various phases must be macroscopically planar, and the concentrations at the interfaces of various phases can be read from the phase diagram (Figure 11).

If certain phases are absent, it may be caused by nucleation problems or by the "kinetic" stability described later on and in Paul et al. ${ }^{41}$ In a case when there are no nucleation problems associated with the phase formation and the diffusion is the rate-limiting step, the phase sequence after the reaction is determined by the corresponding phase diagram. In principle, in a specific binary system one can also say something about the temporal evolution of the system, if the interdiffusion coefficients (see Section 3) in all the appearing phases are known. However, when one is dealing with higher-order systems the prediction of the reaction layers becomes much more difficult. In a ternary system the additional degree of freedom enables also the formation of two-phase regions and curved interfaces. This means that theoretically many different phase sequences are possible and the final structure cannot be, in general, interpreted directly from the phase diagram. In addition, the concentration and activity gradients are not necessarily into the same direction as generally in the binary systems, thus enabling for example the so-called "up-hill" diffusion.

Phase transformation will be diffusion controlled when the mass transport through the bulk is the rate-limiting step. Then the boundary conditions governing the rate of diffusion can be evaluated by assuming that whenever two phases meet at the interface, their compositions right at the interface are very close to those required by the equilibrium, and the thermodynamic potentials are continuous across the interface. This is called the local equilibrium approximation, ${ }^{29}$ as discussed 


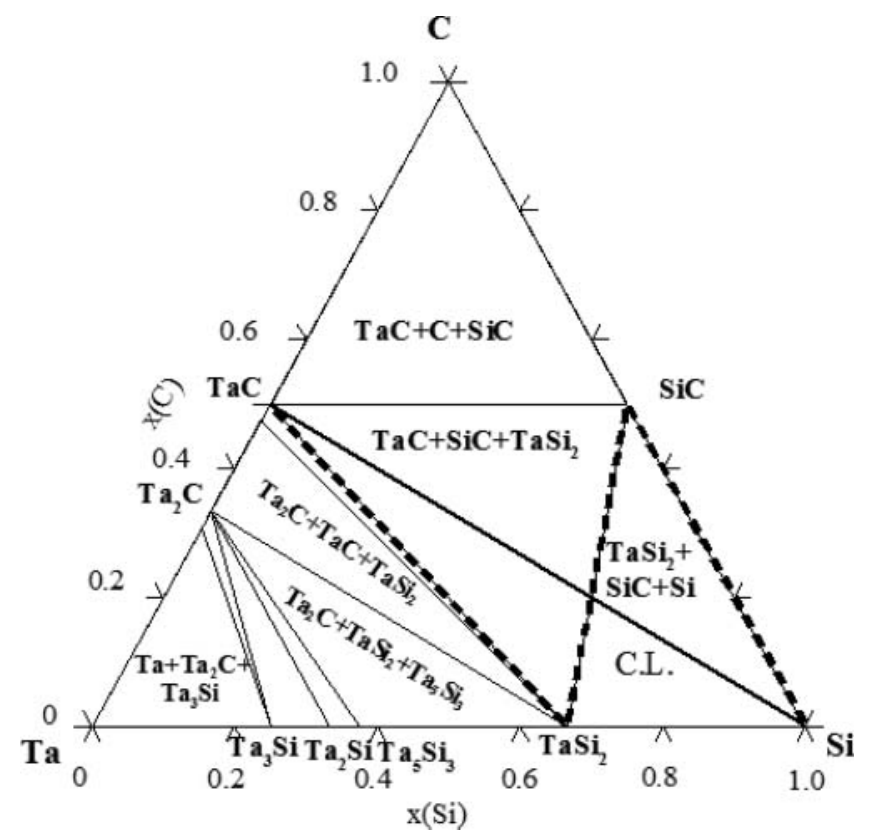

FIG. 10. Isothermal section from the C-Si-Ta system at $800^{\circ} \mathrm{C}$ showing the contact line and superimposed diffusion path.

a)

b)

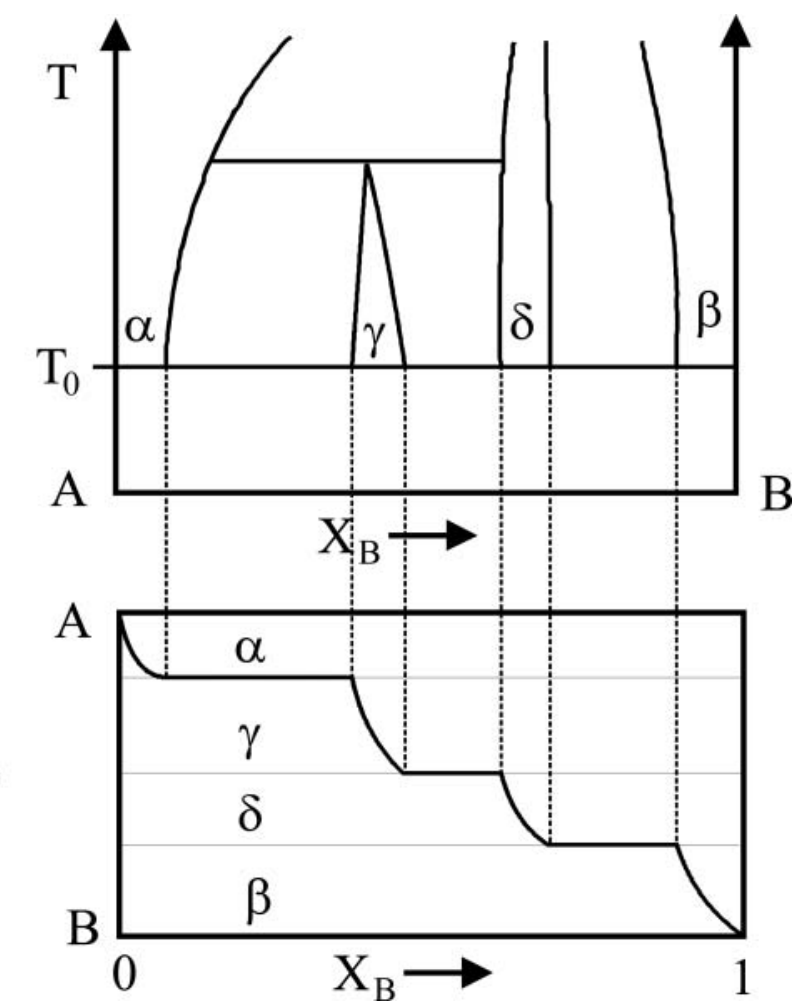

FIG. 11. Schematic binary phase diagram and the corresponding reaction structure at $\mathrm{T}_{0}$. (C) Elsevier. Adapted with permission from Elsevier. ${ }^{34}$ Permission to reuse must be obtained from the rightsholder.) above. If the local equilibrium can be assumed in the system, it is often possible to use phase diagrams coupled with few rules to predict possible or at least to rule out impossible reaction sequences in ternary systems. The first rule is concerned with the principle of mass-balance, which requires that material cannot be created or destroyed during reaction. This requires that the diffusion path, which is a line in the ternary isotherm, representing the locus of the average compositions parallel to the original interface through the diffusion zone,${ }^{42-44}$ crosses the straight line connecting the end members of the diffusion couple at least once. During the reaction, the system will follow only one unique, reproducible diffusion path. Kirkaldy et al. presented number of rules which the diffusion path must obey. ${ }^{45-47}$

The concept of diffusion path can be comprehended with the help of Figure 12, which shows the hypothetical A-B-C phase diagram with two binary compounds $\mathrm{X}$ and $\mathrm{Z}$ and the ternary compound $T .{ }^{34}$ In Figure 12 four diffusion paths are given with the corresponding morphologies of the diffusion zone, for the diffusion couple $\mathrm{C}$ vs. X. They all fulfill the mass-balance requirement. This also gives constraints about the relative thicknesses of the various diffusion layers like $T$ and $\mathrm{Z}$ in Figure 12b. The $\mathrm{Z}$-phase has to be much thinner than the $T$-phase in order to comply with the mass-balance. This is because the Z-phase is much further from the contact-line (e.g., average composition) than the T-phase. Not only the relative thicknesses, but also the total thickness of the diffusion layer is related to the diffusion path. If, for example. in the Zphase the diffusion is very slow and in the T-phase fast, then the total layer width for Figures $12 \mathrm{~b}$ or $12 \mathrm{c}$ will be smaller than in the case of Figure 12d. In the first examples, the continuous Z-layer acts as a kind of diffusion barrier, whereas in the latter case the total layer thickness is governed by the faster diffusion in the T-phase, which is probably only little hindered by the discontinuous Z-particles. One must realize that diffusion path corresponds only to a topological distribution of phases in space.

It is difficult to predict the diffusion path or to exclude impossible ones with the help of the mass-balance requirement alone. Thus, van Loo et al. ${ }^{34}$ introduced another rule, which is based on the thermodynamic driving force behind the diffusion phenomenon. The rule states that no element can diffuse intrinsically against its own activity gradient. If this would take place, it would mean that atom should diffuse from low chemical potential area to high chemical potential areaa process that does not spontaneously occur in nature. By calculating the chemical activities of components as the function of the relative atomic fractions of the elements, and taking into account the above-mentioned mass-balance considerations, the sequence of compounds formed during reaction can often be predicted as can be seen from the following examples.

An example from the literature is shown in Figure 13, which is redrawn from Coates and Kirkaldy. ${ }^{46}$ It shows the 

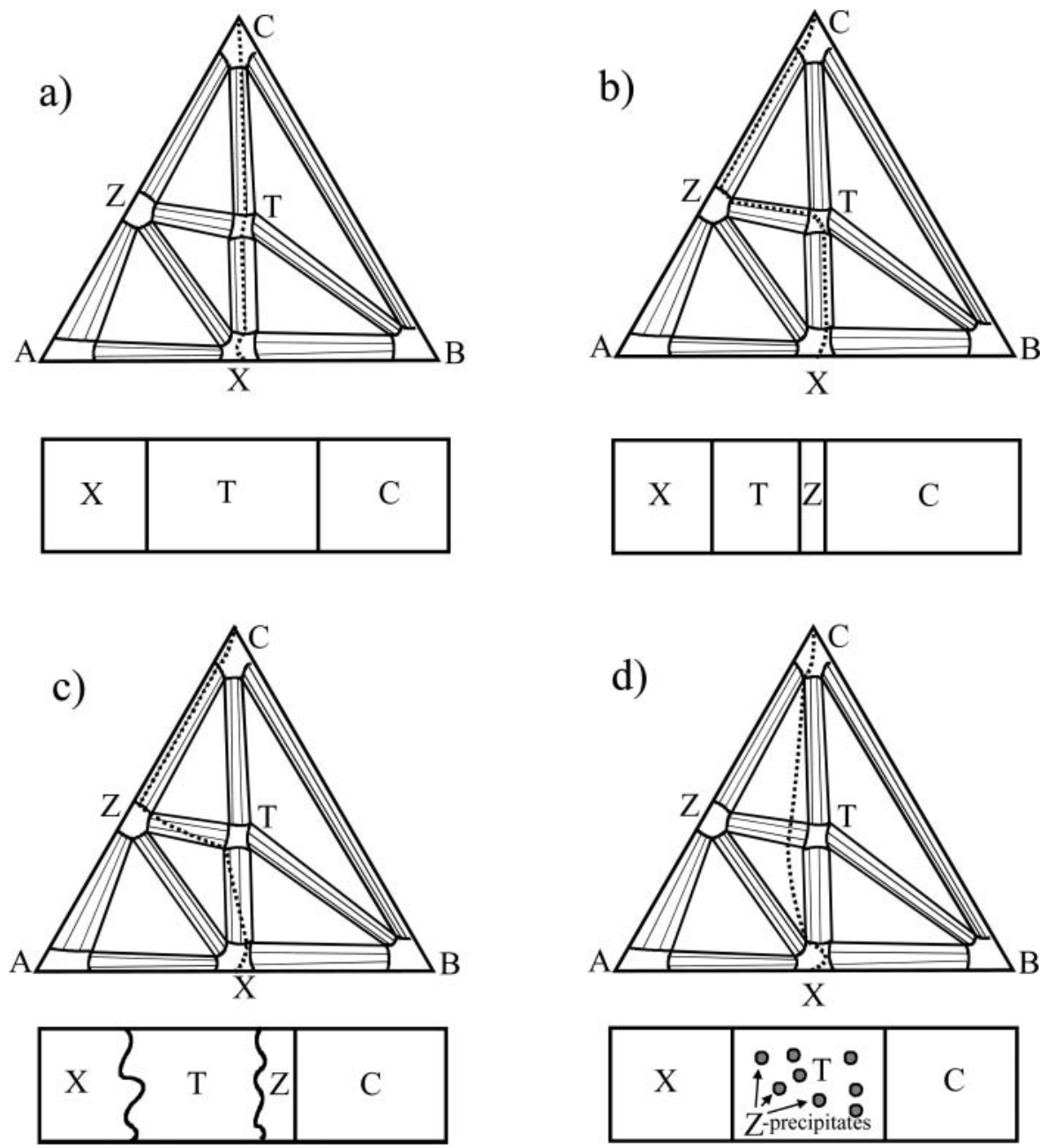

FIG. 12. Examples of possible morphologies for the reaction layer in a diffusion couple X/C. The corresponding diffusion paths are plotted on the isotherms. (C) Elsevier. Adapted with permission from Elsevier. ${ }^{34}$ Permission to reuse must be obtained from the rightsholder.)
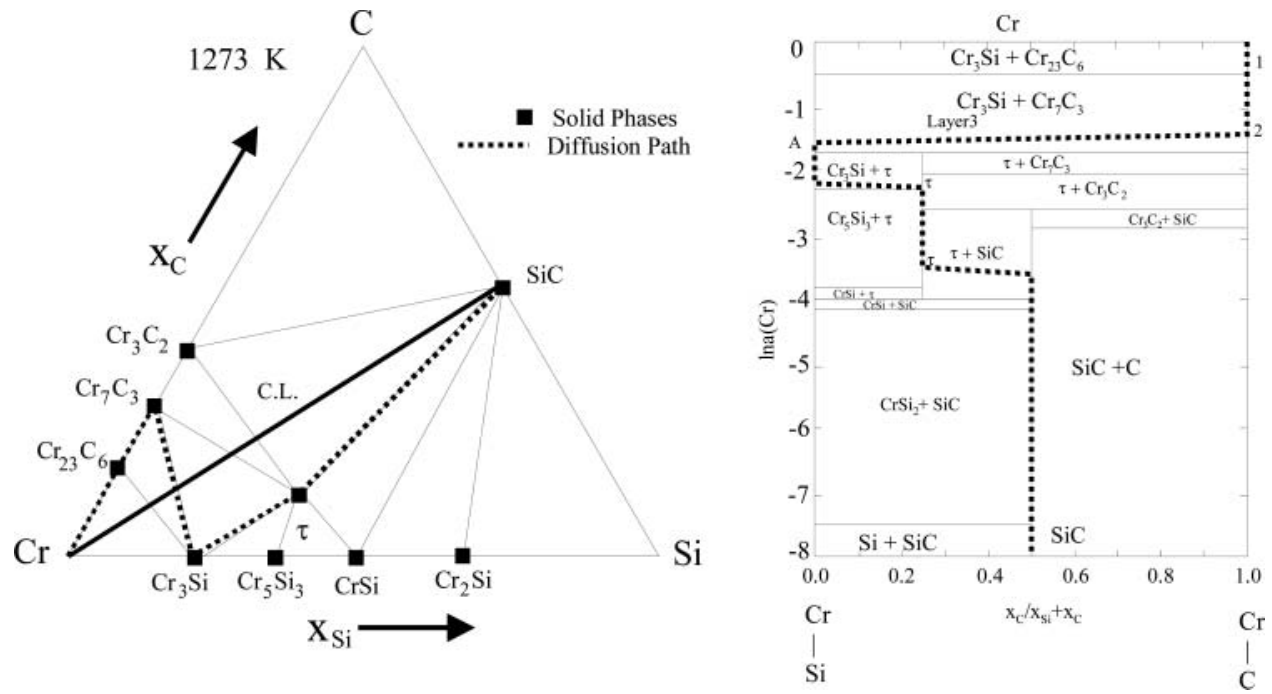

FIG. 13. Experimentally determined isothermal section and the calculated activity diagram at 1273 K. The contact line (C.L.) and the diffusion path are also superimposed onto both diagrams. $\tau$ is the ternary phase. (@) Hanser Publications. Adapted with permission from Hanser Publications. ${ }^{47}$ Permission to reuse must be obtained from the rightsholder.) 
isothermal section from the $\mathrm{Cr}-\mathrm{Si}-\mathrm{C}$ system at $1273 \mathrm{~K}$. The experimentally determined diffusion path is superimposed into the isothermal section and into the activity diagram. From Figure 13 it is evident that $\mathrm{Cr}$ moves along its decreasing activity in the experimentally observed reaction sequence $\mathrm{SiC} / \tau / \mathrm{Cr}_{3} \mathrm{Si}_{1} / \mathrm{Cr}_{3} \mathrm{Si}+\mathrm{Cr}_{7} \mathrm{C}_{3} / \mathrm{Cr}_{7} \mathrm{C}_{3} / \mathrm{Cr}_{23} \mathrm{C}_{6} / \mathrm{Cr}$. The phase sequence $\mathrm{SiC} / \mathrm{Cr}_{3} \mathrm{C}_{2} / \tau / \mathrm{CrSi} / \mathrm{Cr}_{5} \mathrm{Si}_{3} / \mathrm{Cr}_{3} \mathrm{Si} / \mathrm{Cr}$, another example of a diffusion path that fulfills the mass-balance requirement, is impossible from the thermodynamic point of view, since $\mathrm{Cr}$ would have to diffuse against its own activity gradient inside the ternary phase $\tau$ to get from $\mathrm{CrSi}$ to $\mathrm{Cr}_{3} \mathrm{C}_{2}$.

It should be noted that in thin film samples (as when working with very thin diffusion barriers) the assumption of local equilibrium, which is necessary for the above treatment, is not self-evident. The assumption of local equilibrium requires that reactions at the interfaces are fast enough so that all the atoms arriving in the reaction region are used immediately and the rate-determining step is diffusion, as discussed above. However, with very thin layers this requirement may not be always fulfilled. The reasons for this originate mainly from special conditions prevailing during thin film reactions: (a) relatively low reaction temperatures, (b) small dimensions, (c) high density of short-circuit diffusion paths, (d) relatively large stresses incorporated in thin films, (e) relatively high concentration of impurities, (f) metastable structures, (g) large gradients, and so on. These conditions mean at least that the complete thermodynamic equilibrium is practically never met in thin film systems. However, based on experimental results the local equilibrium is generally attained at interfaces quite rapidly and can still be expected to prevail in most cases. ${ }^{33}$ Therefore, the procedure presented above provides a feasible analysis method also for studying thin film reactions. Finally, it must be emphasized that there is no fundamental difference between thin film and bulk diffusion couples, and the differences often observed (i.e., sequential vs. simultaneous phase formation) occur because of the structural features of thin film structures (see the list above).

\section{KINETIC CONSIDERATIONS}

The driving force for interdiffusion is the difference in concentration (or more precisely in chemical potential or activity). Typically, diffusion kinetic analyses are based on the standard solutions of Fick's laws under certain boundary conditions. In the case of the steady state materials flow, i.e., when the concentration remains constant with time, Fick's first law states that the flux of element $i\left(\mathrm{~J}_{\mathrm{i}}\right)$ is directly proportional to the product of the diffusion coefficient (D) and the concentration gradient of an element $\mathrm{i}^{32}$

$$
J=-D \frac{\partial c}{\partial x}
$$

For non-steady state diffusion, in which the concentration varies with distance and time, Fick's second law is applied: ${ }^{32}$

$$
\frac{\partial c}{\partial t}=-\frac{\partial J}{\partial x}=\frac{\partial}{\partial x}\left(D \frac{\partial c}{\partial x}\right)
$$

Thus, at constant temperature the rate of change of concentration is equal to the diffusivity times the rate of change of the concentration gradient. The utilization of Equation (12) requires there to be a significant (measurable) composition difference within a phase. Then the diffusion coefficients can be obtained by using either Bolzmann-Matano or Sauer-Freise analysis. ${ }^{32}$ However, if the system includes phases that have narrow homogeneity ranges (like many intermetallic compounds in solder interconnections), the above-mentioned analyses are not applicable and the method derived by Wagner ${ }^{48}$ needs to be used.

The total Gibbs energy of the system, as shown in Equation (1), can be expressed as a function of chemical potentials, which are related to the activities of the components as follows: ${ }^{21}$

$$
\mu_{i}^{\phi} \equiv \mu_{i}^{0}(T)+R T \ln a_{i}
$$

Since the chemical potential of a component $i$ will have the same value in all the equilibrated phases, the difference in activity of a component (i.e., the driving force for its diffusion) will vanish at equilibrium. In the case of local equilibrium there are concentration gradients in the adjoining phases, but due to the chemical interaction between component atoms the diffusion is not necessarily driven by these gradients. Instead, the difference in chemical potential is the real driving force for diffusion as already discussed. A fundamental condition is that no atom can diffuse intrinsically against its own activity gradient as discussed above and in van Loo. ${ }^{34}$ If a maximum is found experimentally in the activity profile of a component it is caused by the intrinsic movement of the other components. This condition is used as a criteria when thermodynamic prerequisites for the diffusion of certain species in a given reaction sequence is rationalized with the help of activity diagrams (Figure 8). In addition, the thermodynamic data obtained from the simulations can be utilized also in quantitative diffusion flux calculations, as shown next.

The intrinsic flux of a component A in, for instance, an A-B binary alloy will be written in terms of gradient in chemical potential $\mu$ :

$$
J_{\mathrm{A}}=-B_{\mathrm{A}} C_{\mathrm{A}} \frac{\partial \mu_{\mathrm{A}}}{\partial x}
$$

where $B_{\mathrm{A}}$ is called the atomic mobility of A. The chemical 
potential of $\mathrm{A}, \mu_{\mathrm{A}}$, can be written in terms of activity, $a_{\mathrm{A}}$ :

$$
\mu_{\mathrm{A}}=\mu_{\mathrm{A}}^{\theta}+\mathrm{R} T \ln a_{\mathrm{A}},
$$

where $\mu_{\mathrm{A}}^{\theta}$ is the chemical potential at the chosen standard state $\left(T=298 \mathrm{~K} ; p^{\theta}=1\right.$ bar) in $\mathrm{J} / \mathrm{mol}$ and $\mathrm{R}$ is the gas constant (8.3143 J/molK). Substituting Equation (15) in Equation (14) and knowing that $\mathrm{d} N_{\mathrm{A}}=\left(V_{\mathrm{m}}^{2} / V_{\mathrm{B}}\right) \mathrm{d} C_{\mathrm{A}}$ [48] and $C_{\mathrm{A}}=N_{\mathrm{A}} / V_{\mathrm{m}}$ one can obtain:

$$
J_{\mathrm{A}}=-B_{\mathrm{A}} \mathrm{R} T \frac{V_{\mathrm{m}}}{V_{\mathrm{B}}}\left(\frac{\partial \ln a_{\mathrm{A}}}{\partial \ln N_{\mathrm{A}}}\right) \frac{\mathrm{d} C_{\mathrm{A}}}{\mathrm{d} x},
$$

with $\frac{\mathrm{d} \ln a_{\mathrm{A}}}{\mathrm{d} \ln N_{\mathrm{A}}}=\frac{\mathrm{d} \ln a_{\mathrm{B}}}{\mathrm{d} \ln N_{\mathrm{B}}}$ being the thermodynamic factor $\left(a_{\mathrm{A}}\right.$ an $a_{\mathrm{B}}$ are the chemical activities of components and mole fraction is now denoted by $N_{i}$ ). The standard state is generally the pure element (Raoultian) reference state. In a binary system there is only one thermodynamic factor, but this is not the case in ternary systems (Note 2). It should also be noted that even in a binary system the situation may become more complicated if the vacancies are not present in their equilibrium amount. In that case their chemical potential is no longer zero and the binary system turns effectively to a ternary one.

The mobility of $\mathrm{A}, B_{\mathrm{A}}$, can be experimentally determined from a tracer experiment. If one deposits an "infinitely" thin layer of a radioactive isotope of $\mathrm{A}$ on the surface of an homogeneous A-B alloy, the activity as a function of the distance in the diffusion direction after annealing can be measured using the sectioning technique. By applying the method of Gruzin, ${ }^{50}$ in which it is assumed that the atoms $\mathrm{A}$ and isotopes $\mathrm{A}^{*}$ move identically, a so-called tracer diffusion coefficient $D_{\mathrm{A}}^{*}$ can be derived. The Nernst-Einstein relation directly connects the tracer diffusion coefficient to the atomic mobility:

$$
D_{i}^{*}=B_{i} \mathrm{R} T \text {. }
$$

When we now take Fick's law, Equations (16) and (17), we arrive at a general relation between the intrinsic and tracer diffusion coefficients:

$$
D_{\mathrm{A}}=D_{\mathrm{A}}^{*} \frac{V_{\mathrm{m}}}{V_{\mathrm{B}}}\left(\frac{\partial \ln a_{\mathrm{A}}}{\partial \ln N_{\mathrm{A}}}\right) .
$$

If the pertinent thermodynamic data are available, Equation (18) allows the calculation of intrinsic diffusivities from tracer diffusion coefficients. At this point, it is appropriate to remember that when we have calculated the phase and stability diagrams for the system under investigation we have this thermodynamic data. In this way, we can utilize tracer diffusion coefficients that are available in the literature, which will greatly reduce the amount of experimental work necessary when phase growth behavior in specific system is investigated. It is to be noted here that for example when using marker experiments to determine intrinsic diffusion coefficients $\left(D_{i}\right.$ 's) (needed in the thermodynamic-kinetic analysis) they can be only determined at the Kirkendall-plane (i.e., at one composition). Thus, for a phase with wide solubility range many diffusion couples and/or multifoil experiments should be carried out to determine the $\mathrm{D}_{\mathrm{i}}$ 's over the appropriate concentration range. However, when thermodynamic assessment of the system is at hand the $\mathrm{D}_{\mathrm{i}}$ 's can be calculated with the help of Equation (18).

It is often the case that the phase under investigation grows with very narrow homogeneity range following the phase diagram and it is not possible to determine the vanishingly small concentration gradient to calculate the interdiffusion coefficient. To circumvent this problem, Wagner ${ }^{20}$ introduced the concept of integrated diffusion coefficient $\left(\tilde{D}_{\text {int }}\right)$ and can be expressed in terms of composition of $i$ as

$$
\tilde{D}_{\text {int }}=\int_{N_{V}^{\prime}}^{N_{V}^{\prime \prime}} \tilde{D} d N_{i}=\tilde{D} \Delta N_{i}
$$

where $\tilde{D}\left(\mathrm{~m}^{2} / \mathrm{s}\right)$ is the interdiffusion coefficient, $N_{i}$ is the composition of I, and $\Delta N_{i}=N_{i}^{\prime \prime}-N_{i}^{\prime}$ is the narrow homogeneity range of the product phase.

Further, interdiffusion coefficient, $\tilde{D}$ is related to the tracer diffusion coefficient of the species, $D_{A}^{*}$ and $D_{B}^{*}$ by

$$
\tilde{D}=\left(N_{A} D_{B}^{*}+N_{B} D_{A}^{*}\right) W\left(\frac{d \ln a_{B}}{d \ln N_{B}}\right)
$$

where $N_{A}$ and $N_{B}$ are the composition of $\mathrm{A}$ and $\mathrm{B}$ in the ABphase, $\frac{d \ln a_{B}}{d \ln N_{B}}$ is the thermodynamic factor, $a_{B}$ is the activity of the element $\mathrm{B}$ and $W$ is the vacancy wind effect and can be in most cases considered as one. ${ }^{50}$ By replacing Equation (20) in Equation (19) and following standard utilization of common tangent construction in Gibbs energy diagrams: ${ }^{30,51}$

$$
\begin{aligned}
\tilde{D}_{\text {int }} & =\int_{I}^{I I}\left(N_{A} D_{B}^{*}+N_{B} D_{A}^{*}\right) N_{B} d \ln a_{B} \\
& =\left(N_{A} D_{B}^{*}+N_{B} D_{A}^{*}\right) N_{B}\left[\ln a_{B}^{I}-\ln a_{B}^{I I}\right],
\end{aligned}
$$

where I and II represents the interfaces from which the product phase grows.

Furthermore, following Equation (21) and from the standard thermodynamic relation, $\mu_{B}=\mu_{B}^{o}+R T \ln a_{B}$, we can 


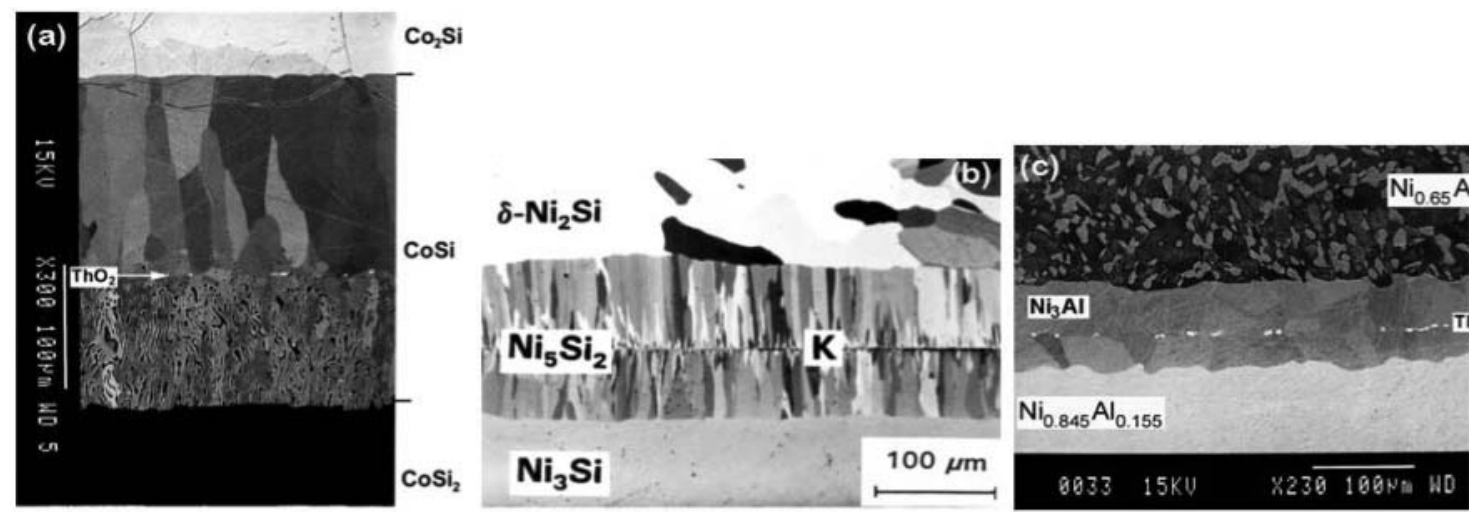

FIG. 14. Micrographs showing the microstructures and position of Kirkendall planes in different systems.

write as

$$
\begin{aligned}
\tilde{D}_{\text {int }} & =\left(N_{A} D_{B}^{*}+N_{B} D_{A}^{*}\right) \frac{N_{B}\left(\mu_{B}^{I I}-\mu_{B}^{I}\right)}{R T} \\
& =-\left(N_{A} D_{B}^{*}+N_{B} D_{A}^{*}\right) \frac{N_{B} \Delta_{r} G_{B}^{o}}{R T},
\end{aligned}
$$

where $G_{B}$ is the free energy of pure $\mathrm{B}, \mu_{B}$ is the chemical potential of $\mathrm{B}$, and $\Delta_{r} G_{B}^{o}$ is the driving force for the diffusion of B. The values of $\Delta_{r} G_{B}^{o}$ under different ambient conditions can be calculated from the appropriate data.

\subsection{A Physico-Chemical Approach to Explain the Morphological Evolution in an Interdiffusion Zone}

In many cases a characteristic morphology develops in the product phase which grows by reactive diffusion. For example, microstructures from three incremental diffusion couples from $\mathrm{Co}-\mathrm{Si}, \mathrm{Ni}-\mathrm{Si}$ and $\mathrm{Ni}-\mathrm{Al}$ systems are shown in Figure 14. It can be seen that a duplex morphology is present always when there is a Kirkendall marker plane present inside a phase.

The experimental results shown above indicate that the mechanism of the phase layer growth depends on the properties of the interface where it grows. In reactive diffusion, the product phase layers are grown because of the chemical reactions of diffusing component at the interfaces. Thus, even though one can use the phenomenological approach outlined above to investigate the thickness evolution of growing reaction layers, the reactions at the reaction interfaces are important if morphological evolution in the interdiffusion zone is to be investigated. It is to be noted that the interfacial reactions are not typically the rate controlling process in the examples discussed below, since in these the diffusion of components through the product phase take much longer time than the reactions at the interface, especially after the initial steps of the phase growth. However, there are many examples, specifically in thin film condition, where the growth of the phase may be reaction controlled. ${ }^{33}$ For the following examples (Chapter 5), we will always consider that diffusion is the rate controlling process. The equivalence of the physicochemical approach and the phenomenological relations discussed above is shown in detail in the Appendix.

\section{THERMODYNAMIC-KINETIC METHOD}

In Sections 2 and 3 the two fundamental subjects, energetics, and kinetics that can be utilized to rationalize the phase growth were briefly introduced. If one considers the phenomena of phase growth at a very general level one can see that there are always two factors that are involved, namely the thermodynamic driving force $\Delta \mathrm{G}$ and the kinetic "factor" $\mathrm{K}$. Thus, the phase growth can be described as a product of the two contributing factors $\Delta G x K$. When one looks at this very generic expression at least three different cases can be thought of: (i) very large driving force $(\Delta G)$, but very sluggish kinetics $(K)$, which will lead to slow or no growth of the phase in question; (ii) very low driving force $(\Delta G)$ but very facile kinetics $(K)$, which again can lead to slow or no growth; and (iii) both factors are large enough so that the phase growth will be feasible. Thus, even with these very elementary considerations it is evident that if one only looks at the energetic or kinetic part alone, severe errors may be induced to the analysis. This is the very core of the thermodynamic-kinetic method (Figure 1). It combines both aspects outlined in the above sections to a one method that can be used for many different applications, as will be shown in Section 5. In addition, the method enables one to use both quantitative thermodynamic and diffusion kinetic data by providing clear guidelines what thermodynamic quantities or which diffusion coefficients should be used, for instance. To provide here a few connections between thermodynamics and diffusion kinetics one can think of: (i) using driving forces for diffusion obtained from the Gibbs free energy diagrams to calculate integrated diffusion coefficient based on the tracer diffusion data (Equation (22)); (ii) utilize the activity data to calculate intrinsic diffusion coefficients; (iii) use of Gibbs energy diagrams to investigate the effect of alloying elements on the driving forces for diffusion; and (iv) use the physicochemical approach to rationalize how the 
TABLE 1

The integrated diffusion coefficients, $\tilde{D}_{\text {int }}$, molar volumes, $v_{m}$ of the Co-silicides and the ratio's of intrinsic fluxes of $\mathrm{Si}$ and

$\mathrm{Co}, V_{C o} D_{S i} / V_{S i} D_{C o}$ at $1100^{\circ} \mathrm{C}$ in different phases are listed

\begin{tabular}{ccc}
\hline & \multicolumn{2}{c}{ Phase } \\
\cline { 2 - 3 } & $\mathrm{Co}_{2} \mathrm{Si}$ & $\mathrm{CoSi}$ \\
\hline$\tilde{D}_{\text {int }}\left[\mathrm{m}^{2} / \mathrm{s}\right]^{*}$ & $(1.5 \pm 0.5) \times 10^{-14}$ & $(4.6 \pm 0.3) \times 10^{-14}$ \\
$\frac{D_{S i}^{*}}{D_{C o}^{*}}=\frac{V_{C o} D_{S i}}{V_{S i} D_{C o}}$ & $0.06 \pm 0.025$ & $35 \pm 15$ \\
$v_{m}\left[\mathrm{~m}^{3} \cdot \mathrm{mole}^{-1}\right]$ & $6.56 \times 10^{-6}$ & $6.60 \times 10^{-6}$ \\
\hline
\end{tabular}

*average values obtained from different diffusion couples

aforementioned changes affect the reactions and dissociation at different interfaces and so forth. Some of the ways to use thermodynamic-kinetic method are shown in Section 5. It must be evident, however, that a large amount of other possibilities also exist.

\section{EXAMPLES OF THE USE OF THERMODYNAMIC- KINETIC METHOD}

In this section we will show several examples of how to utilize the above outlined thermodynamic-kinetic method in various ways to rationalize reactive phase growth in different systems.

\subsection{Physicochemical Approach to Study Co-Si System}

Because of the extensive data available, we consider the phase growth in Co-Si system. Similar method can be used also in other systems. The useful data at $1100^{\circ} \mathrm{C}$ are listed in

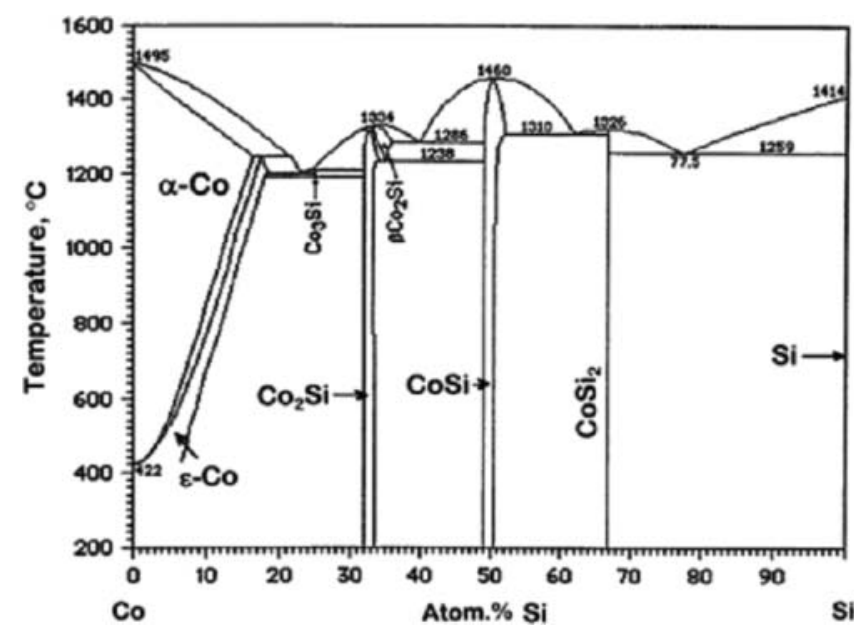

FIG. 15. Co-Si binary phase diagram. (C) ASM International. Adapted with permission from ASM International. ${ }^{52}$ Permission to reuse must be obtained from the rightsholder.)

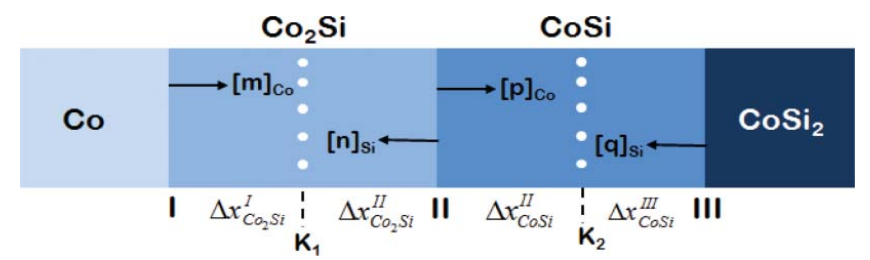

FIG. 16. Schematic diffusion couple $\mathrm{Co} / \mathrm{CoSi}_{2}$.

Table 1. At first, we consider a diffusion couple of $\mathrm{Co} / \mathrm{CoSi}{ }_{2}$, in which, according to the phase diagram shown in Figure 15, two phases, $\mathrm{Co}_{2} \mathrm{Si}$ and $\mathrm{CoSi}$ should grow in the interdiffusion zone.

Schematic diffusion couple is shown in Figure 16. As shown in the figure, it is necessary to consider the presence of a Kirkendall marker plane in both phases. In the following, we consider that the total fluxes of $\mathrm{Co}$ and $\mathrm{Si}$ atoms that cross the Kirkendall marker plane in the $\mathrm{Co}_{2} \mathrm{Si}$ phase are $[\mathrm{m}]_{\mathrm{Co}}$ and $[n]_{\mathrm{Si}}$, respectively. Similarly, the total flux of Co and $\mathrm{Si}$ that cross the Kirkendall marker plane in the CoSi phase are $[p]_{\mathrm{Co}}$ and $[q]_{\mathrm{Si}}$, respectively. Growth of the $\mathrm{Co}_{2} \mathrm{Si}$ phase occurs at the interface I by the reaction $\mathrm{Co}$ with $\mathrm{Si}$ that has diffused through this phase after being released by dissociation from the interface II. At the interface II, the same phase grows owing to the dissociation of $\mathrm{Si}$ from the CoSi phase. At the same time, the phase also grows because of reaction between $\mathrm{CoSi}$ and diffusing Co that has been released from the interface I. Likewise, CoSi phase grows at the interface II because of dissociation of $\mathrm{Co}$ from the $\mathrm{Co}_{2} \mathrm{Si}$ phase and reaction of diffusing $\mathrm{Si}$ with the same phase. The dissociated Co atoms subsequently diffuse through the CoSi product phase and react with the $\mathrm{CoSi}_{2}$ phase to produce $\mathrm{CoSi}$ at the interface III. Si that reacts with the $\mathrm{Co}_{2} \mathrm{Si}$ phase at the interface II originates from the dissociation of the $\mathrm{CoSi}_{2}$ phase at the interface III. Thus, it is clear that phases $\mathrm{Co}_{2} \mathrm{Si}$ and $\mathrm{CoSi}$ grow (i) by consuming the neighboring phase(s) and (ii) at the same time they get consumed because of the growth of the neighboring phase (s). Hence, the two phases do not grow independently in this reaction couple. This is the situation irrespectively of the number of phases growing in the reaction couple (as long as it is equal or larger than two).

In terms of reaction equations these can be written as:

At the interface $\mathrm{I}\left(\mathrm{Co} / \mathrm{Co}_{2} \mathrm{Si}\right.$ on the $\mathrm{CO}_{2} \mathrm{Si}$-side $)$

$$
2 n \mathrm{Co}+n[\mathrm{Si}]_{d} \rightarrow 3 n \mathrm{Co}_{2 / 3} \mathrm{Si}_{1 / 3}
$$

At the interface II $\left(\mathrm{Co}_{2} \mathrm{Si} / \mathrm{CoSi}\right.$ on the $\mathrm{Co}_{2} \mathrm{Si}-$ side $)$

$$
\begin{gathered}
4 n \mathrm{Co}_{1 / 2} \mathrm{Si}_{1 / 2} \rightarrow n[\mathrm{Si}]_{d}+3 n \mathrm{Co}_{2 / 3} \mathrm{Si}_{1 / 3} \\
2 m \mathrm{Co}_{1 / 2} \mathrm{Si}_{1 / 2}+m[\mathrm{Co}]_{d} \rightarrow 3 m \mathrm{Co}_{2 / 3} \mathrm{Si}_{1 / 3}
\end{gathered}
$$


At the interface II $\left(\mathrm{Co}_{2} \mathrm{Si} / \mathrm{CoSi}\right.$ on the $\mathrm{CoSi}-$ side $)$

$$
\begin{aligned}
& 3 p \mathrm{Co}_{2 / 3} \mathrm{Si}_{1 / 3} \rightarrow p[\mathrm{Co}]_{d}+2 p \mathrm{Co}_{1 / 2} \mathrm{Si}_{1 / 2} \\
& 3 q \mathrm{Co}_{2 / 3} \mathrm{Si}_{1 / 3}+q[\mathrm{Si}]_{d} \rightarrow{ }_{4 q o_{1 / 2}} \mathrm{Si}_{1 / 2}
\end{aligned}
$$

At the interface III ( $\mathrm{CoSi} / \mathrm{CoSi}_{2}$ on the $\mathrm{CoSi}-$ side $)$

$$
\begin{aligned}
& 3 p \mathrm{Co}_{1 / 3} \mathrm{Si}_{2 / 3}+p[\mathrm{Co}]_{d} \rightarrow 4 p \mathrm{Co}_{1 / 2} \mathrm{Si}_{1 / 2} \\
& 3 q \mathrm{Co}_{1 / 3} \mathrm{Si}_{2 / 3} \rightarrow q[\mathrm{Si}]_{d}+2 q \mathrm{Co}_{1 / 2} \mathrm{Si}_{1 / 2} .
\end{aligned}
$$

Therefore, $3 n$ moles of $\mathrm{Co}_{2} \mathrm{Si}$ phase is produced at the interface I. At the interface II, $(3 m+3 n)$ moles of $\mathrm{Co}_{2} \mathrm{Si}$ is produced and at the same time $(3 p+3 q)$ moles gets consumed. At the same interface, at the other side, $(2 p+4 q)$ moles of $\mathrm{CoSi}$ is produced and $(4 m+2 n)$ moles get consumed. At the interface III, $(4 p+2 q)$ moles of CoSi is produced:

$$
\begin{aligned}
& v_{m}^{\mathrm{Co}_{2 / 3} \mathrm{Si}_{1 / 3}} \times 3 n=\Delta x_{\mathrm{Co}_{2} \mathrm{Si}}^{I} \\
& v_{m}^{\mathrm{Co}_{2 / 3} \mathrm{Si}_{1 / 3}} \times(3 m+3 n-3 p-3 q)=\Delta x_{\mathrm{Co} 2}^{I I} \mathrm{Si} \\
& v_{m}^{\mathrm{Co}_{1 / 2} \mathrm{Si}_{1 / 2}} \times(2 p+4 q-4 m-2 n)=\Delta x_{\mathrm{CoSi}}^{I I} \\
& v_{m}^{\mathrm{Co}_{1 / 2} \mathrm{Si}_{1 / 2}} \times(4 p+2 q)=\Delta x_{\mathrm{CoSi}}^{I I I}
\end{aligned}
$$

The integrated diffusion coefficients can be written as

$$
\begin{aligned}
& \tilde{D}_{\mathrm{int}}^{\mathrm{Co}_{2} \mathrm{Si}}=\frac{v_{m}^{\mathrm{Co}_{2} \mathrm{Si}}}{2 t}\left[\mathrm{~N}_{\mathrm{Si}}^{\mathrm{Co}_{2} \mathrm{Si}} p+N_{\mathrm{Co}}^{\mathrm{Co}_{2} \mathrm{Si}} q\right]\left(\Delta x_{\mathrm{Co}_{2} \mathrm{Si}}^{I}+\Delta x_{\mathrm{Co}_{2} \mathrm{Si}}^{\mathrm{II}}\right) \\
& \tilde{D}_{\mathrm{int}}^{\mathrm{CoSi}}=\frac{v_{m}^{\mathrm{COSi}}}{2 t}\left[N_{\mathrm{Si}}^{\mathrm{CoSi}} m+N_{\mathrm{Co}}^{\mathrm{Co}_{2} S i} n\right]\left(\Delta x_{\mathrm{CoSi}}^{I I}+\Delta x_{\mathrm{CoSi}}^{I I I}\right) .
\end{aligned}
$$

The ratio of diffusivities can be written as

$$
\begin{aligned}
& \left.\frac{D_{\mathrm{Si}}^{*}}{D_{\mathrm{Co}}^{*}}\right|_{\mathrm{Co}_{2} \mathrm{Si}}=\left.\frac{\bar{v}_{\mathrm{Co}} D_{\mathrm{Si}}}{\bar{v}_{\mathrm{Si}} D_{\mathrm{Co}}}\right|_{\mathrm{Co}_{2} \mathrm{Si}}=\frac{q}{p} \\
& \left.\frac{D_{S i}^{*}}{D_{C o}^{*}}\right|_{C o S i}=\left.\frac{\bar{v}_{C o} D_{S i}}{\bar{v}_{S i} D_{C o}}\right|_{C o S i}=\frac{n}{m} .
\end{aligned}
$$

Using the values of molar volumes, integrated diffusion coefficients and the ratio of the intrinsic or tracer diffusion coefficients, as listed in Table 1, we find the values as

$\Delta x_{\mathrm{Co}_{2} \mathrm{Si}}^{I}=32 \mu \mathrm{m}, \Delta x_{\mathrm{Co}_{2} \mathrm{Si}}^{\mathrm{II}}=133 \mu \mathrm{m} \Delta x_{\mathrm{CoSi}}^{I I}=168.5 \mu \mathrm{m}$, $\Delta x_{C o S i}^{I I I}=294.5 \mu \mathrm{m}, m=26.8, n=1.6, p=0.6$ and $q=21.0$, $\mathrm{mol} / \mathrm{m}^{2}$.

One interesting fact that should be noted here is that the thicknesses of all the sublayers are positive. Thus, despite getting consumed by the neighboring phases at the interface II, the values $\Delta x_{\mathrm{CO}_{2} \mathrm{Si}}^{\mathrm{II}}$ and $\Delta x_{\mathrm{CoSi}}^{\mathrm{II}}$ are still positive. This means both phases will have stable Kirkendall marker plane and

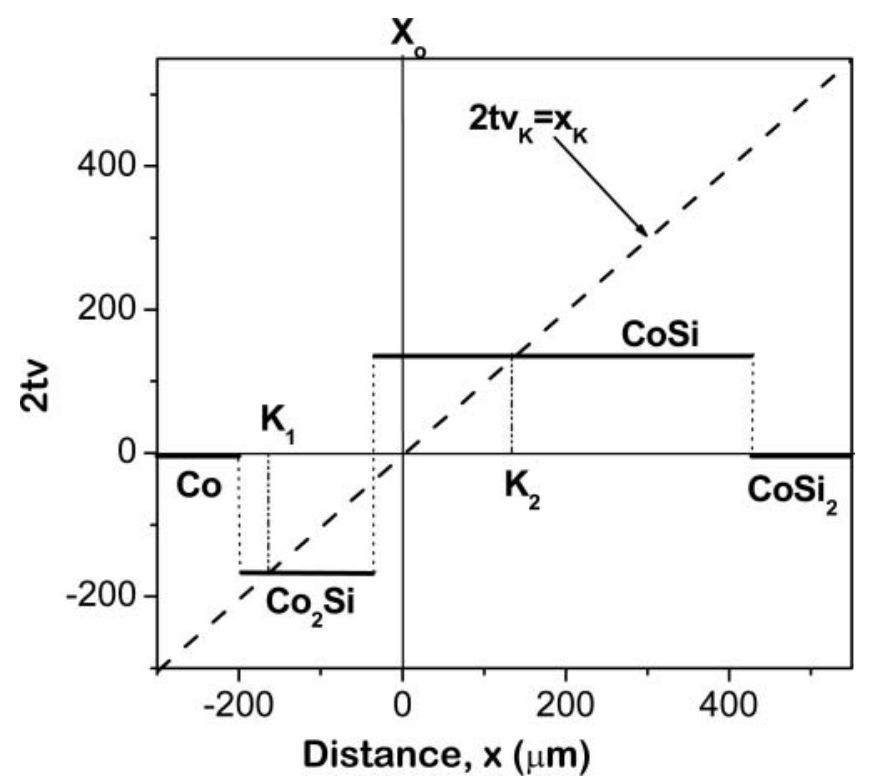

FIG. 17. Kirkendall velocity profile.

bifurcation of the Kirkendall marker plane is expected. ${ }^{53}$ This can be shown with the Kirkendall velocity diagram construction. Velocity of the phases can be estimated as

$$
\begin{aligned}
& V_{m}^{\mathrm{Co}_{2} \mathrm{Si}}(n-m)=2 t v_{K}^{\mathrm{Co}_{2} \mathrm{Si}}=x_{K}^{\mathrm{Co}_{2} \mathrm{Si}}=-165.3 \mu \mathrm{m} \\
& V_{m}^{\mathrm{CoSi}}(q-p)=2 t v_{K}^{\mathrm{CoSi}}=x_{K}^{\mathrm{CoSi}}=134.6 \mu \mathrm{m} .
\end{aligned}
$$

Note that here we have assumed the partial molar volume of the component to be equal to the molar volume of the phase. It should be noted here that for the velocity diagram plot, we have not determined the initial contact plane, as this cannot be carried out properly in the present case. However, if the range of the $y$ and $x$ axes are kept the same, the straight

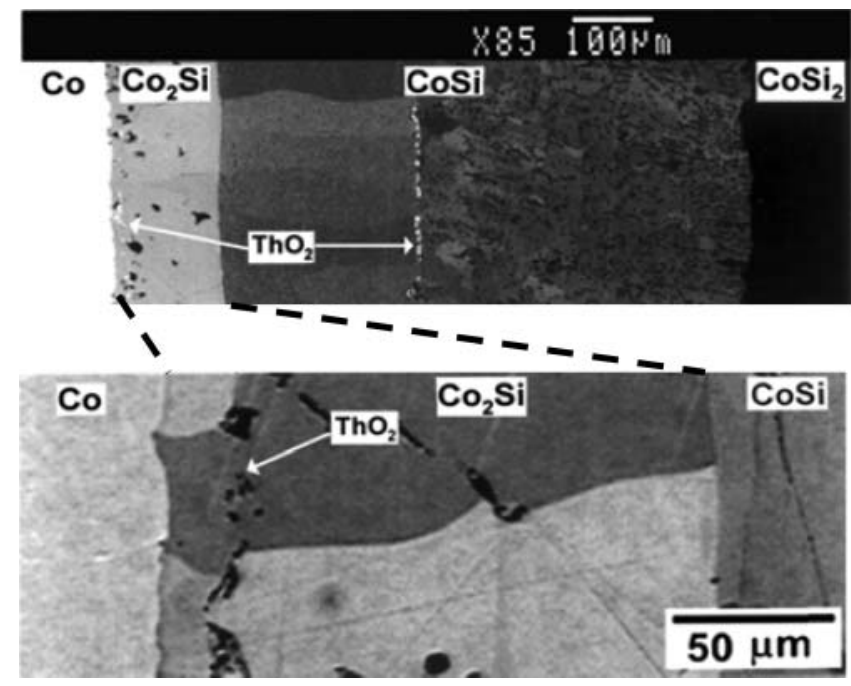

FIG. 18. Micrographs from the $\mathrm{Co} / \mathrm{CoSi}_{2}$ diffusion couple. 


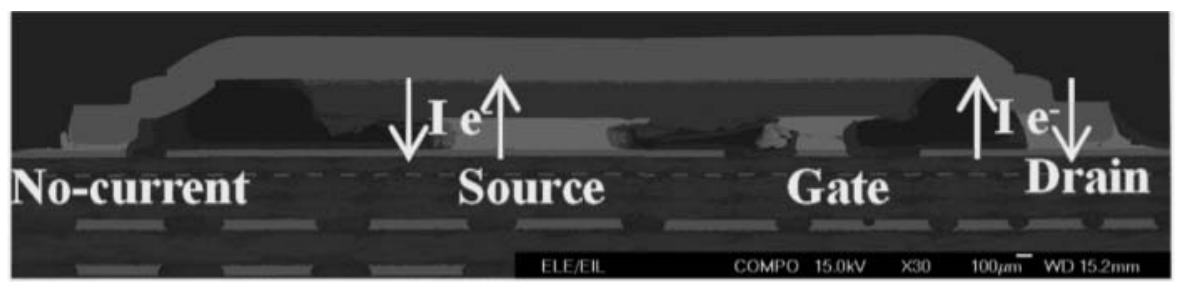

FIG. 19. SEM micrograph of the structure of the component used in the electromigration study.

line $2 t v_{K}=x_{K}$ will have an angle of $45^{\circ}$. That means the straight line can be drawn from one corner of the diagram to another, as shown in Figure 17. The location of the initial contact plane is the position at which the line intersects $2 t v=0$. The points of intersection by the straight line $2 t v_{K}=x_{K}$ and the line representing the marker velocity in a given phases indicate the location of the Kirkendall marker plane in that phase. Since we have considered the phases with an average composition, the velocity of the phase is drawn by the straight lines with slope of zero. The interdiffusion zone in the $\mathrm{Co} / \mathrm{CoSi}_{2}$ phase is shown in Figure 18. It can be seen that the thickness of the phase layers are similar within the range of experimental error. As estimated, both phases have the Kirkendall marker plane. The presence of duplex morphology is also evident in both phases indicating the location of the marker planes. Note here that there was very small dissolution of $\mathrm{Si}$ in the Co end member, which is neglected in this analysis. This result into minor error in the values estimated.

\subsection{Effect of Electron Flux on the Growth of $\varepsilon$ and $\eta$-Phases in Cu-Sn System}

Let us build on the above discussion and consider the effect of additional driving forces, such as electric field, on the growth of interfacial phases. Figure 19 shows a cross-section of the component with the directions of the current and electron flux superimposed. The electron flux enters the component from the source contact and leaves from the drain contact. In the forthcoming analysis of the effect of the electron flow on the IMC growth only the PWB side is considered. This is because, at the component side, the presence of Ag finish will make the analysis less quantitative.
Figure 20 shows the interfacial microstructures from solder|PWB interfaces from the samples that have been annealed at $110^{\circ} \mathrm{C}$ for $750 \mathrm{~h}$ and both the drain as well as source contacts after $750 \mathrm{~h}$ of constant current stressing. Due to the relatively complex geometry of the interconnections and the differences in cross-sectional areas, the current crowding effects and thus the differences in current densities cannot be easily addressed. However, even if only the direction of the electron flux is taken into consideration, the marked differences in the total IMC growth kinetics as well as the relative thicknesses on the $\mathrm{Cu}_{6} \mathrm{Sn}_{5}$ and $\mathrm{Cu}_{3} \mathrm{Sn}$ intermetallic compounds can be observed when these differences are compared with the results obtained using the diffusion couple experiments. ${ }^{54}$ Closer examination of Table 2 and Figure 20 reveals that when the flow of electrons is towards the PWB, the $\eta$ and $\varepsilon$ layers are almost of the same thickness, whereas in the opposite situation the thickness of $\mathrm{Cu}_{3} \mathrm{Sn}$ is drastically reduced.

From the results of the steady current experiments, it can be seen that in the drain contact the electron flux comes from the solder side to the interface. Thus, the PWB pad is acting as the anode, meaning that the Sn flux towards the PWB is increased in both IMC layers whereas the flux of $\mathrm{Cu}$ from the PWB is decreased, which, based on the experimental results, seems to favor the growth of $\mathrm{Cu}_{3} \mathrm{Sn}$. This can be analyzed in more detail with the help of Figure 21 and the following reaction equations.

\subsection{The Reaction Scheme}

\subsubsection{The Reaction Scheme}

The reactions occurring at different interfaces of the reaction couple, as shown in Figure 21, can be expressed as

TABLE 2

Thickness data of the intermetallic compounds grown at the interface

\begin{tabular}{lccc}
\hline & $\mathrm{Cu}_{3} \mathrm{Sn}$ & $\mathrm{Cu}_{6} \mathrm{Sn}_{5}$ & $\mathrm{Cu}_{6} \mathrm{Sn}_{5}$ to $\mathrm{Cu}_{3} \mathrm{Sn} \mathrm{ratio}$ \\
\hline No current & $0.8 \mu \mathrm{m}$ & $3 \mu \mathrm{m}$ & 3.8 \\
& $0.093 \mathrm{~mol} / \mathrm{m}^{2}$ & $0.283 \mathrm{~mol} / \mathrm{m}^{2}$ & 1.1 \\
Constant current from PWB & $2.1 \mu \mathrm{m}$ & $2.3 \mu \mathrm{m}$ & \\
& $0.244 \mathrm{~mol} / \mathrm{m}^{2}$ & $0.217 \mathrm{~mol} / \mathrm{m}^{2}$ & 4.2 \\
Constant current from solder & $0.9 \mu \mathrm{mc} \sim \sim \mathrm{no} \mathrm{change})$ & $3.8 \mu \mathrm{m}$ & \\
& $0.1 \mathrm{~mol} / \mathrm{m}^{2}$ & $0.360 \mathrm{~mol} / \mathrm{m}^{2}$ & \\
\hline
\end{tabular}




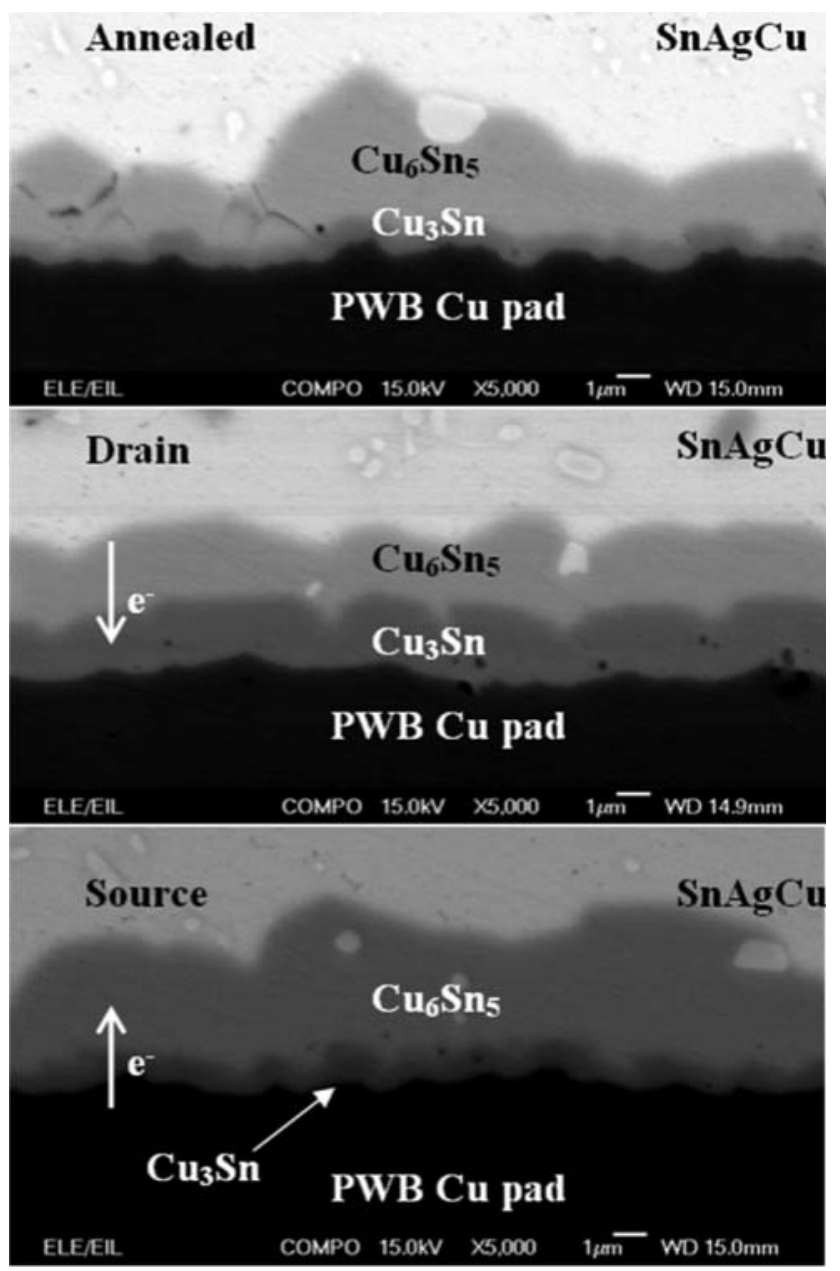

FIG. 20. SEM micrograph showing how the interfacial reaction layer structure depends on the direction of the electron flux.

follows:

Interface I :

$3 q C u+q[S n] d \rightarrow 4 q C u_{3 / 4} S_{1 / 4}$

Interface $\mathrm{II}-\mathrm{Cu}_{3} \mathrm{Sn}$ side :

$\frac{11}{9} p C u_{6 / 11} S n_{5 / 11}+p[C u]_{d} \rightarrow \frac{20}{9} p C u_{3 / 4} S n_{1 / 4}$

$\frac{11}{3} q C u_{6 / 11} S n_{5 / 11}+q[S n]_{d} \rightarrow \frac{8}{3} q C u_{3 / 4} S n_{1 / 4}$

Interface $\mathrm{II}-\mathrm{Cu}_{6} \mathrm{Sn}_{5}$ side :

$\frac{20}{9} r C u_{3 / 4} S n_{1 / 4} \rightarrow r[C u]_{d}+\frac{11}{9} r C u_{6 / 11} S n_{5 / 11}$

$\frac{8}{3} s C u_{3 / 4} S n_{1 / 4}+s[S n]_{d} \rightarrow \frac{11}{3} s C u_{6 / 11} S n_{5 / 11}$

Interface III :

$\frac{5}{6} r S n+r[C u]_{d} \rightarrow \frac{11}{6} r C u_{6 / 11} S n_{5 / 11}$

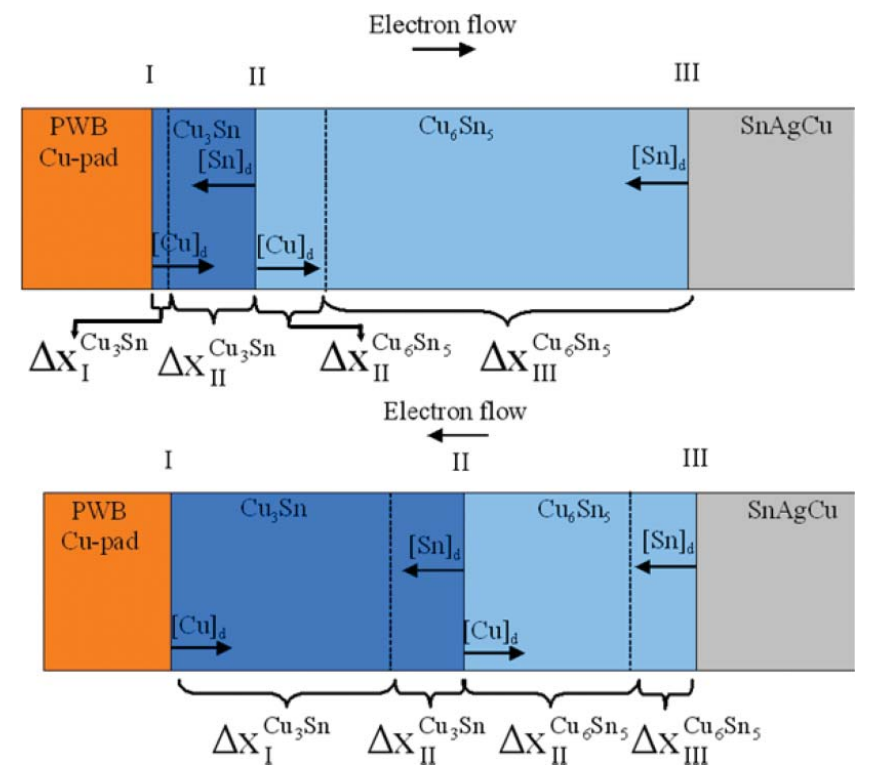

FIG. 21. Schematic presentation of the interfacial reactions occurring in the reaction couple.

Here, $p$ and $q$ are the moles of $\mathrm{Cu}$ and $\mathrm{Sn}$, respectively, transferred per unit area through the $\mathrm{Cu}_{3} \mathrm{Sn}$ phase during the total diffusion time $t$. Similarly, $r$ and $s$ are the number of moles of $\mathrm{Cu}$ and $\mathrm{Sn}$ transported during interaction per unit area through the $\mathrm{Cu}_{6} \mathrm{Sn}_{5}$-phase layer. From the equations written above, it is clear that at the interface II, not only $\left(\frac{20}{9} p+\frac{8}{3} q\right)$ moles of $\mathrm{Cu}_{3} \mathrm{Sn}$ grow, but also $\left(\frac{20}{9} r+\frac{8}{3} s\right)$ moles get consumed because of the growth of the $\mathrm{Cu}_{6} \mathrm{Sn}_{5}$ phase. Similarly, $\left(\frac{11}{9} r+\frac{11}{3} s\right)$ moles of $\mathrm{Cu}_{6} \mathrm{Sn}_{5}$ grow at the same interface, but $\left(\frac{11}{9} p+\frac{11}{3} q\right)$ moles get consumed by the $\mathrm{Cu}_{3} \mathrm{Sn}$ phase.

The thickness of the parts of the product phase layers resulting from the interfacial reactions given above can be expressed

TABLE 3

Summary of the experimental results

\begin{tabular}{lccc} 
After soldering & $\mathrm{Cu}_{6} \mathrm{Sn}_{5}[\mu \mathrm{m}]$ & $\mathrm{Cu}_{3} \mathrm{Sn}[\mu \mathrm{m}]$ & $\mathrm{IMC}$ tot $[\mu \mathrm{m}]$ \\
\hline No current & 1 & 0.1 & 1.1 \\
Drain & 1 & 0.1 & 1.1 \\
Source & 1 & 0.1 & 1.1 \\
1500 cycles & & & \\
No current & 1.8 & 1.4 & 3.2 \\
Drain & 2.4 & 1.2 & 3.6 \\
Source & 3.6 & 0.3 & 3.9 \\
3000 cycles & & & \\
No current & 1.9 & 1.9 & 3.8 \\
Drain & 2.7 & 1.7 & 4.2 \\
Source & 4.4 & 0.5 & 4.9 \\
\hline
\end{tabular}


as

$$
\begin{aligned}
& 4 q \times V_{m}^{C u_{3} S n}=\Delta x_{I}^{K_{1}} \\
& \left(\frac{20}{9} p+\frac{8}{3} q-\frac{20}{9} r+\frac{8}{3} s\right) \times V_{m}^{C u_{3} S n}=\Delta x_{I I}^{K_{1}} \\
& \left(\frac{11}{9} r+\frac{11}{3} s-\frac{11}{9} p-\frac{11}{3} q\right) \times V_{m}^{C u_{6} S n_{5}}=\Delta x_{I I}^{K_{2}} \\
& \frac{11}{9} r \times V_{m}^{C u_{6} S n_{5}}=\Delta x_{I I I}^{K_{2}}
\end{aligned}
$$

where $\Delta x_{I}^{K_{1}}$ and $\Delta x_{I I}^{K_{1}}$ are the thicknesses of the sublayers in the $\mathrm{Cu}_{3}$ Sn phase. $\Delta x_{I I}^{K_{2}}$ and $\Delta x_{I I I}^{K_{2}}$ are the thicknesses of sublayers in the $\mathrm{Cu}_{6} \mathrm{Sn}_{5}$ phase. The subscript $\mathrm{K}$ refers to the Kirkendall plane formed at the location where the two growth fronts (i.e., from the interfaces I and II) meet. The subscript 1 refers to $\mathrm{Cu}_{3} \mathrm{Sn}$ and 2 to the $\mathrm{Cu}_{6} \mathrm{Sn}_{5}$ phase. In Table 3, the experimental results about the effect of the electron flow on the growth of the IMCs are presented in a different way. In addition to thickness, the amount of each phase has been tabulated in terms of $\mathrm{mole} / \mathrm{m}^{2}$ for the sake of discussion.

\subsubsection{PWB as the Anode}

Let us first consider that there is an equal increase in the flux of $\mathrm{Sn}$ and an equal decrease in the flux of $\mathrm{Cu}$ in both phases. First, the two cases will be addressed separately and then the combined effect of the changes in the $\mathrm{Cu}$ and $\mathrm{Sn}$ fluxes is addressed.

(1) Increase in the Sn flux through the phases. Owing to the diffusion of Sn, 4 parts (in terms of moles) of the $\mathrm{Cu}_{3} \mathrm{Sn}$ product phase will grow at the interface I plus a further $8 / 3$ parts at the interface II by consuming the $\mathrm{Cu}_{6} \mathrm{Sn}_{5}$ phase. On the other hand, 8/3 parts will get consumed because of the growth of the $\mathrm{Cu}_{6} \mathrm{Sn}_{5}$ phase at the interface II. So in total there will be a net gain of 4 parts of the $C u_{3} S n$ phase in this case.

On the other hand, 11/3 parts of the $\mathrm{Cu}_{6} \mathrm{Sn}_{5}$ phase will grow at the interface II and the same amount will get consumed because of the growth of the $\mathrm{Cu}_{3} \mathrm{Sn}$ phase at that interface. So there should be no net change in the layer thickness of the $\mathrm{Cu}_{6} \mathrm{Sn}_{5}$ phase.

(2) Decrease in the Cu flux through the phases. If the flow of $\mathrm{Cu}$ decreases at the same rate through both phases, there will be 20/9 parts (in terms of moles) less production of $\mathrm{Cu}_{3} \mathrm{Sn}$ at the interface II. Further, because of the decreased diffusion rate of $\mathrm{Cu}$ through the $\mathrm{Cu}_{6} \mathrm{Sn}_{5}$ phase, there will be 20/9 less consumption of the $\mathrm{Cu}_{3} \mathrm{Sn}$ phase at the interface II. So there should be no net change in the layer thickness of the $C u_{3} S n$ phase because of the flow of electrons from solder to the PWB.

On the other hand, as a result of the lower production of the $\mathrm{Cu}_{3} \mathrm{Sn}$ phase at the interface II, there will be $11 / 9$ parts less consumption of the $\mathrm{Cu}_{6} \mathrm{Sn}_{5}$ phase at that interface. At the same time (because of the decreased flow rate of $\mathrm{Cu}$ through the $\mathrm{Cu}_{6} \mathrm{Sn}_{5}$ phase), there will 11/9 parts less production of the $\mathrm{Cu}_{6} \mathrm{Sn}_{5}$ phase due to the dissociation of the $\mathrm{Cu}_{3} \mathrm{Sn}$ phase at the interface II. Finally, there will be lower production of $11 / 6$ parts of the $\mathrm{Cu}_{6} \mathrm{Sn}_{5}$ phase at the interface III. So there should be a net loss in the thickness of the $\mathrm{Cu}_{6} \mathrm{Sn}_{5}$ phase compared to the situation when there is no flow of electrons.

(3) Combined effect of $\mathrm{Sn}$ and $\mathrm{Cu}$ fluxes. Thus, if the $\mathrm{Cu}$ and $\mathrm{Sn}$ fluxes are affected similarly in both phases, then for every 4 parts of $\mathrm{Cu} 3 \mathrm{Sn}$ phase increase there will be a corresponding $11 / 6$ parts decrease in the layer thickness of the $\mathrm{Cu}_{6} \mathrm{Sn}_{5}$ phase. This means that for a 1-part increase in the thickness of the $\mathrm{Cu}_{3} \mathrm{Sn}$ phase there will be a corresponding 0.46 parts decrease in the thickness of the $\mathrm{Cu}_{6} \mathrm{Sn}_{5}$ phase. In our experimental results we actually get for a 0.151 parts $\left(\mathrm{mol} / \mathrm{m}^{2}\right)$ increase in the thickness of the $\mathrm{Cu}_{3} \mathrm{Sn}$ phase a corresponding decrease of 0.066 parts in the $\mathrm{Cu}_{6} \mathrm{Sn}_{5}$ phase. This can be put another way: for a 1-part $\mathrm{Cu}_{3} \mathrm{Sn}$ phase increase, we get 0.44 parts of decrease in the $\mathrm{Cu}_{6} \mathrm{Sn}_{5}$ phase. This is very close to the analysis presented above and can thus be taken to indicate that the components ( $\mathrm{Sn}$ and $\mathrm{Cu}$ ) are indeed affected in a similar fashion by the electron flow. To conclude, it is now selfevident that it is time to re-examine the assumption that $\mathrm{Sn}$ should be strongly affected by the electron flux owing to its higher effective valence $\left(Z^{*}\right)$.

\subsubsection{PWB as the Cathode}

Again, we consider there to be an equal decrease of Sn flux and an increase of $\mathrm{Cu}$ in both phases. The good match between the analysis results based on this assumption with the experimental results, shown above, gives us further confidence that this approach is justified.

(1) Increase in $\mathrm{Cu}$ flux through the phases. When the amount of $\mathrm{Cu}_{3} \mathrm{Sn}$ increases by 20/9 parts (in moles) by consuming the $\mathrm{Cu}_{6} \mathrm{Sn}_{5}$ phase at the interface II because of the increase of $\mathrm{Cu}$ flux, 20/9 parts of the same phase will get consumed because of the growth of the $\mathrm{Cu}_{6} \mathrm{Sn}_{5}$ phase at the same interface. So there will be no net gain or loss in the thickness of the $\mathrm{Cu}_{3} \mathrm{Sn}$ phase because of the increase in the diffusion rate of $\mathrm{Cu}$. Owing to the increase in the flow of $\mathrm{Cu}$ through the $\mathrm{Cu}_{3} \mathrm{Sn}$ phase, the increased consumption of $11 / 9$ of the $\mathrm{Cu}_{6} \mathrm{Sn}_{5}$ phase will occur at the interface II. However, at the same time, 11/9 parts of the same phase will grow by dissociation of the $\mathrm{Cu}_{3} \mathrm{Sn}$ phase, because of the increase in flow of $\mathrm{Cu}$ through this phase. A further increase of 11/6 parts of the $\mathrm{Cu}_{6} \mathrm{Sn}_{5}$ phase will occur due to the increase in the flow of $\mathrm{Cu}$ through the $\eta$ phase. So there should be no net gain in the thickness of the $\mathrm{Cu}_{3} S n$ phase, but a net gain of 11/6 parts in the thickness of the $\mathrm{Cu}_{6} \mathrm{Sn}_{5}$ phase.

(2) Decrease in Sn flux through the phases. Owing to the decreased diffusion rate of $\mathrm{Sn}$ through the $\mathrm{Cu}_{3} \mathrm{Sn}$ phase there will be a corresponding four parts decrease in the layer thickness. Similarly, there will be $8 / 3$ parts less produced at the interface II caused by the dissociation of the $\mathrm{Cu}_{6} \mathrm{Sn}_{5}$ phase. Furthermore, because of the decreased diffusion rate of $\mathrm{Sn}$ through the $\mathrm{Cu}_{6} \mathrm{Sn}_{5}$ phase, the consumption of the same phase will be $8 / 3$ parts less at the same interface. So the net loss for the $\mathrm{Cu}_{3} \mathrm{Sn}$ should be 4 parts. 
TABLE 4

Summary of the experimental and calculated results

\begin{tabular}{|c|c|c|c|c|c|c|c|c|}
\hline \multirow[b]{2}{*}{ PWB acting as: } & \multicolumn{4}{|c|}{ Effect of electron flux } & \multicolumn{2}{|c|}{ Theoretical result } & \multicolumn{2}{|c|}{ Experimental result } \\
\hline & $\begin{array}{l}\text { Flux of } \mathrm{Sn} \\
\quad \text { in } \mathrm{Cu}_{3} \mathrm{Sn}\end{array}$ & $\begin{array}{l}\text { Flux of } \mathrm{Cu} \\
\quad \text { in } \mathrm{Cu}_{3} \mathrm{Sn}\end{array}$ & $\begin{array}{l}\text { Flux of } \mathrm{Sn} \text { in } \\
\mathrm{Cu}_{6} \mathrm{Sn}_{5}\end{array}$ & $\begin{array}{l}\text { Flux of } \mathrm{Cu} \\
\quad \text { in } \mathrm{Cu}_{6} \mathrm{Sn}_{5}\end{array}$ & $\begin{array}{l}\text { Thickness } \\
\text { of } \mathrm{Cu}_{3} \mathrm{Sn}\end{array}$ & $\begin{array}{l}\text { Thickness } \\
\text { of } \mathrm{Cu}_{6} \mathrm{Sn}_{5}\end{array}$ & $\begin{array}{l}\text { Thickness } \\
\text { of } \mathrm{Cu}_{3} \mathrm{Sn}\end{array}$ & $\begin{array}{l}\text { Thickness } \\
\text { of } \mathrm{Cu}_{6} \mathrm{Sn}_{5}\end{array}$ \\
\hline Anode & $\Uparrow$ & $\Downarrow$ & $\Uparrow$ & $\Downarrow$ & $\Uparrow$ & $\Downarrow$ & $\Uparrow$ & $\Downarrow$ \\
\hline Cathode & $\Downarrow$ & $\Uparrow$ & $\Downarrow$ & $\Uparrow$ & \pm 0 & $\Uparrow$ & \pm 0 & $\Uparrow$ \\
\hline
\end{tabular}

Because of the decrease of $\mathrm{Sn}$ flux through the $\mathrm{Cu}_{6} \mathrm{Sn}_{5}$ phase, there will be $11 / 3$ parts less production of the phase at the interface II by consuming the $\mathrm{Cu}_{3} \mathrm{Sn}$ phase. At the same time there will be 11/3 parts less consumption of the same phase because of the low diffusion rate of $\mathrm{Sn}$ through the $\mathrm{Cu}_{3} \mathrm{Sn}$ phase. So there should be no net gain in the $\mathrm{Cu}_{6} \mathrm{Sn}_{5}$ phase layer thickness because of low flux of Sn through both phases.

(3) Combined effect of $\mathrm{Sn}$ and $\mathrm{Cu}$ fluxes. Hence, when we consider the increase in the flow of $\mathrm{Cu}$ and the corresponding decrease in the flow of $\mathrm{Sn}$ to occur equally through both phases, there will be a net gain of $11 / 6$ parts in the thickness of $\mathrm{Cu}_{6} \mathrm{Sn}_{5}$ and a net decrease of four parts in the thickness of the $\mathrm{Cu}_{3} \mathrm{Sn}$ phase. However, the diffusion rate of $\mathrm{Sn}$ is known to be small compared to $\mathrm{Cu}$ in the $\mathrm{Cu}_{3} \mathrm{Sn}$ phase, as shown in the ratios of the tracer diffusion coefficients: ${ }^{38}$

$$
\begin{aligned}
& \left.\frac{D_{C u}^{*}}{D_{S n}^{*}}\right|_{C u_{3} S n}=\frac{p}{q} \approx 30 \\
& \left.\frac{D_{C u}^{*}}{D_{S n}^{*}}\right|_{C u_{6} S n_{5}}=\frac{r}{s} \approx 0.35 .
\end{aligned}
$$

Consequently, the role of $\mathrm{Sn}$ in this phase can be neglected-especially in this particular case as the diffusion of $\mathrm{Sn}$ is further hindered by the electron flux.

Overall, therefore, there should be an increase in the layer thickness of the $\mathrm{Cu}_{6} \mathrm{Sn}_{5}$ phase, which is what we see in the

\section{TABLE 5}

Thermodynamic calculations showing the effect of dissolved $\mathrm{Ni}$ on the stabilities of $\mathrm{Cu}_{3} \mathrm{Sn}$ and $\mathrm{Cu}_{6} \mathrm{Sn}_{5}$ and the values of chemical potential of $\mathrm{Cu}$ in equilibrium with $\left(\mathrm{Cu}, \mathrm{Ni}_{6} \mathrm{Sn}_{5}\right.$ as a function of the Ni mole fraction in the IMC compound

\begin{tabular}{llll}
\hline $\mathrm{x}(\mathrm{Ni})$ & $\begin{array}{l}\Delta \mathrm{G}_{\mathrm{m}} \\
\left(\mathrm{Cu}_{6} \mathrm{Sn}_{5}\right)(\mathrm{J} / \mathrm{mol})\end{array}$ & $\begin{array}{l}\Delta \mathrm{G}_{\mathrm{m}}\left(\mathrm{Cu}_{3} \mathrm{Sn}\right) \\
(\mathrm{J} / \mathrm{mol})\end{array}$ & $\begin{array}{l}\mu_{\mathrm{Cu}} \\
(\mathrm{J} / \mathrm{mol})\end{array}$ \\
\hline 0 & -6952 & -8267 & -12742 \\
0.01 & -7679 & -8270 & -12815 \\
0.05 & -10226 & -8597 & -13239 \\
0.1 & -13070 & -8418 & -14071 \\
0.15 & -15636 & -8859 & -15252 \\
\hline
\end{tabular}

experiment. The results from the above analysis and from the experiments are summarized in Table 4 below.

\subsubsection{Combined Effect of Electrical and Chemical Potential Gradients}

What if one would have $\mathrm{Ni}$ at the opposite (component) side of the interconnection in the case of PWB is acting as the cathode? In this case the effect of chemical driving force due to the presence of $\mathrm{Ni}$ will be superimposed on top of the effect of electrical potential. This issue will be discussed next.

First, let us consider the presence of only the chemical potential as the driving force. (i) We have shown above that the dissolution of $\mathrm{Ni}$ in $\mathrm{Cu}_{6} \mathrm{Sn}_{5}$ will increase the driving force for diffusion of $\mathrm{Sn}$ and $\mathrm{Cu}$ through $\eta$-layer significantly. If there is about 5 at- $\%$ of $\mathrm{Ni}$ in the $(\mathrm{Cu}, \mathrm{Ni})_{6} \mathrm{Sn}_{5}$ the diffusion flux driven by the chemical potential should increase over $(\mathrm{Cu}, \mathrm{Ni})_{6} \mathrm{Sn}_{5}$ and decrease over that of $\mathrm{Cu}_{3} \mathrm{Sn}$. (ii) As can be seen from Table 5 , the stability of $(\mathrm{Cu}, \mathrm{Ni})_{6} \mathrm{Sn}_{5}$ with 5 at. $\% \mathrm{Ni}$ is significantly higher than that without Ni. This may significantly influence the interfacial reactions at interface II. Especially the decomposition of $\mathrm{Cu}_{6} \mathrm{Sn}_{5}$ should be hindered in the case of thermal annealing, owing to the higher stability of the $(\mathrm{Cu}, \mathrm{Ni})_{6} \mathrm{Sn}_{5}$ compound. This will again favor the growth of $\mathrm{Cu}_{6} \mathrm{Sn}_{5}$. (iii) From Table 5 it is seen that the chemical potential of $\mathrm{Cu}$ at the $(\mathrm{Cu}, \mathrm{Ni})_{6} \mathrm{Sn}_{5}$ interface with about 5 at.\% $\mathrm{Ni}$ dissolved is markedly higher than that at the component side where there is, according to energy-dispersive X-ray spectroscopy (EDS) analysis, about 15 at.\% Ni dissolved in the $(\mathrm{Cu}$, $\mathrm{Ni})_{6} \mathrm{Sn}_{5}$ compound. This difference in chemical potential (about 15\%; see Table 5) provides another, significant, driving force for $\mathrm{Cu}$ to diffuse from the PWB-side $\mathrm{Cu}_{6} \mathrm{Sn}_{5}$ /solder interface to the corresponding interface at the component side. Thus, it is expected that the amount of $\mathrm{Cu}_{6} \mathrm{Sn}_{5}$ produced in the reaction at interface III will be decreased. If one combines all the information given above it may be concluded that the presence of, for example, 5 at- $\% \mathrm{Ni}$ in $(\mathrm{Cu}, \mathrm{Ni})_{6} \mathrm{Sn}_{5}$ compound will favor the growth of $(\mathrm{Cu}, \mathrm{Ni})_{6} \mathrm{Sn}_{5}$ and hinder the growth of $\mathrm{Cu}_{3} \mathrm{Sn}$.

Next, consider that the electron flux is added on top of the chemical potential difference. (i) The electron flux drives $\mathrm{Cu}$ to diffuse through, not only $\mathrm{Cu}_{3} \mathrm{Sn}$ and $\mathrm{Cu}_{6} \mathrm{Sn}_{5}$ layers, but also through the solder interconnection to the component side. This 
additional driving force for the $\mathrm{Cu}$ diffusion will influence the interfacial reactions especially at interface III. The experimental results indicate that it will decrease the growth of $\mathrm{Cu}_{6} \mathrm{Sn}_{5}$ with respect to the case when the electron flow is absent. This will be at least to some degree counterbalanced by the corresponding increase in the $\mathrm{Cu}$ flux through the $\mathrm{Cu}_{6} \mathrm{Sn}_{5}$. (ii) The flux of $\mathrm{Cu}$ through the $\mathrm{Cu}_{3} \mathrm{Sn}$ is increased due to the electron flow, but as at the same time the flux of $\mathrm{Cu}$ is increased in $\mathrm{Cu}_{6} \mathrm{Sn}_{5}$ also, the net effect is difficult to estimate. Based on the above shown results it appears that the thickness of $\mathrm{Cu}_{3} \mathrm{Sn}$ should remain approximately unaffected by the current flow.

Now we will try to summarize the above analysis. The facts that: (a) $\mathrm{Cu}$ diffusion is accelerated through $\mathrm{Cu}_{6} \mathrm{Sn}_{5}$ both by electrical and chemical potential gradients, but that of $\mathrm{Sn}$ is reduced by electrical current, should end up favoring the growth of $(\mathrm{Cu}, \mathrm{Ni})_{6} \mathrm{Sn}_{5}$ but slightly less than in the absence of electrical driving force; (b) the stability of $\left(\mathrm{Cu}, \mathrm{Ni}_{6}\right)_{6} \mathrm{Sn}_{5}$ is much higher than that of without $\mathrm{Ni}$, so this should favor $(\mathrm{Cu}$, $\mathrm{Ni})_{6} \mathrm{Sn}_{5}$ over $\mathrm{Cu}_{3} \mathrm{Sn}$ irrespectively of the presence of electrical driving force; (c) the increase of the flux of Sn through $(\mathrm{Cu}$, $\mathrm{Ni})_{6} \mathrm{Sn}_{5}$ is hindered by the presence of electric current thus slightly reducing the growth rate of $\eta$-phase when compared to the situation where there is no current present; and (d) the flux of $\mathrm{Cu}$ away from the $\mathrm{Cu}_{6} \mathrm{Sn}_{5}$ /solder interface is increased in both cases and is manifested as the decrease in growth of $\mathrm{Cu}_{6} \mathrm{Sn}_{5}$ or $(\mathrm{Cu}, \mathrm{Ni})_{6} \mathrm{Sn}_{5}$ in both cases. The net result should be that when both driving forces are present the $\mathrm{Cu}_{6} \mathrm{Sn}_{5}$ should be somewhat thinner and the $\mathrm{Cu}_{3} \mathrm{Sn}$ should be somewhat thicker in comparison to the case when there is only chemical potential gradient driving the diffusion (in the absence of electrical driving force).

\subsection{Use of Stability Diagrams to Rationalize Reactions in the Cu-Si-Ta-O-C System}

The current trend of scaling down the dimensions of integrated circuits in order to achieve better electrical performance places serious demands for materials used in silicon-based devices. In particular, thin film interconnections are becoming the limiting factor in determining performance and reliability of integrated circuits. The interconnection delay, usually defined as the $R C$-delay, where $R$ is the resistance of the interconnection and $C$ is the associated total capacitance, is one of the most important factors determining the device/circuit performance. ${ }^{55}$ Reducing the $R C$-delay to lower than or equal to the device delay has become both a material and an interconnection design/ architecture challenge. Aluminum has been the most widely used material for metallization in very-large-scale integration (VLSI) and ultralarge-scale integration (ULSI) circuits during the past decades. However, as critical dimensions of devices have approached submicron dimensions, reliability requirements have ruled out the possibility of using pure aluminum. In order to improve reliability, alloys with several additives such as $\mathrm{Si}, \mathrm{Cu}, \mathrm{Ti}, \mathrm{Pd}, \mathrm{Cr}$, $\mathrm{Mg}$, and $\mathrm{Mn}$, have been tested. ${ }^{56}$ The improvement in the electromigration performance thus achieved remains to date limited and is offset by the corresponding increase in interconnection resistivity. ${ }^{56}$

Hence, emphasis and burden have been placed on materials, e.g., switching from $\mathrm{Al} / \mathrm{W}$ based metallizations to $\mathrm{Cu}$-based interconnections. Unfortunately, the interaction between $\mathrm{Si}$ and $\mathrm{Cu}$ is rapid and detrimental to the electrical performance of Si even at temperatures below $473 \mathrm{~K} \cdot{ }^{57-59}$ Mobility of copper is also relatively fast in $\mathrm{SiO}_{2}$ and many polymers used as dielectric layers. ${ }^{60,61}$ Moreover, copper corrodes easily upon exposure to moisture or oxygen and a technique to passivate the copper surface is essential for multilevel copper interconnection. ${ }^{62}$ Therefore, owing to these multiple material problems, it is necessary to implement a barrier layer into the $\mathrm{Cu}$ metallization scheme and to encapsulate copper conductors from all sides. In this respect, diffusion barriers in $\mathrm{Cu}$ metallizations differ from the ones used in $\mathrm{Al}$ metallizations, where a diffusion barrier is generally used only at one interface. The need to encapsulate $\mathrm{Cu}$ conductor imposes also boundary conditions for diffusion barrier thickness. Among the most promising candidates to be used for this purpose are tantalum-based alloys and binary tantalum nitrides and carbides.

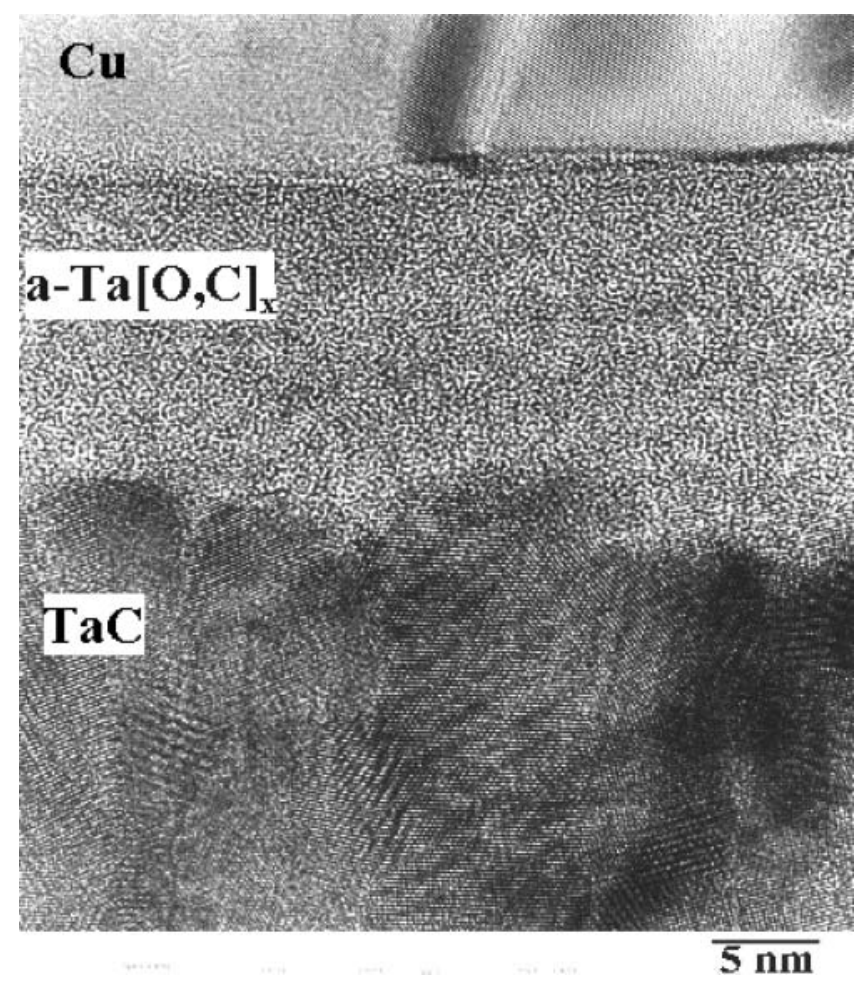

FIG. 22. HREM micrograph from the amorphous $\mathrm{Ta}[\mathrm{O}, \mathrm{C}]_{\mathrm{x}}$ phase from the sample annealed at $600^{\circ} \mathrm{C}$ for $30 \mathrm{~min}$. (C) AIP. Adapted with permission from AIP. ${ }^{63}$ Permission to reuse must be obtained from the rightsholder.) 


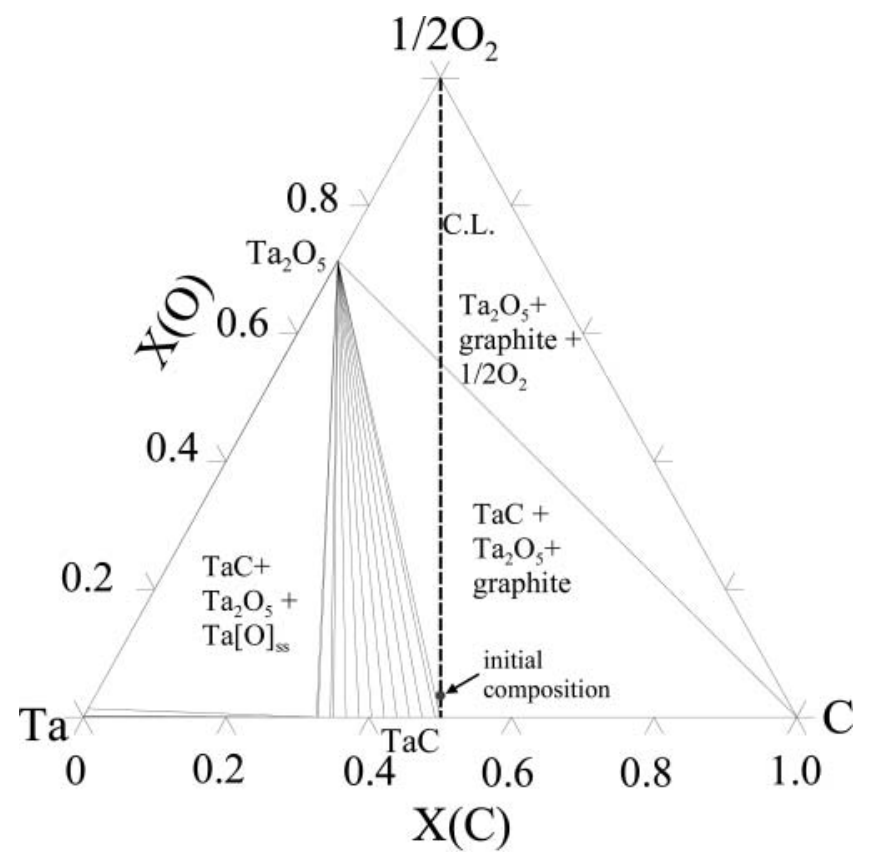

FIG. 23. Isothermal section from the evaluated metastable ternary Ta-C-O phase diagram at $600^{\circ} \mathrm{C}$ under the external oxygen pressure of about $0.2 \times 10^{-4} \mathrm{~Pa}$. The tie-lines in the TaC$\mathrm{Ta}_{2} \mathrm{O}_{5}$ two- phase region are shown in the diagram. The contact-line (C.L.) between the $\mathrm{TaC}$ film and oxygen indicating the initial unstable equilibrium as well as the approximate composition of the $\mathrm{TaC}[\mathrm{O}]_{\mathrm{gb}}$ are also shown. (C) AIP. Adapted with permission from AIP. ${ }^{63}$ Permission to reuse must be obtained from the rightsholder.)

\subsubsection{Si/TaC/Cu System}

In this investigation copper and tantalum carbide films were sputtered onto cleaned and oxide-stripped (100) n-type Si substrates in a dc/rf-magnetron sputtering system. The deposition of $\mathrm{TaC}$ was obtained from the TaC-target (hot-pressed, $6.2 \mathrm{wt}-\%$ of $\mathrm{C}$, main impurity $\mathrm{Nb} \sim 0.3 \mathrm{wt}-\%$ ) in argon atmosphere. The pressure before the deposition runs was approximately $10^{-5} \mathrm{~Pa}$. The thickness of the tantalum carbide layers was $70 \mathrm{~nm}$. The copper films with thickness of $400 \mathrm{~nm}$ were subsequently sputter-deposited without breaking the vacuum. Details of the experimental set-up and analyses can be found from Laurila et al. ${ }^{63,64}$

The as deposited and films annealed up to $550^{\circ} \mathrm{C}$ showed clearly discrete layers according to the RBS measurement. ${ }^{64}$ After annealing at $600^{\circ} \mathrm{C}$ the RBS spectrum suggested that interdiffusion of $\mathrm{Ta}$ and $\mathrm{Cu}$ had taken place. ${ }^{64}$ Investigations with transmission electron microscope (TEM) revealed that after annealing at $600^{\circ} \mathrm{C}$ the formation of an amorphous layer at the $\mathrm{TaC} / \mathrm{Cu}$ interface took place (Figure 22). The composition of the layer was determined to be Ta with marked amounts of oxygen and carbon from the very thin foil (tens of

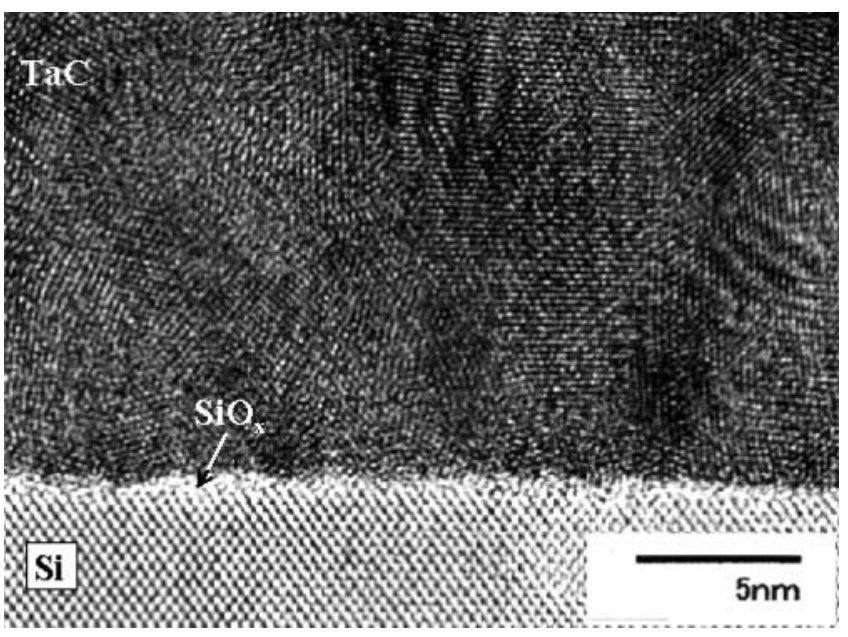

FIG. 24. HREM micrograph from the $\mathrm{Si} / \mathrm{TaC}$ interface from the sample annealed at $600^{\circ} \mathrm{C}$ for $30 \mathrm{~min}$.

nanometers thick) with the X-ray energy dispersive spectrometry (EDS) in the analytical TEM. Equally high amounts of oxygen and carbon were not detected from either side of the amorphous layer. The layer is most probably $\mathrm{Ta}[\mathrm{O}, \mathrm{C}]_{\mathrm{x}}$ (i.e., metastable oxide) containing some carbon released from the partly dissociated $\mathrm{TaC}$ layer. The formation of the amorphous layer was most likely caused by the presence of oxygen in the films (mainly at the grain boundaries) and also because of the diffusion of extra oxygen to the films from the annealing environment. The reasons leading to the formation of the layer can be analyzed with the help of Figure 23 that shows the evaluated metastable ternary Ta-C-O phase diagram. The grounds for using the metastable phase diagram instead of the stable one have been previously discussed. ${ }^{65}$ As the oxygen content of the $\mathrm{TaC}$ films is in the order of $1-2$ at- $\%{ }^{65}$ the initial composition is inside the $\mathrm{TaC}_{-} \mathrm{Ta}_{2} \mathrm{O}_{5}$-graphite three-phase region. The initial situation, marked as a point on the contact line (C.L.) connecting the end members of the diffusion couple (1/ $2 \mathrm{O}_{2} / \mathrm{TaC}$ ) in the isothermal section (Figure 23), is highly unstable, since the oxygen inside the TaC film (most probably located mainly at grain boundaries) has been forced there during the sputter-deposition.

The solubility of $\mathrm{Ta}_{2} \mathrm{O}_{5}$ into $\mathrm{TaC}$ is not known, but it is not expected to be substantial at low temperatures. Thus, there must be a large driving force for the formation of Ta-oxide that is in fact more stable than TaC. When the $\mathrm{TaC}[\mathrm{O}]_{\mathrm{gb}}$ films are annealed at elevated temperatures, oxygen starts to dissolve into the $\mathrm{TaC}$ matrix, since the solubility is expected to increase as temperature is elevated. This will ultimately result in the formation of the stable $\mathrm{Ta}_{2} \mathrm{O}_{5}$ and graphite. However, the kinetics of the system inhibits the formation of stable Ta-oxide (and thereby also graphite, issue that will be addressed below) at this considerably low temperature and the metastable amorphous layer is formed instead. As the 


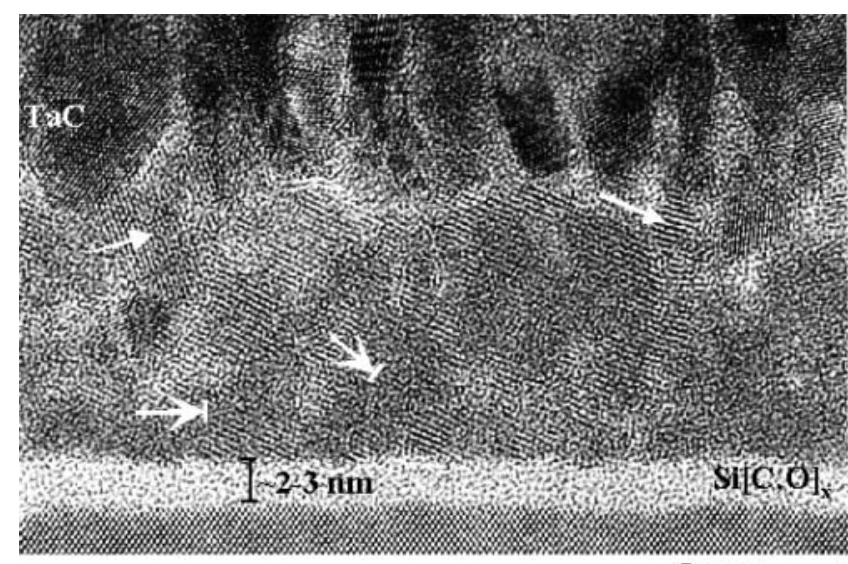

$5 \mathrm{~nm}$

FIG. 25. HREM micrograph from the $\mathrm{Si} / \mathrm{TaC}$ interface from the sample annealed at $750^{\circ} \mathrm{C}$ for $30 \mathrm{~min}$. Normal arrows indicate the crystalline phase and arrows with a line at their end indicate the amorphous phase.

solubilities of impurities to metastable amorphous phases are generally higher than into stable crystalline ones, the amorphous layer can be expected to act as a "drain" for the excess oxygen. At the $\mathrm{Si} / \mathrm{TaC}$ interface formation of a very thin amorphous layer was observed after annealing at $600^{\circ} \mathrm{C}$. Based on the high-resolution micrograph shown in Figure 24 the amorphous layer appears to be quite transparent to electrons and therefore consist of relatively light elements. It is expected that the layer is an amorphous mixture of silicon and oxygen. The reasons for this interpretation are as follows. First, the lower part of $\mathrm{TaC}$ film also contains some oxygen

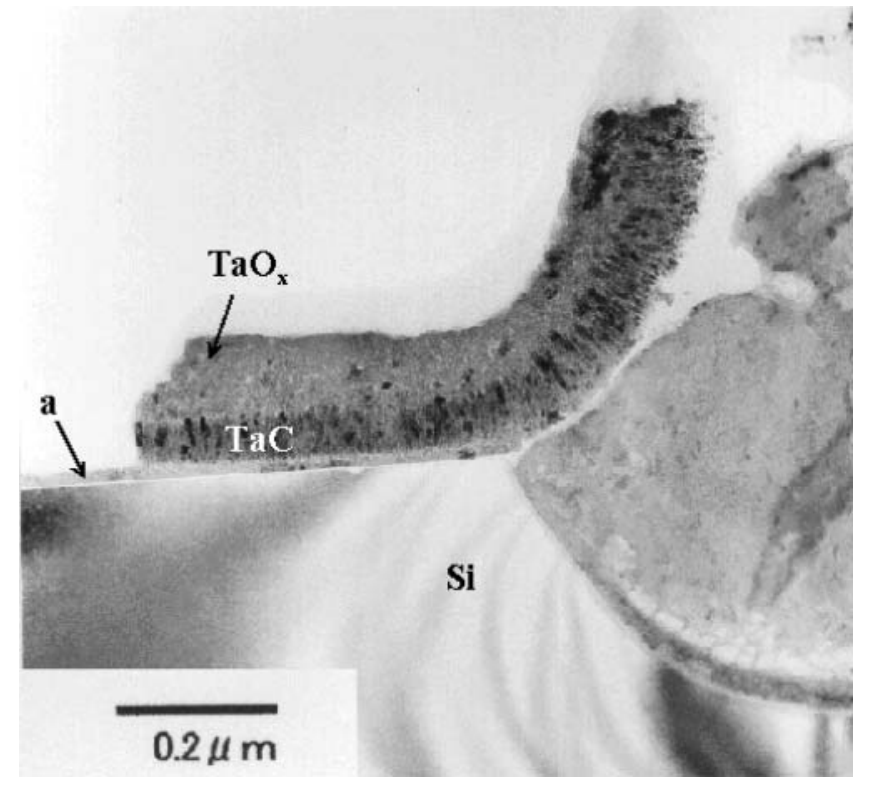

FIG. 26. Bright field TEM micrograph from the $\mathrm{Si} / \mathrm{TaC} / \mathrm{Cu}$ sample annealed at $750^{\circ} \mathrm{C}$ for $30 \mathrm{~min}$. incorporated during the deposition (as shown by EDS elemental mapping). Second, again oxygen has been forced into the TaC layer during processing and the thin film system is far away from equilibrium. As discussed above, the equilibrium solubility of $\mathrm{Ta}_{2} \mathrm{O}_{5}$ into $\mathrm{TaC}$ is not known, but it is not anticipated to be substantial and therefore segregation of oxygen to grain boundaries and interfaces can be expected. ${ }^{66,67}$

This would lead to the accumulation of oxygen at the $\mathrm{Si}$ / $\mathrm{TaC}$ interface and consequently to the formation of the thin amorphous interphase. In order to verify the composition of the amorphous layer EDS analyses were carried out. However, as the thickness of the layer is very small (Figure 25) reliable chemical analysis was not possible.

It should be noted that no sputter cleaning was applied to the $\mathrm{Si}$ substrate before $\mathrm{TaC}$ film deposition and therefore the "diffuse" interface is not caused by processing. Further, the layer is not expected to be an artifact resulting from sample preparation owing to its visual appearance and moreover, due to effect of temperature to its thickness as will be discussed below. After annealing at $750^{\circ} \mathrm{C}$ the amorphous layer at $\mathrm{Si} /$ $\mathrm{TaC}$ interface is clearly thicker than after annealing at $600^{\circ} \mathrm{C}$ (Figure 25). However, the thickness was still so small that it was not possible to reliably analyze the composition of the layer. It is expected that the layer is a $\mathrm{Si}[\mathrm{O}, \mathrm{C}]_{\mathrm{x}}$ type layer, i.e., amorphous mixture of silicon, oxygen, and carbon and the growth of the layer is due to the stability of stable and metastable Ta-oxides with respect to TaC. In addition to the growth of the amorphous layer, a mixture of amorphous (arrows with a line in their head) and crystalline phases (normal arrows) can be seen inside $\mathrm{TaC}$ layer at $750^{\circ} \mathrm{C}$ (Figure 25). The thickness of this phase "mixture" is quite large $(10 \mathrm{~nm})$. Figure 26 indicates that the phase "mixture" may be growing at the expense

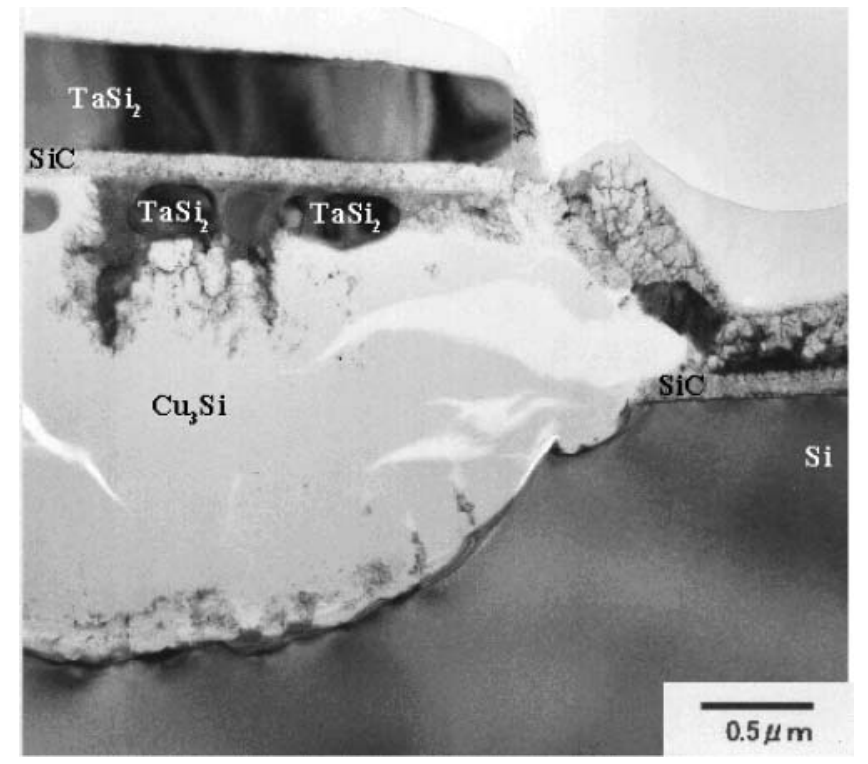

FIG. 27. Bright field TEM micrograph from the $\mathrm{Si} / \mathrm{TaC} / \mathrm{Cu}$ sample annealed at $800^{\circ} \mathrm{C}$ for $30 \mathrm{~min}$. 
of $\mathrm{TaC}$ layer and thus some of the carbon dispersed inside the amorphous layer is anticipated to be expelled from the partly decomposed $\mathrm{TaC}$ layer. Furthermore, the micrograph indicates that there is a boundary between the phase mixture and $\mathrm{TaC}$. This may be quite important from the mechanical point of view as can be seen from Figure 26 that shows lower magnification micrograph from the whole structure. The ruptured $\mathrm{TaC}$ film seen in the micrograph is actually composed of three different layers. From Figure 26 it appears that the bottom layer (the two-phase mixture shown with higher magnification in Figure 25) is still in contact with $\mathrm{Si}$ whereas the other two layers have been torn away during sample fabrication. The large $\mathrm{Cu}_{3} \mathrm{Si}$ inclusion is also clearly visible on the right-hand side.

At $800^{\circ} \mathrm{C}$ the layered metallization structure is completely destroyed owing to the extensive interfacial reactions. $\mathrm{TaC}$ layer seen at $750^{\circ} \mathrm{C}$ has been completely consumed at $800^{\circ} \mathrm{C}$. Instead, one can see the formation of uniform $\mathrm{TaSi}_{2}$ layer as well as a layer of $\mathrm{SiC}$ (Figure 27). The formation of the mixture of amorphous and crystalline layers inside the $\mathrm{TaC}$ layer observed at $750^{\circ} \mathrm{C}$ is expected to be related to the formation of $\mathrm{TaSi}_{2}$ and $\mathrm{SiC}$ layers seen in this micrograph. It is probable that the "mixed" layer acted at least partly as a "precursor" for the crystalline $\mathrm{TaSi}_{2}$ and $\mathrm{SiC}$ layers. The large $\mathrm{Cu}_{3} \mathrm{Si}$ "precipitates" seen already at $750^{\circ} \mathrm{C}$ are also clearly present. There is also considerable amount of oxygen distributed through the layer as shown by the elemental analyses with EDS. This indicates that the Si substrate has been oxidized after the rupture of the overlying films. The thermodynamically expected formation of graphite was not detected even at $800^{\circ} \mathrm{C}$. It is anticipated that owing to the very difficult nucleation of graphite the carbon will stay dispersed inside the amorphous phase. There are many reasons for the difficult nucleation of graphite. One probable reason is that the crystal structure is quite complex, and so nuclei do not form easily. Another reason may be that because the coordination number is small, the formation of graphite in a purely solid state system requires a considerable increase in volume. The strain energy involved in this process makes the nucleation of graphite more difficult, since the mechanical energy associated with the formation of graphite must be extracted from the available free energy driving the nucleation process, as discussed above. It is expected that in this system carbon, which is released from the partially decomposed $\mathrm{TaC}$ layer and incorporated into the growing amorphous $\mathrm{Ta}[\mathrm{O}, \mathrm{C}]_{\mathrm{x}}$ layer, stabilizes the amorphous structure.

In order to analyze the phase formation at the $\mathrm{Si} / \mathrm{TaC}$ interface, one should have a firm thermodynamic description available. In principle, to investigate the reactions in the present system, the thermodynamic description of the five-component $\mathrm{Si}-\mathrm{Ta}-\mathrm{C}-\mathrm{O}-\mathrm{Cu}$ system should be used, since both $\mathrm{Cu}$ and $\mathrm{O}$ influence the reactions at the $\mathrm{Si} / \mathrm{TaC}$ interface. Unfortunately, there does not exist adequately reliable data on all the multicomponent systems required. Therefore, the reactions at the $\mathrm{Si} / \mathrm{TaC}$ interfaces at $800^{\circ} \mathrm{C}$ are examined with the help of the assessed Si-Ta-C ternary phase diagram together with the calculated activity diagrams (Figures 28a and 28b), since they already provide a considerable amount of useful information about the interfacial reactions. The main goal is to evaluate the possible reaction sequence at the interface. Hence, the ternary Si-Ta-C phase diagram was evaluated from the assessed binary thermodynamic data, ${ }^{68-70}$ and is presented in Figure 28. The question of carbon solubility in $\mathrm{Ta}_{5} \mathrm{Si}_{3}$, which is expected to be substantial based on the other $\mathrm{Me}_{5} \mathrm{Si}_{3}$ silicides (e.g., $\mathrm{Ti}_{5} \mathrm{Si}_{3} \sim 10$ at- $\%$ ), ${ }^{71}$ must be carefully considered in the Si-Ta-C system. However, owing to the
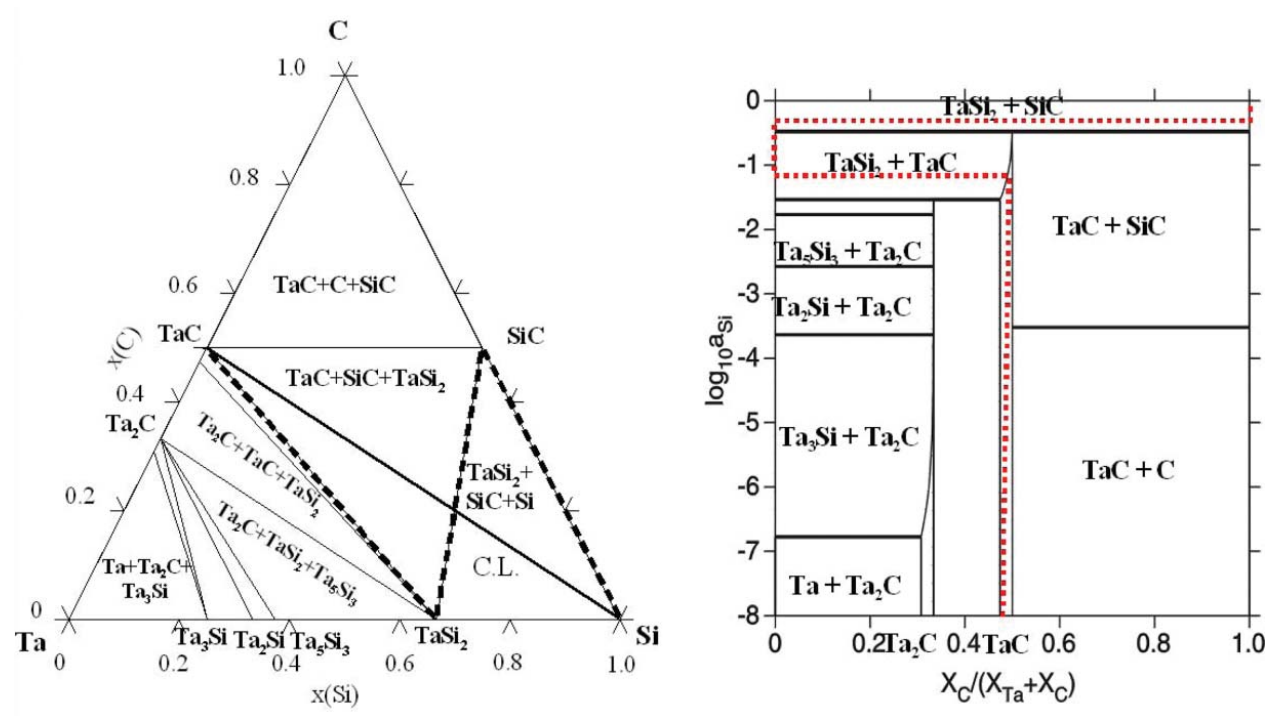

FIG. 28. Isothermal section and the corresponding activity diagram for $\mathrm{Si}$ from the C-Si-Ta system at $800^{\circ} \mathrm{C}$. 
lack of reliable ternary data in the literature, ternary solubility has not been incorporated. Possible ternary compounds have similarly been excluded from the diagrams. Assuming that the local equilibrium is achieved at the interfaces of the thin film system, it is possible to use phase diagrams coupled with certain kinetic rules to predict possible or at least to rule out impossible reaction sequences. First, the mass-balance requires that the diffusion path, which is a line in the ternary isotherm, representing the locus of the average compositions parallel to the original interface through the diffusion zone, ${ }^{34}$ crosses the straight line connecting the end members of the diffusion couple at least once. Second, no element can diffuse intrinsically against its own activity gradient ${ }^{34}$ (i.e., from a low chemical potential area to a high chemical potential area). If such is observed it is induced by the movement of other components.

From the phase diagram it is evident that the $\mathrm{Si} / \mathrm{TaC}$ interface is not in equilibrium and driving force for the formation of additional phases between the substrate and the $\mathrm{TaC}$ layer therefore exists (Figure 28a). Although there exists a $\mathrm{TaC}+$ $\mathrm{TaSi}_{2}$ two-phase region in the phase diagram (Figure 28a), $\mathrm{SiC}$ must be formed to incorporate the carbon released after the formation of $\mathrm{TaSi}_{2}$ in the reaction between $\mathrm{Si}$ and $\mathrm{TaC}$, because of the mass balance requirement. The formation of $\mathrm{SiC}$ and $\mathrm{TaSi}_{2}$ was confirmed with TEM investigations and therefore gives support to the assessed phase diagram. As shown in Figure 27 the reacted structure consists of layers of $\mathrm{SiC}$ and $\mathrm{TaSi}_{2}$ on top of the silicon substrate. The original $\mathrm{TaC}$ is completely consumed during the reaction, since no traces of it can be found at $800^{\circ} \mathrm{C}$. The reaction structure seems to be $\mathrm{Si}$, then a layer of $\mathrm{SiC}$, on top of that a layer of $\mathrm{TaSi}_{2}$ and finally on the top layer of $\mathrm{TaC}$ (i.e., $\mathrm{Si} / \mathrm{SiC}_{\mathrm{TaSi}} / \mathrm{TaC}$ ), in which the $\mathrm{TaC}$ is used completely to yield the final structure $\mathrm{Si} / \mathrm{SiC} / \mathrm{TaSi}_{2}$. Silicon is expected to be the first species moving at this interface owing to the following reasons. First, Si has been found to be the mobile species during the formation of $\mathrm{TaSi}_{2}$ that occurs around $650^{\circ} \mathrm{C}$ in the binary $\mathrm{Ta}-\mathrm{Si}$ system by $\mathrm{Si}$ indiffusion whereas the movement of $\mathrm{Ta}$ has not been observed under similar conditions. ${ }^{72}$ Second, chemical bonding between $\mathrm{Ta}$ and $\mathrm{C}$ in the $\mathrm{TaC}$ compound is expected to be strong, and breaking of these bonds, which is required for the release and subsequent diffusion of $\mathrm{Ta}$, would require large amounts of energy. Owing to the facts stated above, diffusion of tantalum or carbon in this system is not considered to be highly probable. Consequently, $\mathrm{Si}$ is anticipated to be the main diffusing species at the $\mathrm{Si} / \mathrm{TaC}$ interface around $800^{\circ} \mathrm{C}$.

Whether the above-presented phase formation sequence is thermodynamically possible, can be investigated with the help of Figure 28b. As can be seen from the calculated activity diagram, Si can move along its lowering activity gradient in the proposed reaction sequence and therefore diffusion of $\mathrm{Si}$ in this particular reaction sequence is allowed on thermodynamic grounds. The examinations of the calculated activity diagrams for carbon and tantalum do not restrict diffusion of these elements in the suggested reaction sequence either (Figure 28b). However, as already discussed, carbon and tantalum are strongly bonded to each other in the $\mathrm{TaC}$ compound and are not expected to move easily. Therefore, the reaction most likely starts by $\mathrm{Si}$ indiffusion into $\mathrm{TaC}$ (most probably via grain boundaries). This is followed by the formation of $\mathrm{TaSi}_{2}$, which then leads to the accompanied dissociation of $\mathrm{TaC}$. The released carbon is then available for the formation of $\mathrm{SiC}$ in the reaction with $\mathrm{Si}$. This mechanism will finally yield the experimentally observed structure $\mathrm{Si} /$ $\mathrm{SiC} / \mathrm{TaSi}_{2}$. Thus, carbon and tantalum would not have to move and undergo only local rearrangement. Almost identical behavior has been observed in a very similar $\mathrm{NbC} / \mathrm{Si}$ diffusion couple. ${ }^{73}$ It must be emphasized than in the present analysis diffusion of oxygen and copper and their influence on the interfacial reactions between $\mathrm{Si}$ and $\mathrm{TaC}$ have been ignored.

\subsection{Understanding the Diffusion and Growth Behavior in Cu-Nb-Sn System}

$\mathrm{Nb}-\mathrm{Ti}$ is a widely used superconductor material. However, its use is limited to applications of magnetic field up to $8 \mathrm{~T}^{74}$ At present, $\mathrm{Nb}_{3} \mathrm{Sn}$ intermetallic compound with A15 structure is considered to be one of the most suitable superconductors for the applications where field requirements go beyond the limit of $\mathrm{Nb}$ - $\mathrm{Ti}$ superconductors. However, intermetallic compounds are in general brittle and cannot be drawn as wire. To circumvent this problem, different manufacturing technologies have been developed for $\mathrm{Nb}_{3} \mathrm{Sn}$, such as bronze method, internal tin process, powder metallurgy route, Jelly roll process, ECN technique, and so forth. ${ }^{74,75}$

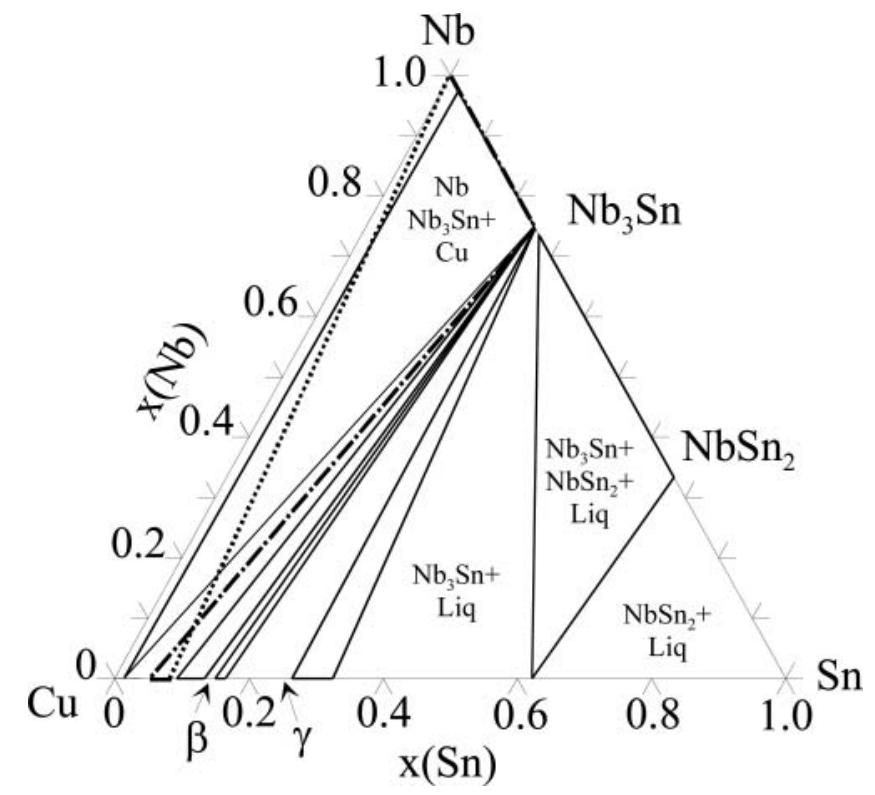

FIG. 29. Isothermal section from the $\mathrm{Cu}-\mathrm{Nb}-\mathrm{Sn}$ system at $700^{\circ} \mathrm{C}$. 
In the bronze method, several $\mathrm{Nb}$ rods are inserted inside $\mathrm{Cu}(\mathrm{Sn})$ bronze alloy and drawn as a multifilamentary wire. The product phase $\mathrm{Nb}_{3} \mathrm{Sn}$ is grown during the subsequent annealing by solid state diffusion. The efficiency of a superconductor wire largely depends on the presence of microstructural defects, such as grain boundaries and Kirkendall pores, grain size distribution, possible layer thickness differences, the variation of chemical composition over the cross section $^{75-79}$ and so on. Since the evolution of microstructure is determined by the thermodynamics and kinetics of the system, the combined thermodynamic-kinetic approach provides a feasible tool to rationalize the formation of the observed reaction structures. There are basically two fundamental questions concerning the growth of $\mathrm{Nb}_{3} \mathrm{Sn}$ by the bronze technique.

1. Why $\mathrm{Sn}$ is the only diffusing species during the reaction?

2. Why there is such a drastic increase in the thickness of the $\mathrm{Nb}_{3} \mathrm{Sn}$ grown under same conditions, when Sn content of the $\mathrm{Cu}(\mathrm{Sn})$ alloy is increased from 7 at- $\%$ to 8 at- $\%$ ?

What has been stated earlier indicates the thermodynamickinetic approach can be utilized to find answers to the above two questions.

With the aim to calculate the thermodynamic parameters to understand the diffusion process, the ternary phase diagram of the $\mathrm{Cu}-\mathrm{Nb}-\mathrm{Sn}$ system was calculated with the help of the assessed data from Hamalainen et al., ${ }^{80}$ Toffolon et al., ${ }^{81}$ and Shim et al. ${ }^{82}$ In these calculations, all intermetallic compounds were modeled as binary compounds, since dissolution of ternary elements were found to be negligible based on the available information. In addition, no ternary compounds are known to exist in the $\mathrm{Cu}-\mathrm{Nb}-\mathrm{Sn}$ system. Isothermal section

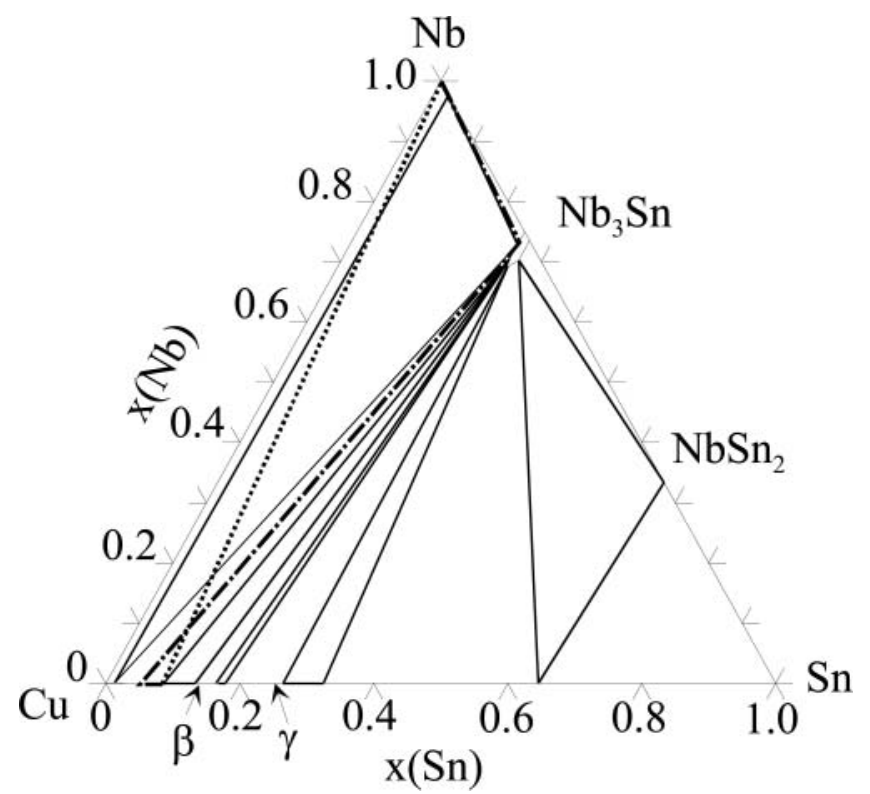

FIG. 30. Isothermal section from the $\mathrm{Cu}-\mathrm{Nb}-\mathrm{Sn}$ system at $700^{\circ} \mathrm{C}$ where ternary solubility to $\mathrm{Nb}_{3} \mathrm{Sn}$ has been introduced.

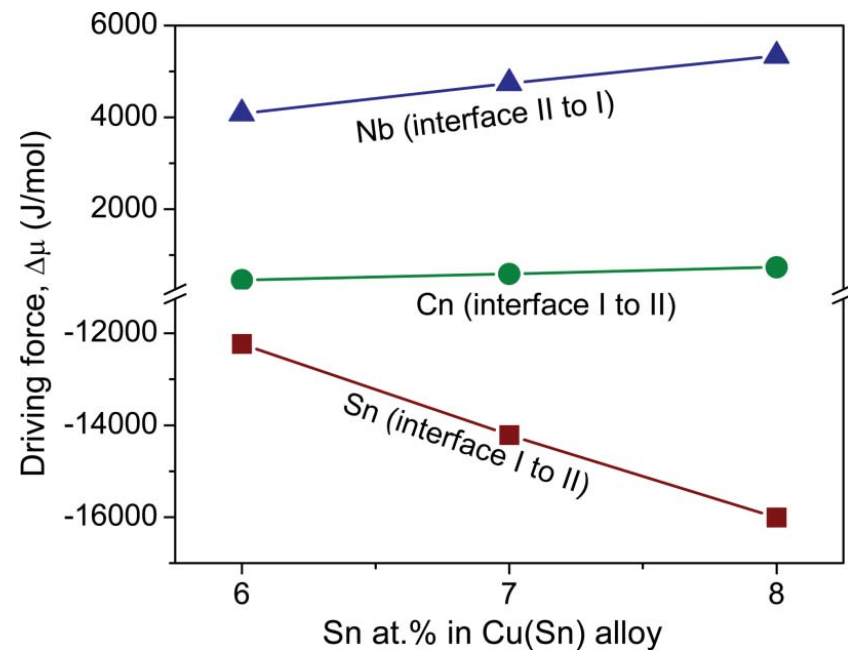

FIG. 31. Changes in the driving forces for diffusion of different species as a function of Sn content.

calculated at $700^{\circ} \mathrm{C}$ is shown in Figure 29. It is in general consistent with the recent publication on the thermodynamic assesment of the $\mathrm{Cu}-\mathrm{Nb}-\mathrm{Sn}$ system, ${ }^{82}$ except for two details. First, in Shim et al. ${ }^{82}$ the $\mathrm{Nb}_{6} \mathrm{Sn}_{5}$ phase is stable already below $700^{\circ} \mathrm{C}$, different from our calculations and results of Pan et al. ${ }^{82}$ Second, there is also some ternary solubility to both $\mathrm{Nb}_{3} \mathrm{Sn}$ and $\mathrm{Nb}_{6} \mathrm{Sn}_{5}$ in the diagram by Li et al.$^{81}$ However, as the most relevant equilibrium to our analysis is the three-phase triangle $\mathrm{Cu}-\mathrm{Nb}_{3} \mathrm{Sn}-\mathrm{Nb}$, the occurrence of $\mathrm{Nb}_{6} \mathrm{Sn}_{5}$ phase that establishes equilibrium with the liquid phase, has no effect on the equilibria between $\mathrm{Nb}_{3} \mathrm{Sn}$ and $\mathrm{Cu}, \beta$ or $\gamma$ phases, even if it is stable already at $700^{\circ} \mathrm{C}$ or below. We also induced ternary solubility to $\mathrm{Nb}_{3} \mathrm{Sn}$ (up to 10 at-\%) and it did not have any effect on the three-phase triangle of interest (Figure 30) and did not markedly influence the values of chemical potentials of the species. Thus, from our analysis point of view these minor differences can be disregarded.

With the same set of assessed thermodynamic data the values of driving forces for the diffusion (the difference in chemical potential between two moving interfaces, $\Delta \mu$ in the diffusion couple) of given species over $\mathrm{Nb}_{3} \mathrm{Sn}$ layer at $700^{\circ} \mathrm{C}$, $750^{\circ} \mathrm{C}$, and $775^{\circ} \mathrm{C}$, as a function of Sn content of 6,7 , and 8 at. $\%$ in $\mathrm{Cu}-\mathrm{Sn}$ alloy were calculated. The results are tabulated in Figure 31. Following the data on driving force, it is clear that only the diffusion of Sn through the product layer is allowed from the thermodynamic point of view. If $\mathrm{Nb}$ or $\mathrm{Cu}$ would diffuse intrinsically they should move against their own activity gradient, which is not possible. ${ }^{34}$ However, if we consider the possible atomic mechanism of diffusion, based on the structure of the $\mathrm{Nb}_{3} \mathrm{Sn}$, the diffusion of $\mathrm{Nb}$ should be much easier than diffusion of $\mathrm{Sn}^{84}$ However, as seen above, from the thermodynamic point of view there is no possibility for diffusion of $\mathrm{Nb}$ (and $\mathrm{Cu}$ ) in $\mathrm{Nb}_{3} \mathrm{Sn}$ in $\mathrm{Nb} / \mathrm{Cu}(\mathrm{Sn}$ ) diffusion couple, as there exist no driving force. Thus, the only way for the 


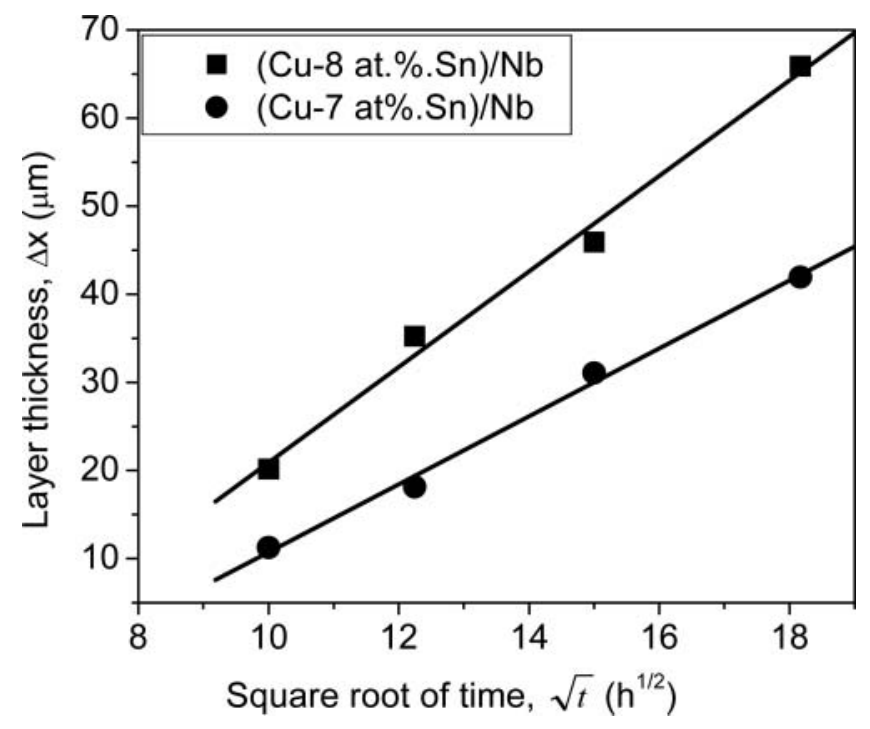

FIG. 32. Experimentally measured thickness of the $\mathrm{Nb}_{3} \mathrm{Sn}$ phase with two different $\mathrm{Cu}(\mathrm{Sn})$ alloys.

product layer to grow is by diffusion of $\mathrm{Sn}$. That is also the reason why the $\mathrm{TiO}_{2}$ particles used as inert markers are found near the $\mathrm{Cu}(\mathrm{Sn}) / \mathrm{Nb}_{3} \mathrm{Sn}$ interface. The fact that $\mathrm{Sn}$ must be the only intrinsically diffusing species in this reaction layer sequence, from the thermodynamic point of view, is evident also based on the isothermal section shown in Figure 29 which shows also the diffusion path for the reaction sequence under investigation. When we have a diffusion couple $\mathrm{Cu}(\mathrm{Sn}) / \mathrm{Nb}$ (the contact line connecting the end-members is drawn as dashed line) the diffusion path must proceed, as drawn in Figure 29. This is because of the requirement that the contact line between the end-members must be crossed at least once; otherwise, the mass balance would not be fulfilled. ${ }^{34}$ Thus, as can be seen from the figure, the diffusion path must always start from the $\mathrm{Cu}(\mathrm{Sn})$ end towards the $\mathrm{Cu}$ corner (i.e., towards higher activity of $\mathrm{Cu}$ ) and then go to $\mathrm{Nb}_{3} \mathrm{Sn}$ and finally to $\mathrm{Nb}$. This also means that there should not be $\mathrm{Cu}$ inside $\mathrm{Nb}_{3} \mathrm{Sn}$, as in order to get there, it would have to move against its own activity gradient.

Further from the experimental results, we have seen that there is considerable increase in the growth rate and decrease in activation energy just because of small increase in Sn content from 7 to 8 atomic percent in the $\mathrm{Cu}-\mathrm{Sn}$ alloy. This can be rationalized by considering the changes in chemical potentials between the two interfaces in the diffusion couple owing to the change in the Sn content. For example at $775^{\circ} \mathrm{C}$, the difference in the chemical potential of Sn changes from -14217 in $\mathrm{Nb} /(\mathrm{Cu}-7$ at. $\% \mathrm{Sn})$ couple to $-16008 \mathrm{~J} /$ mole in $\mathrm{Nb} /(\mathrm{Cu}-8$ at.\% $\mathrm{Sn}$ ) at the same temperature (Figure 31 ). The change is around $12.5 \%$. We can roughly consider that the flux of elements is linearly proportional to the driving force, if we neglect any other differences in the properties of the end members, which might be caused by the change in the Sn content. Thus, we can estimate that the amount of Sn flux through the product layer $\left(\mathrm{Nb}_{3} \mathrm{Sn}\right)$ will increase approximately by $12.5 \%$. Further, since one mole of $\mathrm{Sn}$ produces four moles of the product layer, we can expect that there will be at least $50 \%$ increase in the layer thickness because of the change in Sn content from 7 to 8 at.\%. The results presented in the Figure 32 are consistent with this calculation. So the increase in layer thickness because of such a small change in $\mathrm{Sn}$ content in the (Cu-Sn) alloy is expected from the thermodynamic point of view. Since the change in driving force plays an important role in the activation energy, the considerable change in activation energy because of the change in $\mathrm{Sn}$ content is also rational. Consequently, the high value of activation energy for the growth of

Note 1: By utilizing the Gibbs free energy all forms of work (excluding expansion
work) can be taken into account $-(\Delta \mathbf{G})_{p, T} \geq w^{t}=\Sigma \mu_{i} n_{i}+\gamma \mathrm{A}+\mathbf{z} \mathbf{F U}+\ldots$, where the
first term is the chemical part, the second is the surface energy contribution, the third
is the electrical component, etc. Thus, Gibbs energy gives the amount of maximum
additional (non-expansion) work that the system can perform. For all spontaneous
processes the change in Gibbs energy must be negative. It should also be noted that
the temperature and pressure of the system do not have to be constant during the
whole process. It is adequate that they are the same at the initial and final stages. An
example is an exothermic reaction taking place at temperature $T$, where the reaction
heat is transferred to the environment at the end of the reaction, thus making $T_{\text {initial }}$
equal to $\mathrm{T}_{\text {final. }}$ This is, of course, a consequence of the fact that the Gibbs energy is a
state function and its value is only dependent on the initial and final states, not the
path between them.

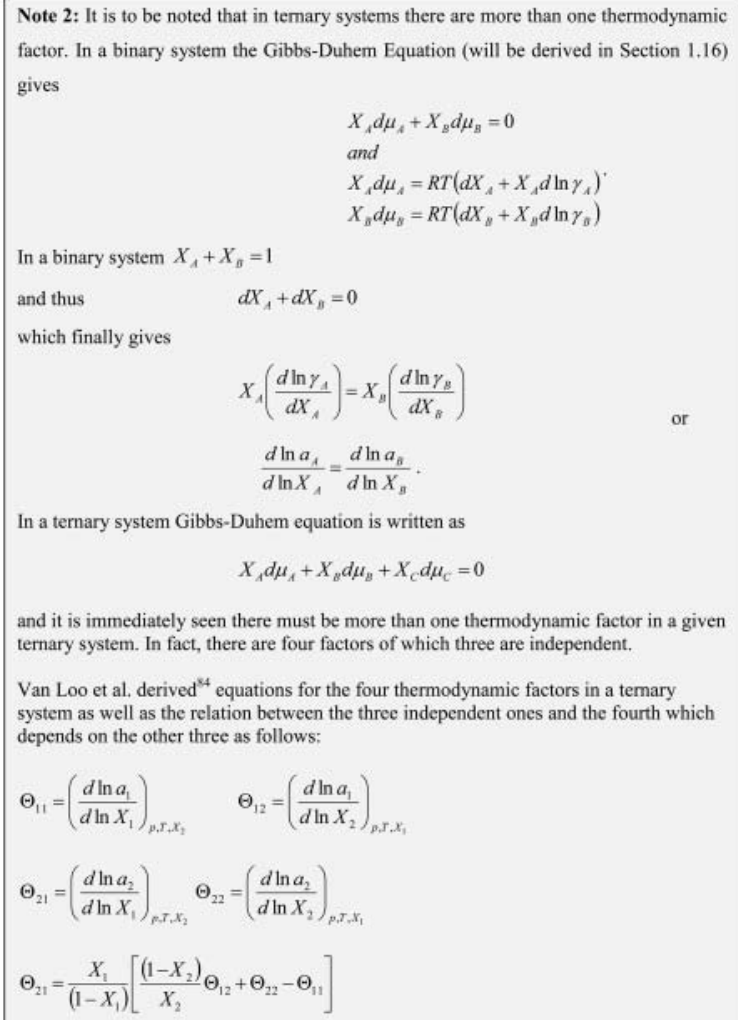


$\mathrm{Nb}_{3} \mathrm{Sn}$ is also reasonable, since the phase growth occurs by diffusion of Sn, which is heavily dependent on the concentrations of antisite defects and vacancies present in the structure. $^{83}$

\section{CONCLUSIONS}

It was shown above that the thermodynamic-kinetic method can be used to rationalize the evolution of interfacial reaction zone in a wide variety of different cases. The power of the method is clearly in its generality. Its use is not restricted to metal-metal reaction couples or even to inorganic materials. It can be as well used in biological applications, as long as there is adequate data available. Especially in the field of soft matter, the data is unfortunately often missing. However, even without actual data about the system under investigation, this method can be used as an aid for reasoning. We have thermodynamics that give us criteria what can happen. It does not contain any information about time frame of the change and thus must be combined with kinetics (i.e. diffusion fluxes and their calculations). These together give us the microstructure (that contain also defect structures), which in turn will dictate how the system (for example an interconnection) will behave under operational conditions. In order to know the morphology and distribution of phases in the microstructure experimental investigation is needed, for example by Scanning Electron Microscopy (SEM) or Transmission Electron Microscopy (TEM). It is argued that by using the method outlined above, it is possible to avoid the so called "trial-and-error" approach that easily leads to confusing and even completely erroneous results. Finally, the "rise" of atomistic simulation techniques will further strengthen this method by providing information that is hard or even impossible to access experimentally.

\section{REFERENCES}

1. J. K. Kivilahti, The chemical modeling of electronic materials and interconnections, J. Met. 54(12), 52 (2002).

2. T. Laurila, V. Vuorinen, and M. Paulasto-Kröckel, Impurity and alloying effects on interfacial reaction layers in lead-free soldering, Mater. Sci. Eng. R R68, 1-38 (2010).

3. T. Laurila, V. Vuorinen, and J. K. Kivilahti, Interfacial reactions between lead-free solders and common base materials, Mater. Sci. Eng. R R49(1-2), 1-60 (2005).

4. K. Rönkä, F. van Loo, and J. Kivilahti, The local nominal composition - useful concept for microjoining and interconnection applications, Scripta Mater. 37(10), 1575 (1997).

5. D. Hong, V. Vuorinen, X.M. Tao, T. Laurila, and M. PaulastoKröckel, Thermodynamic reassessment of $\mathrm{Au}-\mathrm{Cu}-\mathrm{Sn}$ ternary system, J. Alloys Comp. 588, 449-460 (2014).

6. H. Dong, T. Xiaoma, T. Laurila, V. Vuorinen, and M. PaulastoKröckel, Thermodynamic modeling of Au-Ce-Sn ternary system, Calphad 42, 38-50 (2013).

7. H. Dong, V. Vuorinen, T. Laurila, and M. Paulasto-Kröckel, Thermodynamic reassessment of Au-Ni-Sn ternary system, Calphad 43, 61-70 (2013).
8. P. Turchi, L. Kaufman, and Z-K. Lui, Modeling of Ni-Cr-Mo based alloys: Part I - phase stability, Calphad 30, 70 (2006).

9. P. Turchi, A. Gonis, V. Drchal, and J. Kudrnovsky, Thermodynamic properties and phase diagram by the statistical moment and cluster variation methods: Application to pure metals and Ta-W alloys, Phys. Rev. B 64, 085112 (2001).

10. L. Kaufman, P. Turchi, W. Huang, and Z-K. Liu, Thermodynamics of the Cr-Ta-W system by combining the "Ab Initio" and CALPHAD methods, Calphad 25(3), 419 (2001).

11. S-K Lin, C-K. Yeh, W. Xie, Y-C. Liu, and M. Yoshimura, Scientific Reports 3, 2731-2734 (2013).

12. G. Ghosh and M. Asta, Phase stability, phase transformations, and elastic properties of $\mathrm{Cu}_{6} \mathrm{Sn}_{5}$ : $\mathrm{Ab}$ initio calculations and experimental results, J. Mater. Res. 20, 3102-3117 (2005).

13. G. Ghosh, S. Delsante, G. Borzone, M. Asta, and R. Feroo, Phase stability and cohesive properties of Ti-Zn intermetallics: Firstprinciples calculations and experimental results, Acta Mater. 54, 4977-4997 (2006).

14. A. Paul and T. Laurila, Comments on "Effects of current density on the formation and microstructure of $\mathrm{Sn}-9 \mathrm{Zn}, \mathrm{Sn}-8 \mathrm{Zn}-3 \mathrm{Bi}$ and $\mathrm{Sn}-3 \mathrm{Ag}-0.5 \mathrm{Cu}$ solder joints," Intermetallics 28, 164-165 (2012).

15. M. Tang, L. Colombo, J. Zhu, and T. Diaz de la Rubia, Intrinsic point defects in crystalline silicon: Tight-binding molecular dynamics studiesof self-diffusion, interstitial-vacancy recombination, and formation volumes, Phys. Rev. B. 55, 14279 (1997).

16. T. Laurila, J. Karppinen, V. Vuorinen, A. Paul, and M. PaulastoKröckel, Effect of isothermal aging and electromigration on the microstructural evolution of solder interconnections during thermomechanical loading, J. Electron. Mater. 40(7), 1517-1526 (2011).

17. R. T. DeHoff and N. Kulkarni, The trouble with diffusion, Mater. Res. 5, 209-229 (2002).

18. R. Martin, Electronic Structure: Basic Theory and Practical Methods, Cambridge University Press, Cambridge (2008).

19. P. Hohenberg and W. Kohn, Inhomogeneous electron gas, Phys. Rev. 136, 864 (1964).

20. W. Kohn and L. J. Sham, Self-consistent equations including exchange and correlation effects, Phys. Rev. B 140, A1113 (1965).

21. M. A. Caro, S. Schulz, and E. P. O'Reilly, Comparison of stress and total energy methods for calculation of elastic properties of semiconductors, J. Phys. Condens. Matt. 25, 025803 (2013).

22. A. Gulans, M. J. Puska, and R. M. Nieminen, Linear-scaling selfconsistent implementation of the van der Waals density functional, Phys. Rev. B 79, 201105 (2009).

23. M. Walter, J. Akola, O. Lopez-Acevedo, P. Jadzinsky, G. Calero, C. Ackerson, R. Whetten, H. Grönbeck, and H. Häkkinen, A unified view of ligand-protected gold clusters as superatom complexes, Proc. Nat. Acad. Sci. 105(27), 91579162 (2008).

24. J. Enkovaara, C. Rostgaard, J. Mortensen, J. Chen, M. Dułak, L. Ferrighi, J. Gavnholt, C. Glinsvad, V. Haikola, H. A. Hansen, H. Kristoffersen, M. Kuisma, A. H. Larsen, L. Lehtovaara, M. Ljungberg, O. Lopez-Acevedo, P. Moses, J. Ojanen, T. Olsen, V. Petzold, N. A. Romero, J. Stausholm-Møller, M. Strange, G. A. Tritsaris, M. Vanin, M. Walter, B. Hammer, H. Häkkinen, G. Madsen, R. M. Nieminen, J. Nørskov, M. Puska, T. T. Rantala, 
J. Schiøtz, K. Thygesen, and K. Jacobsen, Electronic structure calculations with GPAW: A real-space implementation of the projector augmented-wave method, J. Phys. Conden. Matt. 22 (25), 253202 (2010).

25. K. Kang, Y. Meng, J. Breger, C. Grey, and G. Ceder, Electrodes with high power and high capacity for rechargeable lithium batteries, Science 311(5763), 977-980 (2006).

26. P. Turchi, I. Abrikosov, B. Burton, S. Fries, G. Grimvall, L. Kaufmann, P. Korzhavyi, V. R. Manga, M. Ohno, A. Pisch, A. Scott, and W. Zhang, Interface between quantum-mechanicalbased approaches, experiments, and CALPHAD methodology, Calphad 31, 4-27 (2007).

27. A. van de Walle, M. Asta, and G. Ceder, The alloy theoretic automated toolkit: A user guide, Calphad 26, 539-553 (2002).

28. http://www.brown.edu/Departments/Engineering/Labs/avdw/ atat/

29. H. Lukas, S. Fries, and B. Sundman, Computational Thermodynamics: The Calphad Method, Cambridge University Press, Cambridge (2007).

30. M. Hillert, Phase Equilibria, Phase Diagrams and Phase Transformations, Cambridge Press, Cambridge (1998).

31. N. A. Gokcen, Thermodynamics, Techscience Incorporated, University of Michigan (1975).

32. J. Philibert, Atom Movements: Diffusion and Mass Transport in Solids, Les Editions de Physique, Paris (1991).

33. T. Laurila and J. Molarius, Reactive phase formation in thin film metal/metal and metal/silicon diffusion couples, Crit. Rev. Solid State Mater. Sci. 28, 185 (2003).

34. F. J. J. van Loo, Multiphase diffusion in binary and ternary solidstate systems, Prog. Solid St. Chem. 20, 47 (1990).

35. F. N. Rhines, Phase Diagrams in Metallurgy- Their Development and Applications, McGraw-Hill, New York (1956).

36. H. Yu, V. Vuorinen, and J. K. Kivilahti, Solder/substrate interfacial reactions in the $\mathrm{Sn}-\mathrm{Cu}-\mathrm{Ni}$ interconnection system, J. Electr. Mater. 36(2), 136 (2007).

37. A. Paul, The Kirkendall effect in solid state diffusion, Doctoral Dissertation, Technical University of Eindhoven (2004).

38. A. Paul, C. Ghosh, and W. J. Boettinger, Diffusion parameters and growth mechanism of phases in the $\mathrm{Cu}-\mathrm{Sn}$ system, Metallurg. Mater. Trans. A 42A, 952-963 (2011).

39. V. Vuorinen, T. Laurila, T. Mattila, E. Heikinheimo, and J. K. Kivilahti, Solid-state reactions between $\mathrm{Cu}(\mathrm{Ni})$ alloys and $\mathrm{Sn}, J$. Electron. Mater. 36(10), 1355 (2007).

40. K. Nogita and T. Nishimura, Nickel-stabilized hexagonal $(\mathrm{Cu}$, $\mathrm{Ni})_{6} \mathrm{Sn}_{5}$ in $\mathrm{Sn}-\mathrm{Cu}-\mathrm{Ni}$ lead-free solder alloys, Scr. Mater. 59, 191 (2008).

41. A. Paul, T. Laurila, V. Vuorinen, and S. Divinsky, Thermodynamics, Diffusion And The Kirkendall Effect In Solids, Springer, New York (2014).

42. P. Shewmon, Diffusion in Solids, 2nd ed., TMS, Warrendale (1989).

43. J. S. Kirkaldy and D. J. Young, Diffusion in the Condensed State, The Institute of Metals, UK (1987).

44. J. S. Kirkaldy, Diffusion in multicomponent metallic systems, Can. J. Phys. 36, 899 (1958).

45. J. S. Kirkaldy and L. C. Brown, Diffusion behaviour in ternary, multiphase systems, Can. Met. Q. 2, 89 (1963).

46. D. Coates and J. S. Kirkaldy, Phase interface stability in isothermal ternary systems, Proc. Second Internat. Conf. on Crystal
Growth, North-Holland Publishing, Amsterdam pp. 549-554 (1968).

47. K. Bhanumurthy and R. Schmid-Fetzer, Solid-state reaction bonding of silicon carbide (HIPSiC) below $1000^{\circ} \mathrm{C}$, Z. Metallkd. 87, 61 (1996).

48. C. Wagner, The evaluation of data obtained with diffusion couples of binary single-phase and multiphase systems, Acta Metall. 17, 99 (1969).

49. L. E. Trimble, D. Finn, and A. Cosgarea, Jr., A mathematical analysis of diffusion coefficients in binary systems, Acta Met. 13, 501 (1965).

50. P. L. Gruzin, Self-diffusion in gamma iron, Dokl. Akad. Nauk S. S.S.R. 86, 289 (1952).

51. A. Paul, A. A. Kodentsov, and F. J. J. van Loo, On diffusion in the $\beta$-NiAl phase, J. Alloys Comp. 403, 147 (2005).

52. T. Massalski, Binary Alloy Phase Diagrams, ASM International, Materials Park, Ohio (1996).

53. M. Hillert, Applications of Gibbs Energy-Composition Diagrams, in Lectures on the Theory of Phase Transformations, ed. H. Aaronson, AIME, (1975).

54. M. J. H. van Dal, A. M. Gusak, C. Cserhati, A. A. Kodentsov, and F. J. J. van Loo, Spatio-temporal instabilities of the Kirkendall marker planes during interdiffusion in $\beta$ '-AuZn, Phil. Mag. A 82, 943 (2002).

55. T. Laurila, J. Hurtig, V. Vuorinen, and J. K. Kivilahti, Effect of $\mathrm{Ag}, \mathrm{Fe}, \mathrm{Au}$ and $\mathrm{Ni}$ on the growth kinetics of $\mathrm{Sn}-\mathrm{Cu}$ intermetallic compound layers, Microelectr. Reliab. 49(3), 242-247 (2009).

56. J. Torres, Advanced copper interconnections for silicon CMOS technologies, Appl. Surf. Sci. 91, 112 (1995).

57. S. P. Murarka, "Advanced materials for future interconnections of the future need and strategy, Microelectron. Eng. 37/38, 29 (1997).

58. A. A. Istratov and E. R. Weber, Electrical properties and recombination activity of copper, nickel and cobalt in silicon, Appl. Phys. A 66, 123 (1998).

59. C-A. Chang, Formation of copper silicides from $\mathrm{Cu}(100) / \mathrm{Si}$ (100) and $\mathrm{Cu}(111) / \mathrm{Si}$ (111) structures, J. Appl. Phys. 67, 566 (1990).

60. J. Li and J. W. Mayer, Refractory metal nitride encapsulation for copper wiring, MRS Bull. 18, 52 (1993).

61. F. Faupel, Diffusion in non-crystalline metallic and organic media, Phys. Stat. Sol. A 134, 9 (1992).

62. S. Lakshminarayanan, J. Steigerwald, D. T. Price, M. Bourgwois, T. P. Chow, R. J. Gutman, and S. P. Murarka, Contact and via structures with copper interconnects fabricated using dual Damascene technology, IEEE Electr. Dev. Lett. 15, 307 (1994).

63. T. Laurila, K. Zeng, J. Molarius, I. Suni, and J. K. Kivilahti, TaC as a diffusion barrier between $\mathrm{Si}$ and $\mathrm{Cu}, J$. Appl. Phys. 91, 5391 (2002b).

64. T. Laurila, K. Zeng, J. Molarius, I. Suni, and J. K. Kivilahti, Amorphous layer formation at the $\mathrm{TaC} / \mathrm{Cu}$ interface in the $\mathrm{Si} / \mathrm{TaC} / \mathrm{Cu}$ metallization system, Appl. Phys. Lett. 80, 938 (2002a).

65. T. Laurila, K. Zeng, J. Molarius, I. Suni, and J. K. Kivilahti, Effect of oxygen on the reactions in the $\mathrm{Si} / \mathrm{Ta} / \mathrm{Cu}$ metallization system, J. Mater. Res. 16, 2939-2946 (2001).

66. E. Hondros and M. Seah, Segregation to interfaces, Int. Met. Rev. 22, 262 (1977). 
67. E. Hondros and M. Seah, The theory of grain boundary segregation in terms of surface adsorption analogues, Metall. Trans. A 8A, (1977).

68. J. Lacaze and B. Sundman, An assessment of the Fe-C-Si system, Metall. Trans. A 22, 2211 (1991).

69. K. Frisk and A. F. Guillermet, Gibbs energy coupling of the phase diagram and thermochemistry in the Tantalum-Carbon system, J. Alloys Compd. 238, 167 (1996).

70. L. Chandra Sekaran, Scientific Group Thermodata Europe databank, (1987).

71. W. Wakelkamp, Diffusion and phase relations in the systems TiSi-C and Ti-Si- N, Doctoral thesis, Tech. University of Eindhoven, Netherlands (1991).

72. A. Christou and H. M. Day, Silicide formation and interdiffusion effects in Si-Ta, SiO2-Ta AND Si-PtSi-Ta thin film structures, $J$. Electron. Mat. 5, 1 (1976).

73. C. R. Kao, J. Woodford, and Y. A. Chang, A mechanism for reactive diffusion between $\mathrm{Si}$ single crystal and $\mathrm{NbC}$ powder compact, J. Mater. Res. 11, 850 (1996).

74. R. G. Sharma, Review on the fabrication techniques of A-15 superconductors, Cryogenics 27, 361-377 (1987).

75. M. Suenaga, Metallurgy of Continuous Filamentary A15 Superconductors, in Superconductor Materials Science: Metallurgy Fabrication and Applications, S. Foner and B. B. Schwartz, eds., Plenum, New York pp. 201 (1981).

76. P. J. Lee and D. C. Larbalestier, Compositional and microstructural profiles across Nb3Sn filaments produced by different fabrication methods, IEEE Trans. Appl. Superconduct. 11, 3671-3674 (2001).

77. P. J. Lee and D. C. Larbalestier, Microstructure, microchemistry and the development of very high $\mathrm{Nb3Sn}$ layer critical current density, IEEE Trans. Appl. Superconduct. 15, 34743477 (2005).

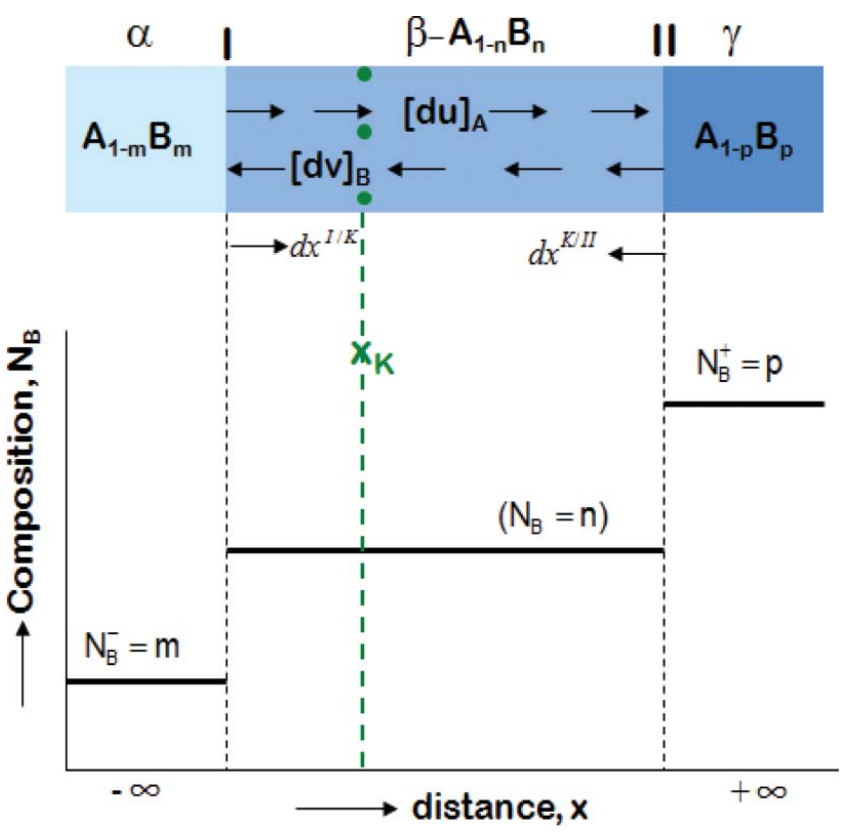

FIG. A1. Composition profile and schematic reaction couple $\alpha / \gamma$.
78. P. J. Lee and D. C. Larbalestier, Microstructural factors important for the development of high critical current density Nb3Sn strand, Cryogenics 48, 283-292 (2008).

79. M. Suenaga and W. Jansen, Chemical compositions at and near the grain boundariesin bronze processed superconducting Nb3Sn, Appl. Phys. Lett. 43, 791-793 (1983).

80. M. Hamalainen, K. Jaaskelainen, and R. Luoma, A thermodynamic analysis of the binary alloy systems $\mathrm{Cu}-\mathrm{Cr}, \mathrm{Cu}-\mathrm{Nb}$ and Cu-V, Calphad 14(2), 125-137 (1990).

81. C. Toffolon, C. Servant, J. C. Gachon, and B. Sundman, Reassessment of the Nb-Sn system, J. Phase Equilibria 23(2), 134 139 (2002).

82. J. H. Shim, C. S. Oh, B. J. Lee, and D. N. Lee, Thermodynamic assessment of the Cu-Sn system, Z Metallkd. 87(3), 205-212 (1996).

83. M. Li, Z. Du, G. Guo, and C. Li, Thermodynamic optimization of the $\mathrm{Cu}-\mathrm{Sn}$ and $\mathrm{Cu}-\mathrm{Nb}-\mathrm{Sn}$ systems, Alloys Comp. 477, 104 (2009).

84. R. Besson, S. Guyot, and A. Legris, Atomic-scale study of diffusion in A15 $\mathrm{Nb}_{3} \mathrm{Sn}$, Phys. Rev. B 75, 054105-1-7 (2007).

85. C. Cserhati, U. Ugaste, M. van Dal, N. Lousberg, A. Kodentsov, and F. J. J. van Loo, On the relation between interdiffusion and tracer diffusion coefficients in ternary solid solutions, Defect Diffus. Forum 194-199, 189-194 (2001).

86. L. S. Darken, Diffusion, mobility and their interrelation through free energy in binary metallic systems, Trans. Aime 175(184), 41 (1948).

\section{APPENDIX}

For the sake of simplicity let us consider a diffusion couple of $\alpha$ and $\gamma$ phases in which a line compound $\beta$ grows in an interdiffusion zone, as shown in Figure A1. The stoichiometric compositions of the $\alpha, \beta$ and $\gamma$ phases are $\mathrm{A}_{1-\mathrm{m}} \mathrm{B}_{\mathrm{m}}, \mathrm{A}_{1-\mathrm{n}} \mathrm{B}_{\mathrm{n}}$, and $\mathrm{A}_{1-\mathrm{p}} \mathrm{B}_{\mathrm{p}}$, respectively. Suppose $\alpha$ is a A-rich and $\beta$ is a B-rich phase. Therefore, as shown in the figure, A dissociates from the $\alpha$ phase at the interface I to produce the product $\beta$ phase. The dissociated $\mathrm{A}$ then diffuse to the interface II and reacts with the $\gamma$ phase to produce the $\beta$ phase. At the same time, $\mathrm{B}$ dissociates from the $\gamma$ phase at the interface II to produce the $\beta$ phase. The dissociated $\mathrm{B}$ diffuse to the interface I to produce the $\beta$ phase. Therefore, at both the interfaces the product phase $\beta$ is grown by dissociation and reaction of components. $[d u]_{\mathrm{A}}$ $\mathrm{mol} / \mathrm{m}^{2}$ is the flux of component A crossed the Kirkendall marker plane in small time $d t$. Similarly the flux of component $\mathrm{B}$ that crosses the marker plane in that small time is $[d v]_{\mathrm{A}} \mathrm{mol} /$ $\mathrm{m}^{2}$. The location of the marker plane in the interdiffusion zone is shown by filled circles and the location is denoted as $x_{K}$. It is evident that the part of the product phase that is grown on the left hand side of the marker plane does so because of reaction and dissociation at the interface I. On the other hand, the part of the phase on the right hand side of the product phase from the Kirkendall marker plane will grow because of the reaction and dissociation at the interface II. Therefore, we need to write the reaction and dissociation equations for the corresponding two different interfaces. 
Reaction and dissociation equations at the interface I:

$$
\begin{aligned}
& \frac{n}{n-m} d u A_{1-m} B_{m}(\alpha \text { phase }) \rightarrow d u[A]_{d} \\
& +\frac{m}{n-m} d u A_{1-n} B_{n}(\beta \text { phase }) \quad \text { dissociation of } \mathrm{A} \\
& \frac{1-n}{n-m} d v A_{1-m} B_{m}(\alpha \text { phase })+d v[B]_{d} \\
& \rightarrow \frac{1-m}{n-m} d v A_{1-n} B_{n}(\beta \text { phase }) \quad \text { reaction of } \mathrm{B}
\end{aligned}
$$

Reaction and dissociation equations at the interface II:

$$
\begin{aligned}
& \frac{n}{p-n} d u A_{1-p} B_{p}(\gamma \text { phase })+d u[A]_{d} \\
& \rightarrow \frac{p}{p-n} d u A_{1-n} B_{n}(\beta \text { phase }) \quad \text { reaction of } \mathrm{A} \\
& \frac{1-n}{p-n} d v A_{1-p} B_{P}(\gamma \text { phase }) \rightarrow d v[B]_{d} \\
& \quad+\frac{1-p}{p-n} d v A_{1-n} B_{n}(\beta \text { phase }) \quad \text { dissociation of } \mathrm{A}
\end{aligned}
$$

The amount of the $\beta$ phase produced at the interface I is $\frac{1}{n-m}[m d u+(1-m) d v]$ and at the interface II is $\frac{n-m}{p-n}[p d u+(1-p) d v] \mathrm{mol} / \mathrm{m}^{2}$. Let us assume that the molar volume of the product $\beta$ phase is $v_{m}^{\beta}$. Further, suppose the thicknesses of the phase layer grown from interface I and II in this small time $d t$ are $d x^{I / K}$ and $d x^{K / I I}$. Therefore, we can write

$$
\begin{aligned}
& \frac{1}{n-m}[m d u+(1-m) d v] v_{m}=d x^{I / K} \\
& \frac{1}{p-n}[p d u+(1-p) d v] v_{m}=d x^{K / I I},
\end{aligned}
$$

where $v_{m}$ is the molar volume of the product phase. Further, we can write for the left-, right-hand side of the end members, and the composition of the product phases as $m=N_{B}^{-}$, $p=N_{B}^{+}$and $n=N_{B}$. Therefore, Equations (A1) can be rewritten as

$$
\begin{aligned}
N_{B}^{-} d u+\left(1-N_{B}^{-}\right) d v & =\frac{N_{B}-N_{B}^{-}}{v_{m}} d x^{I / K} \\
N_{B}^{+} d u+\left(1-N_{B}^{+}\right) d v & =\frac{N_{B}^{+}-N_{B}}{v_{m}} d x^{K / I I}
\end{aligned}
$$

If the flux of diffusing components $\mathrm{A}$ and $\mathrm{B}$ are 0 at time $t$ $=0$ and $u$ and $v$ after the annealing time, $t$, we can write the
Equations (A2) by integrating as

$$
\begin{gathered}
N_{B}^{-} \int_{o}^{u} d u+\left(1-N_{B}^{-}\right) \int_{o}^{v} d v=\int_{x^{-\infty}}^{x_{K}} \frac{N_{B}-N_{B}^{-}}{v_{m}} d x \\
N_{B}^{-} u+\left(1-N_{B}^{-}\right) v=\int_{x^{-\infty}}^{x_{K}} \frac{N_{B}-N_{B}^{-}}{v_{m}} d x \\
N_{B}^{+} \int_{o}^{u} d u+\left(1-N_{B}^{+}\right) \int_{o}^{v} d v=\int_{x_{K}}^{x^{+\infty}} \frac{N_{B}-N_{B}^{-}}{v_{m}} d x \\
N_{B}^{+} u+\left(1-N_{B}^{+}\right) v=\int_{x_{K}^{+\infty}} \frac{N_{B}^{+}-N_{B}}{v_{m}} d x .
\end{gathered}
$$

Next, we would like to write the expressions separately for $u$ and $v$. Multiplying Equation (A3a) by $\left(1-N_{B}^{+}\right)$ and Equation (A3b) by $\left(1-N_{B}^{-}\right)$and then by subtracting, we get

$$
\begin{gathered}
N_{B}^{-}\left(1-N_{B}^{+}\right) u-N_{B}+\left(1-N_{B}^{-}\right) \\
u=\left(1-N_{B}+\right) \int_{x^{-\infty}}^{x_{K}} \frac{N_{B}-N_{B}^{-}}{v_{m}} d x \\
-\left(1-N_{B}^{-}\right) \int_{x_{K}}^{x^{+\infty}} \frac{N_{B}^{+}-N_{B}}{v_{m}} d x \\
u=-\left[\left(1-N_{B}^{+}\right) \int_{x^{-\infty}}^{x_{K}} \frac{N_{B}-N_{B}^{-}}{N_{B}^{+}-N_{B}^{-}} \frac{1}{v_{m}} d x\right. \\
\left.-\left(1-N_{B}^{-}\right) \int_{x_{K}^{+\infty}}^{x_{B}^{+}} \frac{N_{B}^{+}-N_{B}}{N_{B}^{+}-N_{B}^{-}} \frac{1}{v_{m}} d x\right] .
\end{gathered}
$$

Introducing the variable $Y_{B}=\frac{N_{B}-N_{B}^{-}}{N_{B}^{+}-N_{B}^{-}} \quad$ such that $1-Y_{B}=\frac{N_{B}^{+}-N_{B}}{N_{B}^{+}-N_{B}^{-}}$, we can write

$$
\begin{aligned}
& u=-\left[\left(1-N_{B}^{+}\right) \int_{x^{-\infty}}^{x_{K}} \frac{Y_{B}}{v_{m}} d x-\left(1-N_{B}^{-}\right) \int_{x_{K}}^{x^{+\infty}} \frac{1-Y_{B}}{v_{m}} d x\right] \\
& u=-\left[N_{A}^{+} \int_{x^{-\infty}}^{x_{K}} \frac{Y_{B}}{v_{m}} d x-N_{A}^{-} \int_{x_{K}}^{x^{+\infty}} \frac{1-Y_{B}}{v_{m}} d x\right] .
\end{aligned}
$$


Multiplying Equation (A4a) by $N_{B}^{-}$and Equation (A4b) by $N_{B}{ }^{+}$and then by subtracting, we get

$$
\begin{aligned}
& N_{B}^{+}\left(1-N_{B}^{-}\right) v-N_{B}^{-}\left(1-N_{B}^{+}\right) \\
& v=N_{B}^{+} \int_{x^{-\infty}}^{x_{K}} \frac{N_{B}-N_{B}^{-}}{v_{m}} d x-N_{B}^{-} \int_{x_{K}}^{x^{+\infty}} \frac{N_{B}+-N_{B}}{v_{m}} d x \\
& v=N_{B}^{+} \int_{x^{-\infty}}^{x_{K}} \frac{N_{B}-N_{B}^{-}}{N_{B}^{+}-N_{B}^{-}} \frac{1}{v_{m}} d x-N_{B}^{-} \int_{x_{K}}^{x^{+\infty}} \frac{N_{B}+-N_{B}}{N_{B}^{+}-N_{B}^{-}} \frac{1}{v_{m}} d x \\
& v=N_{B}^{+} \int_{x^{-\infty}}^{x_{K}} \frac{Y_{B}}{v_{m}} d x-N_{B}^{-} \int_{x_{K}}^{x^{+\infty}} \frac{1-Y_{B}}{v_{m}} d x .
\end{aligned}
$$

Next, it will be shown that the intrinsic flux (Equation 14) of A that is $J_{A}$ and the intrinsic flux of B that is $J_{B}$ can be related to $u$ and $v$. While doing this the sign of flux of A should be taken as positive since it diffuse from left to right and the flux of B as negative since it diffuse from right to left. Further, as the intrinsic fluxes are inversely proportional to $t^{1 / 2}$ we can write:

$$
\begin{gathered}
u=\int_{0}^{u} d u=\int_{0}^{t} J_{A} d t=\int_{0}^{t} \frac{k}{t^{1 / 2}} d t=\frac{k t^{1 / 2}}{1 / 2}=2 t J_{A}=-2 t D_{A} \frac{\partial C_{A}}{\partial x} \\
v=\int_{0}^{v} d v=-\int_{0}^{t} J_{B} d t=-\int_{0}^{t} \frac{k}{t^{1 / 2}} d t=-2 t J_{B}=2 t D_{B} \frac{\partial C_{B}}{\partial x},
\end{gathered}
$$

where $k$ is the proportionality constant. Note here that $J_{i}=-D_{i} \frac{\partial C_{i}}{\partial x}$. From Equations (A4) and (A5), we can write

$$
\begin{gathered}
D_{A}=\frac{1}{2 t}\left(\frac{\partial x}{\partial C_{A}}\right)\left[N_{A}^{+} \int_{-\infty}^{X_{K}} \frac{Y}{v_{m}} d x-N_{A}-\int_{X_{K}}^{+\infty} \frac{1-Y}{v_{m}} d x\right] \\
D_{B}=\frac{1}{2 t}\left(\frac{\partial x}{\partial C_{B}}\right)\left[N_{B}^{+} \int_{-\infty}^{X_{K}} \frac{Y}{v_{m}} d x-N_{B}^{-} \int_{X_{K}}^{+\infty} \frac{1-Y}{v_{m}} d x\right]
\end{gathered}
$$

These are the relations developed by van Loo. ${ }^{34}$

From the standard thermodynamic relations $\partial C_{A}=\left(\frac{V_{B}}{V_{m}^{2}}\right) \partial N_{A}, \partial C_{B}=\left(\frac{V_{A}}{V_{m}^{2}}\right) \partial N_{B}$ we can write the ratio of intrinsic diffusion coefficients as

$$
\frac{V_{A} D_{B}}{V_{B} D_{A}}=\frac{J_{B}}{J_{A}}=\frac{v}{u} .
$$

We can write this with respect to the ratio of tracer diffusion coefficients as

$$
\frac{D_{B}^{*}}{D_{A}^{*}}=\frac{V_{A} D_{B}}{V_{B} D_{A}}=\frac{J_{B}}{J_{A}}=\frac{v}{u} .
$$

The relation between the interdiffusion coefficients and the intrinsic diffusion coefficients has been derived by Darken ${ }^{85}$ as:

$$
\tilde{D}=C_{A} V_{A} D_{B}+C_{B} V_{B} D_{A}
$$

And, since $N_{B}+N_{A}=1, C_{i}=\frac{N_{i}}{v_{m}}$, we can write the interdiffusion coefficients with respect $u$ and $v$ with the help of Equation (A5) as

$$
\tilde{D}=\frac{V_{m}}{2 t} \frac{\partial x}{\partial N_{B}}\left[N_{B} u+N_{A} v\right] .
$$

In the case of a compound with very narrow homogeneity range, since we cannot measure the composition profile, the integrated diffusion coefficient is used. With respect to $u$ and $v$, we can express this as

$$
\begin{aligned}
\tilde{D}_{\mathrm{int}}^{\beta} & =\int_{N_{B}^{I}}^{N_{B}^{I I}} \tilde{D} d N_{B}=\int_{x_{\beta}^{I}}^{x_{\beta}^{I I}} \frac{v_{m}}{2 t}\left[N_{B} u+N_{A} v\right] d x \\
& =\frac{v_{m}^{\beta}}{2 t}\left[N_{B}^{\beta} u+N_{A}^{\beta} v\right] \Delta x_{\beta} .
\end{aligned}
$$

As explained earlier, the unknown composition range of the $\beta$ phase is $N_{B}^{I I}-N_{B}^{I}$, the thickness of the phase layer is $\Delta x_{\beta}=x_{\beta}^{I I}-x_{\beta}^{I}$. The average molar volume of the phase, $v_{m}^{\beta}$ can be considered as constant and during a fixed annealing time of $t$ fixed amount of fluxes $u$ and $v$ transfers through the Kirkendall marker plane. The values of $u$ and $v$ can be estimated from the composition profile using the relations expressed in Equations (A4a) and (A4b). It should be noted here that by replacing these relations in Equations (A9) and (A10), we can derive the same relations, for the interdiffusion coefficient and the integrated diffusion coefficient derived by Wagner. ${ }^{47}$

The velocity of the marker plane can be estimated by

$$
v_{K}=-\left(\bar{v}_{A} J_{A}+\bar{v}_{B} J_{B}\right) .
$$

Replacing Equation (A5) in the above equation, we get

$$
v_{K}=-\left(\bar{v}_{A} \frac{u}{2 t}-\bar{v}_{B} \frac{v}{2 t}\right)=\frac{1}{2 t}\left(\bar{v}_{B} v-\bar{v}_{A} u\right) .
$$

If the values of the partial molar volumes are not known, we consider $v_{m}=\bar{v}_{A}=\bar{v}_{B}$, where $v_{m}$ is the molar volume of the 
product phase. Therefore, we can write

$$
x_{K}=2 t v_{K}=v_{m}(v-u) .
$$

From the above discussion it is clear that the phase layer grows by different mechanism at the two different interfaces. Based on this we can expect a duplex morphology separated by a Kirkendall marker plane, as shown in Figure 14. The approach outlined above can perfectly well be extended to cases where more than one phase grows in a given system as will be shown in Section 5. Further, we have shown that there exist relations between the phenomenological diffusion theory and the physic-chemical approach. This ensures that we can extensively utilize thermodynamic data in both kinetic "approaches." 